WBS 1.2.1.10

QA: N/A

MOL . 19981007.0180

Civilian Radioactive Waste Management System
Management \& Operating Contractor

\title{
Report on Intact and Degraded Criticality for Selected Plutonium Waste Forms in a Geologic Repository, Volume I: MOX SNF
}

Document Identifier: BBA000000-01717-5705-00020 REV 00

September 18, 1998

Prepared for:

U.S. Department of Energy

Office of Civilian Radioactive Waste Management

1000 Independence Avenue SW

Washington, D. C. 20585

Prepared By:

Civilian Radioactive Waste Management System

Management \& Operating Contractor

1261 Town Center Drive

Las Vegas, NV 89134

Under Contract Number

DE-AC08-91RW00134 
Report on Intact and Degraded Criticality for Selected Plutonium Waste Forms in a Geologic Repository, Volume I: MOX SNF

\section{Civilian Radioactive Waste Management System \\ Management \& Operating Contractor}

\section{Report on Intact and Degraded Criticality for Selected Plutonium Waste Forms in a Geologic Repository, Volume I: MOX SNF}

Document Identifier: BBA000000-01717-5705-00020 REV 00

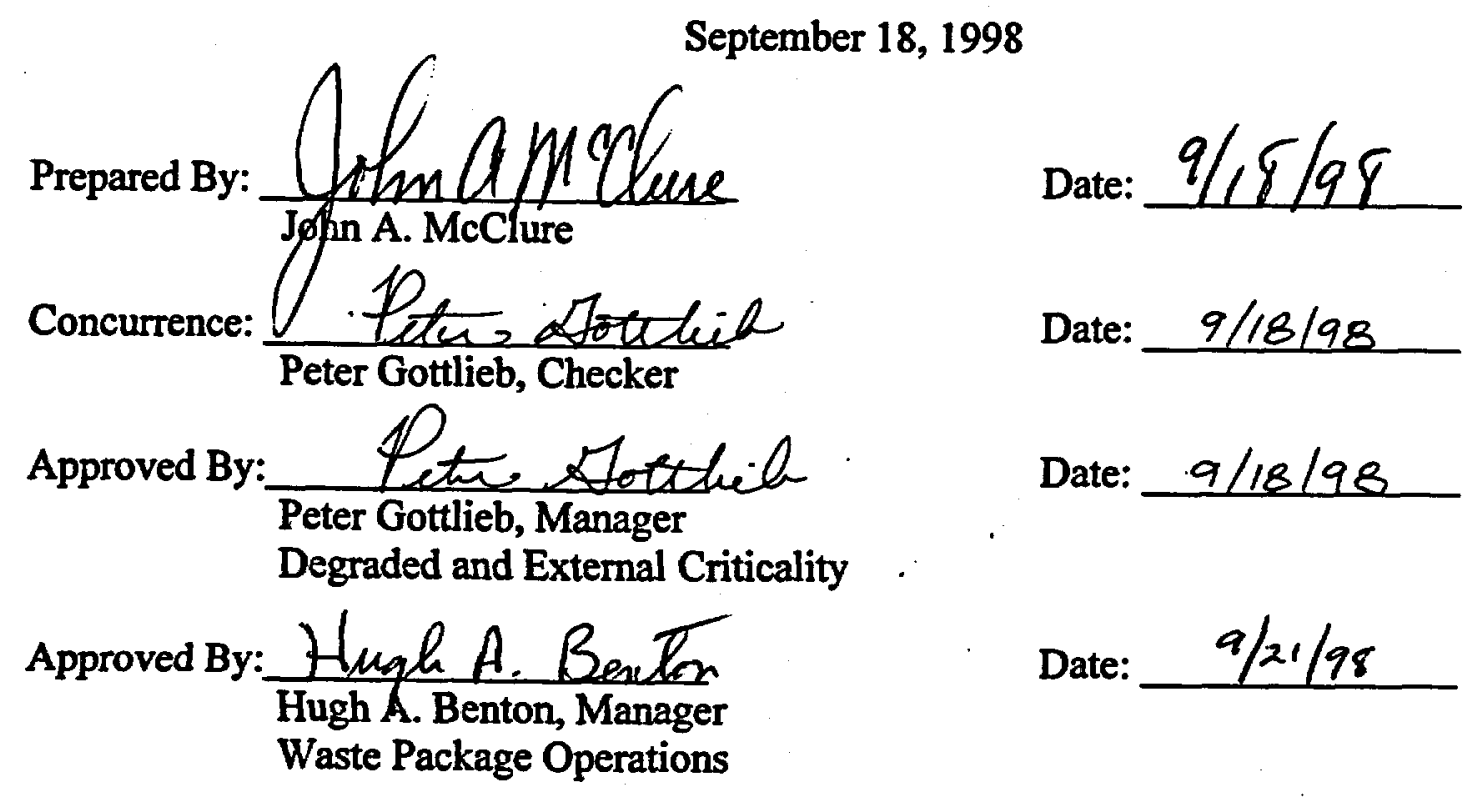


Report on Intact and Degraded Criticality for Selected Plutonium Waste Forms in a Geologic Repository, Volume I: MOX SNF

History of Change Page

Rev/Change Number

Description and Reason for Change

REV 00

Initial Issue 


\section{Report on Intact and Degraded Criticality for Selected Plutonium Waste Forms in a Geologic Repository, Volume I: MOX SNF}

\section{EXECUTIVE SUMMARY}

As part of the plutonium waste form development and down-select process, repository analyses have been conducted to evaluate the long-term performance of these forms for repository acceptance. Intact and degraded mode criticality analysis of the mixed oxide (MOX) spent fuel is presented in Volume I, while Volume II presents the evaluations of the waste form containing plutonium immobilized in a ceramic matrix.

Although the ceramic immobilization development program is ongoing, and refinements are still being developed and evaluated, this analysis provides value through quick feed-back to this development process, and as preparation for the analysis that will be conducted starting in fiscal year (FY) 1999 in support of the License Application.

While no MOX fuel has been generated in the United States using weapons-usable plutonium, Oak Ridge National Laboratory (ORNL) has conducted calculations on Westinghouse-type reactors to determine the expected characteristics of such a fuel. These spent nuclear fuel (SNF) characteristics have been used to determine the long-term potential for criticality in a repository environment.

In all instances the methodology and scenarios used in these analyses are compatible with those developed and used for Commercial Spent Nuclear Fuel (CSNF) and Defense High Level Waste (DHLW), as tailored for the particular characteristics of the waste forms. This provides a common basis for comparison of the results.

This analysis utilizes dissolution, solubility, and thermodynamic data that are currently available. Additional data on long-term behavior is being developed, and later analyses (FY 99) to support the License Application will use the very latest information that has been generated. Ranges of parameter values are considered to reflect sensitivity to uncertainty. Most of the analysis is focused on those parameter values that produce the worst case results, so that potential licensing issues can be identified.

\section{MOX (Volume I)}

This study is concerned with evaluating the criticality potential of the intact and degraded forms of the MOX SNF in waste packages (WPs). Current designs for both the 21 PWR WP and the 12 PWR WP are analyzed. Aluminum thermal shunts were used in both designs to enhance the heat flow rate.

This study also includes an evaluation of the structural, thermal, and shielding impacts of the MOX SNF WP's. Although previous analyses showed these impacts to be within regulatory and safety requirements, a more comprehensive evaluation is appropriate at this time to reflect the current MOX design and to prepare for the License Application analysis phase. 


\section{Report on Intact and Degraded Criticality for Selected Plutonium Waste Forms in a Geologic Repository, Volume I: MOX SNF}

Since the MOX WP's will have criticality performance very similar to the waste packages containing commercial low enriched uranium (LEU) SNF, the criticality evaluations follow the same methodology of initial analysis with the following steps:

1. Criticality evaluation of the intact configuration to demonstrate the effectiveness of the criticality control measures,

2. Criticality evaluation of the same degraded basket configurations that have been used for the commercial LEU SNF,

3. Determination of the configurations having both degraded basket and degraded MOX SNF, using the geochemistry code, EQ6, as has also been done for the commercial LEU SNF, and

4. Criticality evaluation of the combined degraded basket and degraded SNF configurations.

\section{Major Findings, MOX (Volume I)}

Based on the current available data and designs for the MOX fuel, we find the following:

1. Assuming that the MOX SNF will be emplaced at least 10 years following discharge, those assemblies having low burnup ( $\leq 46 \mathrm{GWd} / \mathrm{MTHM}$ ) can be loaded into the standard commercial 21 PWR WP, and those assemblies having high burnup ( $>46 \mathrm{GWd} / \mathrm{MTHM})$ can be loaded into the standard commercial 12 PWR WP. With the expected distribution of burnups in the MOX SNF, this strategy will result in approximately half the MOX assemblies being placed in each of the two types of waste package. This emplacement strategy will also have the following performance aspects:

- The MOX SNF waste packages meet all regulatory requirements.

- There is no credible intact or degradation scenario leading to an internal criticality in the waste packages.

- Structural, thermal, and shielding impacts are no greater (and may be less) than those of the corresponding commercial SNF waste packages.

2. The most severe structural hazard to the waste package is modeled by a finite element analysis of a tipover accident. It is found that the peak stress in the waste package, resulting from such an event, will be at least $15 \%$ less than the ultimate material tensile strength of the material. This shows that the structural behavior of both the 21 PWR WP and the 12 PWR WP will be within design limits. The MOX SNF WP stress values are very similar to values calculated for commercial SNF WP's, as would be expected, since both fuel types have similar SNF assembly weights.

3. Assuming that the MOX SNF will be emplaced at least 10 years following discharge, the 


\section{Report on Intact and Degraded Criticality for Selected Plutonium Waste Forms in a Geologic Repository, Volume I: MOX SNF}

maximum initial heating rates for the MOX SNF were 798 watts/assembly for the 21 PWR WP and 1070 watts/assembly for the 12 PWR WP. These values are less than the 850 watts/assembly and 1500 watts/assembly used as the thermal design basis for commercial LEU PWR SNF, indicating that the MOX assemblies are well within the design envelope of the commercial SNF WP. The peak fuel temperature calculated for the 21 MOX PWR WP was approximately $336^{\circ} \mathrm{C}$, and that for the $12 \mathrm{MOX} \mathrm{PWR}$ was approximately $302^{\circ} \mathrm{C}$. These temperatures are well below the established design limit of $350^{\circ} \mathrm{C}$.

4. Dose rates from both neutron and gamma radiation were calculated for the 21 PWR WP loaded with the highest burnup MOX SNF and the shortest cooling period after reactor discharge (10 years) to serve as a worst case that would give the highest dose rates. Maximum dose values at the exterior surfaces of the waste package were less than 110 $\mathrm{rad} / \mathrm{hr}$. Maximum dose rates from the MOX SNF were much less than from commercial LEU PWR SNF of similar burnup which were calculated to be greater than $150 \mathrm{rad} / \mathrm{hr}$. The 12 MOX PWR WP design has an equivalent amount of shielding with a smaller radiation source, which should result in smaller surface dose rates.

The design limit of $100 \mathrm{rad} / \mathrm{h}$ on the surface rate was specified so that no significant increase could occur in the corrosion rate of the waste package barrier due to any radiolytic compounds synthesized from moist air. For both waste packages, the SNF surface dose rate exceeded the design limit only during the period immediately following emplacement when humidity in the external environment is expected to be low. It is concluded, therefore, that no increase in corrosion rates from radiolysis will occur.

5. Criticality evaluations were performed for the 21 PWR MOX SNF WP and the 12 PWR MOX SNF WP for conditions ranging from intact to fully degraded fuel and basket. The peak $k_{\text {eff }}$ 's ranged from 0.55 to 0.90 where the 0.90 resulted from a worst case configuration. The following observations on the criticality potential of the PWR MOX SNF can be made:

- The 12 PWR WP has a higher $\mathrm{k}_{\text {eff }}$ than the 21 PWR WP for the flooded conditions with intact fuel and basket because the 12 PWR WP has no neutron absorber plates.

- The 12 PWR WP has a lower $k_{\text {eff }}$ than the 21 PWR WP for the flooded conditions with intact fuel, but with degraded basket, because the iron oxide corrosion products displace moderator compensating, in part, for the absence of absorber plates.

- The worst case $\mathrm{k}_{\text {eff }}$ is below the criticality limit of 0.92 for any credible configuration and thus a criticality event internal to the waste package is virtually impossible.

\section{Ceramic (Volume II)}

For the ceramic waste form the principal criticality control measure is the incorporation of neutron absorbing material in the waste form itself. The potential for criticality is determined primarily by the amount of such neutron absorber material remaining in the waste package if, and when, the waste package is breached, and its contents are thereby exposed to aqueous 


\section{Report on Intact and Degraded Criticality for Selected Plutonium Waste Forms in a Geologic Repository, Volume I: MOX SNF}

corrosion. Under such conditions the waste form can be corroded; the fissile material in the waste form (either plutonium or its decay product uranium) will remain in the waste package for hundreds of thousands of years, because it is very insoluble under most water chemistry conditions. The neutron absorber hafnium is even less soluble than the fissile material so it will remain in the WP. However, the more neutronically efficient absorber, gadolinium, could become more soluble under some conditions and could eventually be flushed from the waste package.

This study is concerned with evaluating the potential for criticality of the currently defined ceramic waste form. After a few criticality calculations to demonstrate that the intact configuration is safely below the critical limit, the study is focused on identifying those degraded configurations that are most reactive (result in the highest values of the neutron multiplication factor, $\mathrm{k}_{\mathrm{eff}}$ ). The degraded configurations having the greatest potential for criticality are selected out of the range of configurations arising from the set of degradation scenarios analyzed with the geochemistry code, EQ6. The degradation scenarios examined with the geochemistry code are those most likely to lead to a loss of a major fraction of the neutron absorber material, by virtue of an increase in the solubility of that material.

Shielding, thermal, and structural evaluations were not performed explicitly for immobilized $\mathrm{Pu}$ waste package because the comparison cases with the DWPF WP had not yet been completely evaluated. Nevertheless, conservative comparison with previous evaluations of a similar WP concept does support a finding that inclusion of the immobilized plutonium has a negligible repository impacts.

\section{Major Findings, Ceramic (Volume II)}

Based on the data presently available, and the current canister loading of the current ceramic formulation (28.7 $\mathrm{kg}$ of Pu per canister), we find the following:

1. The ceramic plutonium waste form can be emplaced in the repository at a loading of 5 plutonium containing canisters per waste package; this permits the disposal of immobilized plutonium in the same disposal container/waste package as will be used for the disposal of high level waste (HLW) glass.

- The ceramic plutonium waste package meets all regulatory requirements.

- There is no credible degradation scenario leading to criticality internal to the waste package.

- Thermal and shielding impacts are comparable to, or less than, those of the corresponding HLW waste package.

2. The completely intact configuration has virtually no potential for criticality, since the calculated $\mathrm{k}_{\mathrm{eff}}=0.12$ for the unbreached wasted package, and $\mathrm{k}_{\mathrm{eff}}=0.11$ when all of the void space in the waste package is filled with water. 


\section{Report on Intact and Degraded Criticality for Selected Plutonium Waste Forms in a Geologic Repository, Volume I: MOX SNF}

3. The processes in the expected degradation scenarios will generally have the following sequence:

- breach of the waste package by aqueous corrosion, and wetting of all interior surfaces,

- breach of the stainless steel canisters containing the HLW filler glass and the plutonium ceramic waste form,

- dissolution of the filler glass,

- breach of the inner cans that actually contain the plutonium ceramic disks,

- corrosion of the stainless steel of the canisters and cans, and

- dissolution of the ceramic waste form.

Many of these processes will overlap in time. In fact, the overlap of the last two processes (corrosion of the stainless steel and dissolution of the ceramic waste form) is what gives rise to the possibility of gadolinium removal.

4. The degraded configurations are divided into two types:

- intermediate-level degraded, in which the ceramic disks remain intact, while all the other components of the waste package have been degraded or fragmented (and the soluble degradation products are removed from the waste package), and

- fully collapsed, in which the ceramic disks are also degraded and/or fragmented and all the fragments and insoluble degradation products mixed into a homogeneous layer at the bottom of the waste package.

5. The following are the principal criticality ( $\left.k_{\text {eff }}\right)$ results for the worst cases of these two configuration types:

- For the intermediate degraded configurations there will be no significant loss of the principal neutron absorber, gadolinium, and: $\mathrm{k}_{\mathrm{eff}}<0.38$.

- For the fully collapsed configurations there could be as much as a $13 \%$ loss of the neutron absorbing gadolinium, but the more dominating effect is the geometry being less favorable to criticality than the intermediate degraded configurations, so that $k_{\mathrm{eff}}<0.33$, which is less than 0.38 for the intermediate degraded configurations. 


\section{Report on Intact and Degraded Criticality for Selected Plutonium Waste Forms in a Geologic Repository, Volume I: MOX SNF}

\section{Ceramic (Volume II)}

For the ceramic waste form the principal criticality control measure is the incorporation of neutron absorbing material in the waste form itself. The potential for criticality is determined primarily by the amount of such neutron absorber material remaining in the waste package if, and when, the waste package is breached, thereby exposing its contents to aqueous corrosion. Under such conditions the waste form can be corroded; the fissile material in the waste form (either plutonium or its decay product uranium) will remain in the waste package for hundreds of thousands of years, because it is very insoluble under most water chemistry conditions. The neutron absorber hafnium is even less soluble than the fissile material so it will remain in the waste package. However, the more neutronically efficient absorber, gadolinium, could become more soluble under some conditions and could eventually be flushed from the waste package.

This study is concerned with evaluating the potential for criticality of the currently defined ceramic waste form. After a few criticality calculations to demonstrate that the intact configuration is safely below the critical limit, the study is focused on identifying those degraded configurations that are most reactive (result in the highest values of the neutron multiplication factor, $\mathrm{k}_{\mathrm{eff}}$ ). The degraded configurations having the greatest potential for criticality are selected out of the range of configurations arising from the set of degradation scenarios analyzed with the geochemistry code, EQ3/6. The degradation scenarios examined with the geochemistry code are those most likely to lead to a loss of a major fraction of the neutron absorber material, by virtue of an increase in the solubility of that material.

Shielding, thermal, and structural evaluations were not performed explicitly for immobilized $\mathrm{Pu}$ waste package because the comparison cases with the Defense Waste Processing Facility (DWPF) waste package had not yet been completely evaluated. Nevertheless, conservative comparison with previous evaluations of a similar waste package concept does support a finding that inclusion of the immobilized plutonium has a negligible excess repository impact.

\section{Major Findings, Ceramic (Volume II)}

Based on the data presently available, and the current canister loading of the current ceramic formulation, we find the following:

1. The ceramic plutonium waste form can be emplaced in the repository at a loading of 5 plutonium containing canisters per waste package; this permits the disposal of immobilized plutonium in the same disposal container/waste package as will be used for the disposal of high level waste (HLW) glass.

- The ceramic plutonium waste package meets all regulatory requirements.

- There is no credible degradation scenario leading to criticality internal to the waste package.

- Thermal and shielding impacts are comparable to, or less than, those of the corresponding 


\section{Report on Intact and Degraded Criticality for Selected Plutonium Waste Forms in a Geologic Repository, Volume I: MOX SNF}

HLW waste package.

2. The completely intact configuration has virtually no potential for criticality, since the calculated $k_{\text {eff }}=0.13$ for the unbreached wasted package, and $k_{\text {eff }}=0.11$ when all of the void space in the waste package is filled with water.

2. The processes in the expected degradation scenarios will generally have the following sequence:

- breach of the waste package by aqueous corrosion, permitting wetting of all interior surfaces,

- breach of the stainless steel canisters containing the HLW filler glass and the plutonium ceramic waste form,

- dissolution of the filler glass,

- breach of the inner cans that actually contain the plutonium ceramic disks,

- corrosion of the stainless steel of the canisters and cans, and

- dissolution of the ceramic waste form.

Many of these processes will overlap in time. In fact, the overlap of the last two processes (corrosion of the stainless steel and dissolution of the ceramic waste form) is what gives rise to the possibility of gadolinium removal.

4. The degraded configurations are divided into two types:

- intermediate-level degraded, in which the ceramic disks remain intact, while all the other components of the waste package have been degraded or fragmented (and the soluble degradation products are removed from the waste package), and

- fully collapsed, in which the ceramic disks are also degraded and/or fragmented with all the fragments and insoluble degradation products mixed into a homogeneous layer at the bottom of the waste package.

5. The following are the principal criticality $\left(\mathrm{k}_{\mathrm{eff}}\right)$ results for the worst cases of these two configuration types:

- For the intermediate degraded configurations there will be no significant loss of the principal neutron absorber, gadolinium, and: $\mathrm{k}_{\mathrm{eff}}<0.38$.

- For the fully collapsed configurations there could be as much as a $13 \%$ loss of the neutron absorbing gadolinium, but the more dominating effect is the geometry being less favorable to criticality than the intermediate degraded configurations, so that $k_{e f f}<0.33$, which is less than for the intermediate degraded configurations. 
Report on Intact and Degraded Criticality for Selected Plutonium Waste Forms in a Geologic Repository, Volume I: MOX SNF

\section{ACRONYMS}

AML

AUCF

B\&W

BOC

B-SS

CDA

DBE

DWPF

FY 99

GWd

HFP

HEU

HM

LEU

MGR

MOX

MTHM

PI

PWR

SDD

SNF

TBV

UCF

USDOE

WP

2-D

3-D
Areal Mass Loading

Advanced Uncanistered Fuel

Babcock and Wilcox

Beginning of Cycle

Borated Stainless Steel

Controlled Design Assumptions

Design Basis Event

Defense Waste Processing Facility

Fiscal Year 1999

Gigawatt Days

Hot Full Power

Highly Enriched Uranium

Heavy Metal

Low Enriched Uranium

Monitored Geologic Repository

Mixed Oxide Fuel

Metric Tons Heavy Metal

Principal Isotopes

Pressurized Water Reactor

System Description Document

Spent Nuclear Fuel

To Be Verified

Uncanistered Fuel

United States Department of Energy

Waste Package

Two Dimensional

Three Dimensional 
Report on Intact and Degraded Criticality for Selected Plutonium Waste Forms in a Geologic Repository, Volume I: MOX SNF

Table of Contents

$\underline{\text { Item }}$

Page

EXECUTIVE SUMMARY IV

ACRONYMS $\mathrm{XI}$

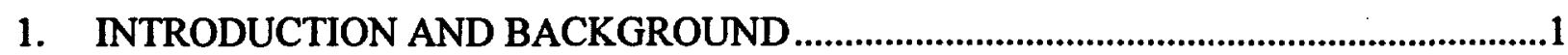

2. WASTE FORM, WASTE PACKAGE, AND WASTE STREAM QUANTITIES.................2

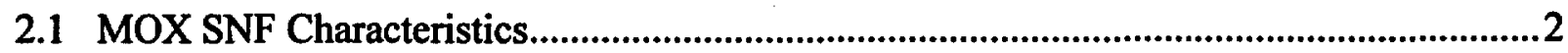

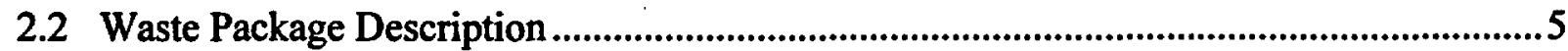

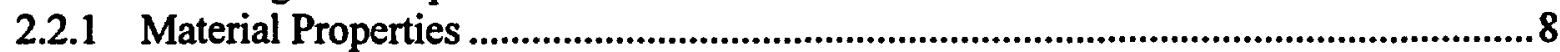

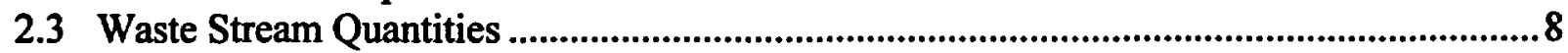

2.4 Waste Package Criticality Control Measures ...............................................................................9

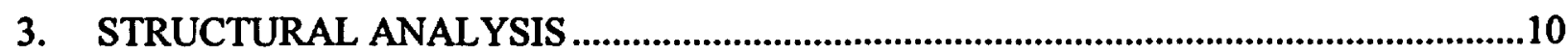

3.1 Structural Analysis Method ................................................................................................10

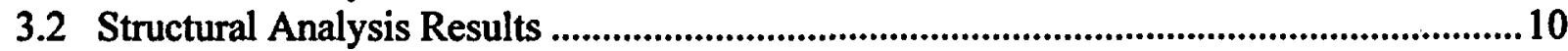

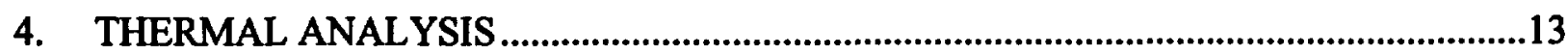

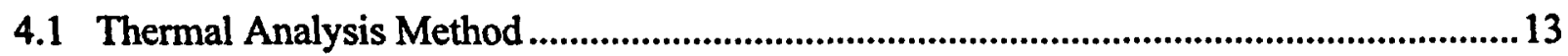

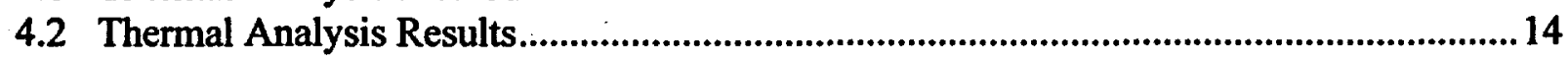

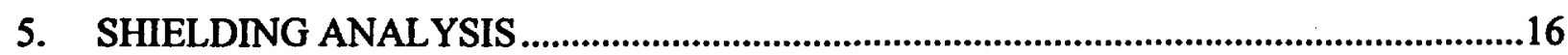

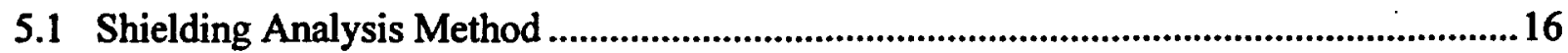

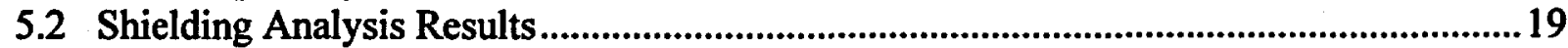

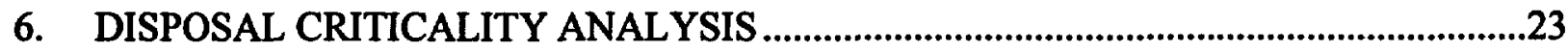

6.1 Disposal Criticality Analysis Methodology for both Intact and Degraded SNF................23

6.2 Criticality Evaluation of the Intact Configuration................................................................25

6.2.1 Intact Fuel and Intact Basket Criticality Model ..............................................................25

6.2.2 Intact Fuel and Intact Basket Criticality Evaluation Results.......................................27

6.3 Degraded Configurations for Criticality Analysis..............................................................30

6.3.1 Methodology for Determining Degraded Configurations ................................................31

6.3.2 Degraded Configurations from Geochemistry Analysis .............................................32

6.3.3 Criticality Evaluation of Degraded Waste Package Configurations ...........................34

6.3.3.1 Configurations for Intact Fuel with Fully Degraded Basket .....................................35

6.3.3.2 Criticality Results for Intact Fuel with Fully Degraded Basket .............................38

6.3.3.3 Configurations for Degraded Fuel and Fully Degraded Basket .............................42

6.3.3.4 Criticality Results for Degraded Fuel and Fully Degraded Basket ........................44

6.4 Summary of Evaluation of Potential Critical Configurations ..............................................46 
Report on Intact and Degraded Criticality for Selected Plutonium Waste Forms in a Geologic Repository, Volume I: MOX SNF

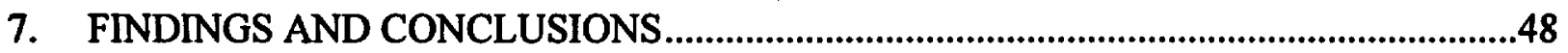

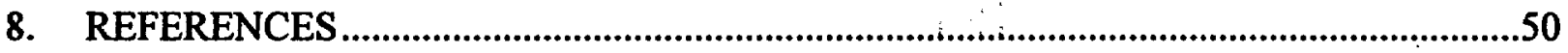




\section{Report on Intact and Degraded Criticality for Selected Plutonium Waste Forms in a Geologic Repository, Volume I: MOX SNF}

Figures

$\underline{\text { Item }}$

Figure 2.1-1. Thermal Power Generation from MOX SNF Actinide Composition.........................5

Figure 2.2-1. 21-PWR UCF Waste Package Assembly ........................................................................6

Figure 2.2-2. 12-PWR UCF Waste Package Assembly .......................................................................7

Figure 4.2-1. Temperature Histories for 21 PWR MOX WP.......................................................14

Figure 4.2-2. Temperature Histories for 12 PWR MOX SNF WP ................................................. 15

Figure 5.2-1. Waste Package Surfaces for Radial Dose Rate Calculation......................................19

Figure 5.2-2. Radiation Dose Rate Over Time from the 21 MOX PWR WP Mid-Region ..........21

Figure 5.2-3. Axial Profile of Dose Rates at the Outside Surface of the 21 MOX PWR WP .....22

Figure 6.1-1. Degradation Sequence of the 21 PWR Basket Structure Following WP Breach....24

Figure 6.2.1-1. Intact 21 PWR MOX Fuel Waste Package...........................................................26

Figure 6.2.1-2. Intact 12 PWR MOX Fuel Waste Package........................................................26

Figure 6.2.2-1. Time Effects on $\mathrm{k}_{\text {eff }}$ for Intact MOX SNF and Intact Baskets in a 21 PWR

Absorber Plate WP

Figure 6.2.2-2. Time Effects on $\mathrm{k}_{\text {eff }}$ for Intact MOX SNF and Intact Baskets in a 12 PWR WP 29

Figure 6.2.2-3. Time Effects on $\mathrm{k}_{\text {eff }}$ for Intact MOX SNF and Intact Baskets in a 12 PWR WP with $\mathrm{Al}$ Shunts

Figure 6.3.2-1. Retention History of Elements of Principal Interest for Criticality Remaining in WP

Figure 6.3.3.1-1. Degraded 21 PWR MOX Fuel Waste Package w/ Uniform Corrosion Product Distribution

Figure 6.3.3.1-2. Degraded 21 PWR MOX Waste Package With Settled Corrosion Product Distribution (58\% solid content)

Figure 6.3.3.1-3. Degraded 12 PWR MOX Fuel Waste Package with Uniform Corrosion Product Distribution

Figure 6.3.3.1-4. Degraded 12 PWR MOX Waste Package With Settled Corrosion Product Distribution ( $58 \%$ solid content)

Figure 6.3.3.2-1. Time Effects on $k_{\text {eff }}$ for Intact MOX and LEU SNF in a 21 PWR WP with a Fully Degraded Basket (No Boron Remaining) and Uniformly Distributed Corrosion Products

Figure 6.3.3.2-2. Time Effects on $\mathrm{k}_{\text {eff }}$ for Intact MOX SNF in a 21 PWR WP with a Fully Degraded Basket (No Boron Remaining) and Settled Corrosion Products.

Figure 6.3.3.2-3. Time Effects on $\mathrm{k}_{\mathrm{eff}}$ for Intact MOX SNF in a 12 PWR WP with a Fully

Degraded Basket and Uniformly Distributed Corrosion Products.

Figure 6.3.3.2-4. Time Effects on $k_{\text {eff }}$ for Intact MOX SNF in a 12 PWR WP with a Fully Degraded Basket and Settled Corrosion Products.

Figure 6.3.3.3-1. Degraded 21 PWR MOX WP with Fuel Rods Collapsed to Bottom of Package

Surrounded by Uniformly Distributed Basket Corrosion Products.

Figure 6.3.3.3-2. Fully Degraded Fuel and Basket Material Uniformly Distributed Throughout

Interior Volume of 21 PWR WP. 


\section{Report on Intact and Degraded Criticality for Selected Plutonium Waste Forms in a}

Geologic Repository, Volume I: MOX SNF

Figure 6.3.3.4-1. Time and Fuel Degradation Effects on $k_{\text {eff }}$ for 21 PWR WP with a Fully Degraded Basket, Square Lattice Collapsed Rods (MOX and LEU), and Uniformly

Distributed Corrosion Products.

Figure 6.3.3.4-2. Time and Fuel Degradation Effects on $k_{\text {eff }}$ for a 21 PWR WP with Fully

Degraded Basket and Fuel, and Uniformly Distributed Corrosion Products 


\section{Report on Intact and Degraded Criticality for Selected Plutonium Waste Forms in a Geologic Repository, Volume I: MOX SNF}

\section{Tables}

$\underline{\text { Item }}$

Table 2.1-1. Mechanical Parameters for Westinghouse 17x17 MOX Fuel Assemblies 2

Table 2.1-2. Initial Heavy Metal Isotopic Content (wt\%) of MOX SNF Assemblies .....................3

Table 2.1-3. MOX Assembly Selection Criteria ...............................................................................

Table 2.1-4. Total Thermal Power Generated from Westinghouse MOX SNF................................4

Table 2.2.1-1. Material Properties of 21 PWR WP Components....................................................8

Table 3.2-1. Finite-Element Structural Analysis Results for the 21 PWR WP .............................12

Table 3.2-2. Finite-Element Structural Analysis Results for the 12 PWR MOX WP. .................12

Table 5.2-1. Major Isotopes Contributing to the Fuel Region Radiation Source........................... 18

Table 5.2-2. Major Isotopes Contributing to the End Fittings Region Radiation Source .............. 18

Table 5.2-3. 10 Year Dose Rates from 21 MOX PWR SNF at External Surface of Waste

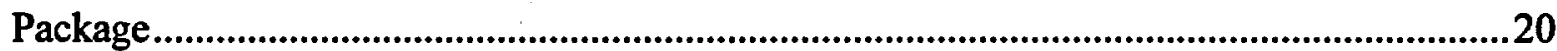

Table 5.2-4. 10 Year Dose Rates at the External Surface from Commercial LEU SNF in the 21

PWR Waste Package

Table 6.3.2-1. Corrosion Products Remaining Following Basket Degradation in the 21 PWR WP

Table 6.3.3.5-1. Peak $k_{\text {eff }}$ for Degraded PWR MOX SNF 


\section{Report on Intact and Degraded Criticality for Selected Plutonium Waste Forms in a Geologic Repository, Volume I: MOX SNF}

\section{INTRODUCTION AND BACKGROUND}

As part of the plutonium waste form development and down-select process, repository analyses have been conducted to evaluate the long-term performance of these forms for repository acceptance. This volume assesses the intact and degraded mode criticality of the mixed oxide (MOX) spent nuclear fuel (SNF). Volume II conducts this assessment for the plutonium waste form immobilized in a ceramic matrix.

Although no MOX fuel has been generated in the United States using weapons-usable plutonium, Oak Ridge National Laboratory (ORNL) has conducted calculations on Westinghouse-type reactors to determine the expected characteristics of such a fuel. This SNF characteristic has been used to determine the long-term potential for criticality in a repository environment.

In all instances, the methodology and scenarios used in these analyses, as tailored for the particular characteristics of the waste forms, are compatible with those developed and used for the Commercial Spent Nuclear Fuel (CSNF) and Defense High Level Waste (DHLW). This provides a common basis for comparison of the results.

This analysis utilizes dissolution, solubility, and thermodynamic data that are currently available. As additional data becomes available, it will be used to support the License Application. Where applicable, ranges of values will be used to bound the results.

The content of this volume is organized as follows:

- Section 2 provides a brief description of the waste packages and the plutonium waste forms and quantities.

- Section 3 discusses the structural analyses conducted on the waste packages.

- Section 4 discusses the thermal analyses conducted on the waste packages.

- Section 5 discusses the radiation shielding analyses conducted on the waste packages.

- Section 6 discusses the criticality evaluations performed on the intact and degraded MOX waste forms. Degradation configurations important for criticality considerations were calculated with the geochemistry code EQ3/6. Results of these calculations were utilized in the criticality evaluations of the degraded configurations and compared to criticality evaluations of low enriched uranium (LEU) SNF.

- Section 7 summarizes the major findings from this study.

This document has been prepared according to Procedure PRO-TS-003, Development of Technical Documents Not Subject to QARD Requirements. The specific activities involved with the production and review of this document have been performed according to an approved Technical Document Preparation Plan (Reference 1). 


\section{Report on Intact and Degraded Criticality for Selected Plutonium Waste Forms in a Geologic Repository, Volume I: MOX SNF}

\section{WASTE FORM, WASTE PACKAGE, AND WASTE STREAM QUANTITIES}

\subsection{MOX SNF Characteristics}

The potential use of MOX fuel in power reactors has been investigated through the development of conceptual designs for commercial pressurized water reactor (PWR) equilibrium reload cycles fueled with MOX assemblies (Ref. 2 and Ref. 3). The most recent design, documented in Reference 3, utilizes 92 fresh MOX assemblies per reload cycle. Two values of fissile $\mathrm{Pu}$, given as weight percent fissile Pu in the heavy metal (HM), were used in this design (Ref. 3, p. 2-11). The fresh reload batch consisted of 20 assemblies with a $4.5 \mathrm{wt} \%$ fissile Pu in HM and 72 assemblies with a $4.0 \mathrm{wt} \%$ fissile $\mathrm{Pu}$ in HM. The core loading for this design was 81.6 metric tons of heavy metal (Ref. 3, p. 2-9) resulting in an average Pu content of $18.48 \mathrm{~kg} /$ assembly. The average burnup for assemblies was targeted at 45 to $50 \mathrm{GWd} / \mathrm{MTHM}$ and ranged from a low value 35 to a high value of $56 \mathrm{GWd}$ /MTHM (Ref. 3, p. 2-39). The steady state discharge distribution consists of 83 assemblies burned for two cycles and 9 assemblies for three cycles (Ref. 3, p. 2-26). All assemblies burned for three cycles were of the $4.0 \mathrm{wt} \%$ fissile Pu in HM type.

The conceptual core design documented in Reference 3 utilized the Westinghouse $17 \times 17$ Vantage 5 commercial assembly type (Ref. 4, p. 2A-30) and is the reference design for this study. Detailed mechanical parameters for these assemblies are given in Reference 5 (Table 5.1-2) and summarized in Table 2.1-1. Assembly dimensions are given primarily in English units and converted into metric units to maintain consistency between calculations using either set of units. Assembly weights are used in the structural analysis (Section 3).

The initial heavy metal isotopic content of the PWR MOX Westinghouse Vantage 5 assembly fuel important for repository considerations is given in Table 2.1-2.

Table 2.1-1. Mechanical Parameters for Westinghouse 17x17 MOX Fuel Assemblies

\begin{tabular}{|c|c|c|c|}
\hline & \multicolumn{3}{|c|}{ Vantage 5 Assembly } \\
\hline Parameter & $\begin{array}{c}\text { Value } \\
\text { Metric Units }\end{array}$ & $\begin{array}{c}\text { Value } \\
\text { English Units }\end{array}$ & References \\
\hline Fuel Length & $365.76 \mathrm{~cm}$ & 144 in. & 3, p. 2-9 \\
\hline Heavy Metal Mass & $422.8 \mathrm{~kg}$ & $932.1 \mathrm{lb}$ & $5, \mathrm{p} .12$ \\
\hline Assembly Weight & $618.8 \mathrm{~kg}$ & $1364.2 \mathrm{lb}$ & 6, p. 6 \\
\hline $\begin{array}{c}\text { Weight of Non-fuel } \\
\text { Material/Assembly }\end{array}$ & $54.4 \mathrm{~kg}$ & $120 \mathrm{lb}$ & 6, p. 6 \\
\hline
\end{tabular}


Report on Intact and Degraded Criticality for Selected Plutonium Waste Forms in a Geologic Repository, Volume I: MOX SNF

Table 2.1-2. Initial Heavy Metal Isotopic Content (wt\%) of MOX SNF Assemblies

\begin{tabular}{|c|c|c|}
\hline Isotopes & $\begin{array}{c}\text { Vantage 5 Assemblies } \\
(4.0 \mathrm{wt} \% \text { Fissile Pu in HM })^{1}\end{array}$ & $\begin{array}{c}\text { Vantage 5 Assemblies } \\
(4.5 \mathrm{wt} \% \text { Fissile Pu in HM })^{1}\end{array}$ \\
\hline${ }^{235} \mathrm{U}$ & 0.191 & 0.190 \\
\hline${ }^{238} \mathrm{U}$ & 95.550 & 95.019 \\
\hline${ }^{239} \mathrm{Pu}$ & 3.983 & 4.481 \\
\hline${ }^{240} \mathrm{Pu}$ & 0.251 & 0.282 \\
\hline
\end{tabular}

The characterization of the potential MOX assemblies with respect to the content of those SNF isotopes of greatest abundance or of most neutronic significance was calculated (Ref. 5) with the SAS2H computer code and the ORIGEN-S computer code. The SAS2H and ORIGEN-S codes are part of the SCALE Code System, Version 4.3 (Ref. 7). A one axial node SAS2H model of the MOX assembly was developed to perform the depletion steps. The multi-cycle burnup histories were derived from the equilibrium MOX core load map (Figure 2-8, Ref. 3, [p. 2-26]). Results from this analysis formed the source data for criticality, thermal, and radiation shielding evaluations of waste package designs for MOX assemblies in the Monitored Geologic Repository (MGR). The particular cases selected under the above criteria are given in Table 2.1-3 together with the controlling criteria. The beginning-of-cycle (BOC) soluble boron concentration $\left(40 \%{ }^{10} \mathrm{~B}\right.$, [Ref. 3, p. 2-14]) was 1301 ppm at hot full power (HFP) conditions and tracked approximately through a reload cycle by a series of burnup steps (Ref. 5, Section 5.5).

Table 2.1-3. MOX Assembly Selection Criteria

\begin{tabular}{|c|c|c|c|}
\hline Case ID & wt\% fissile Pu in HM & $\begin{array}{c}\text { Discharge Burnup } \\
\text { (GWd/MTHM) }\end{array}$ & $\begin{array}{c}\text { Controlling Criteria for } \\
\text { Selection }\end{array}$ \\
\hline 1 & 4.0 & 56.5 & Heat Generation \\
\hline 2 & 4.5 & 46.5 & Heat Generation \\
\hline 3 & 4.0 & 50.1 & $\begin{array}{c}\text { Heat Generation; } \\
\text { Criticality }\end{array}$ \\
\hline 4 & 4.0 & 35.6 & Criticality \\
\hline 5 & 4.5 & 39.4 & Criticality \\
\hline
\end{tabular}

Results from the analysis of Westinghouse MOX SNF relevant to the purpose of this calculation include the thermal power generation and isotopic content of the MOX SNF assemblies as a function of time after discharge from the reactor (Ref. 44). Representative results from the analyses are given in Table 2.1-4 for the thermal power generation in the MOX SNF assemblies.

The total thermal power per assembly generated for each of the heat generation cases as shown in Table 2.1-4 is for a period of 10,000 years beginning 10 years after discharge from the reactor (CDA Key 004 [Ref. 28] specifies that the initial SNF for the repository be at least 10 years old). The total thermal power in the table is the sum of the thermal power generated by radioactive decay of activated light elements, actinides, and fission products. The heating rate contribution from the 


\section{Report on Intact and Degraded Criticality for Selected Plutonium Waste Forms in a Geologic Repository, Volume I: MOX SNF}

different components varies with the assembly burnup value since the SNF isotopic composition is burnup dependent. Over short time periods, heating rates show a direct correlation with burnup due to the short lived isotopes. This correlation does not hold over longer time periods as can be seen by comparing the second and third columns of Table 2.1-4 for times beyond 40 years. This effect is shown graphically in Figure 2.1-1 and also results in a larger source for MOX SNF at times greater than 100-1000 years than is present for LEU SNF (Ref. 24, Figure 5.1). These heating rate values are used as source terms for thermal calculations for the waste packages discussed in Section 4.

Table 2.1-4. Total Thermal Power Generated from Westinghouse MOX SNF

\begin{tabular}{|c|c|c|c|}
\hline $\begin{array}{l}\text { Time } \\
\text { (years) }\end{array}$ & \multicolumn{3}{|c|}{$\begin{array}{l}\text { Total Thermal Power Generation/Assembly } \\
\text { (watts) }\end{array}$} \\
\hline & $56.5 \mathrm{GWd} / \mathrm{MTHM}$ & $50.1 \mathrm{GWd} / \mathrm{MTHM}$ & $46.5 \mathrm{GWd} / \mathrm{MTHM}$ \\
\hline 0.5 & 1044.8 & 871.9 & 785.3 \\
\hline 1.0 & 1027.6 & 856.8 & $\overline{772.4}$ \\
\hline 2.0 & 995.5 & 831.7 & 753.5 \\
\hline 3.0 & 968.5 & 809.9 & 736.0 \\
\hline 4.0 & 944.9 & 791.3 & 721.6 \\
\hline 5.0 & 922.4 & 773.9 & 709.4 \\
\hline 6.0 & 903.1 & 758.7 & 697.5 \\
\hline 7.0 & 884.0 & 744.6 & 687.5 \\
\hline 8.0 & 867.0 & 731.7 & 676.7 \\
\hline 9.0 & 850.2 & 719.9 & 668.0 \\
\hline 10.0 & 835.4 & 708.1 & 659.4 \\
\hline 20.0 & 707.5 & 613.4 & 587.2 \\
\hline 30.0 & 613.4 & 541.4 & 530.3 \\
\hline 40.0 & 541.1 & 485.1 & 485.1 \\
\hline 50.0 & 483.1 & 440.1 & 446.0 \\
\hline 60.0 & 438.0 & 403.4 & 415.7 \\
\hline 70.0 & 401.0 & 374.3 & 390.0 \\
\hline 80.0 & 371.5 & 349.4 & 368.2 \\
\hline 90.0 & 347.8 & 329.9 & 349.6 \\
\hline 100.0 & 327.9 & 313.1 & 334.5 \\
\hline 250.0 & 210.2 & 211.1 & 233.0 \\
\hline 500.0 & 144.0 & 148.0 & 165.0 \\
\hline 750.0 & 106.0 & 109.0 & 122.0 \\
\hline 1000.0 & 80.8 & 83.6 & 94.0 \\
\hline 5000.0 & 23.4 & 24.6 & 28.6 \\
\hline 10000.0 & 16.1 & 17.0 & 20.0 \\
\hline
\end{tabular}




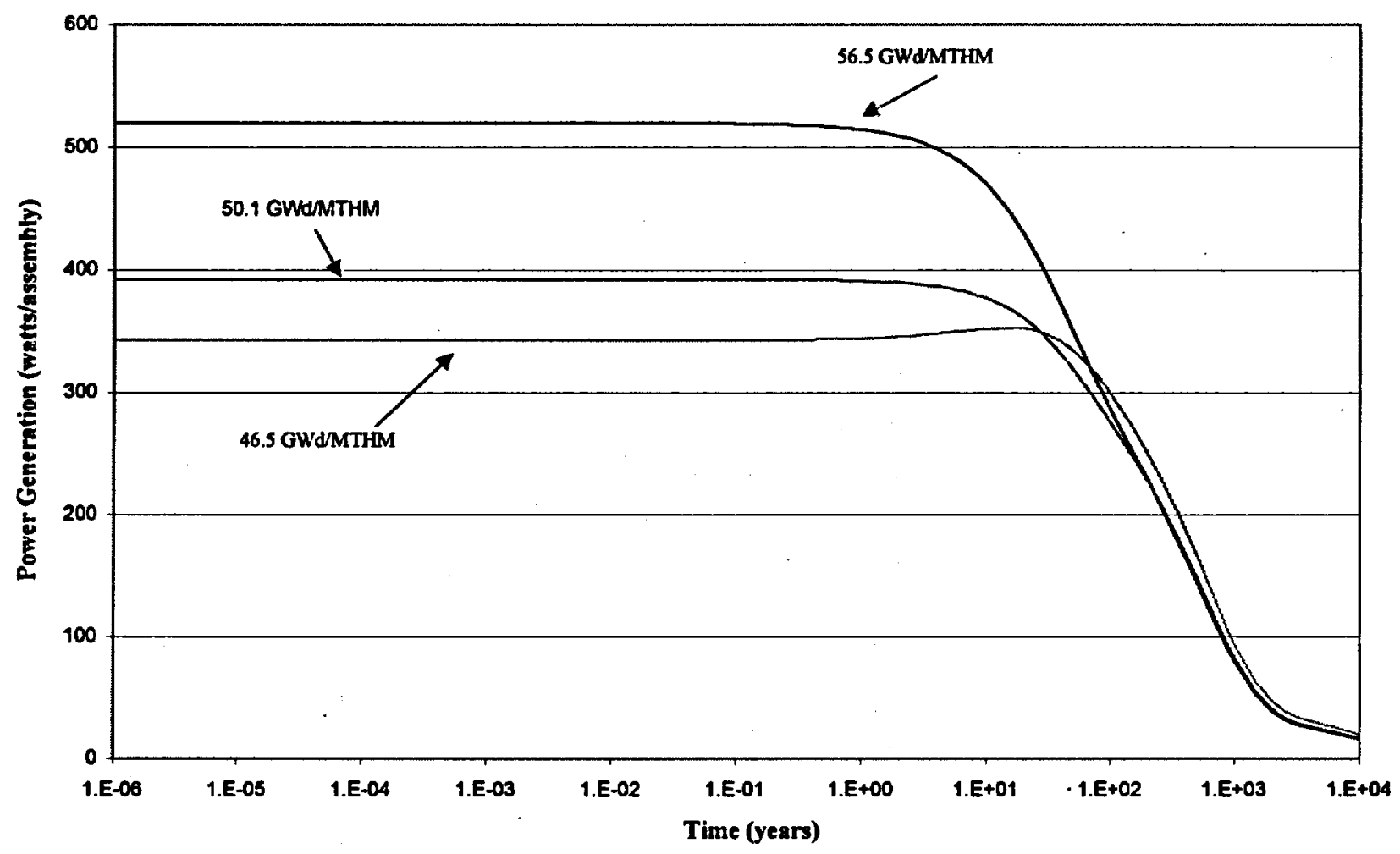

Figure 2.1-1. Thermal Power Generation from MOX SNF Actinide Composition.

Principal Isotope (PI) burnup credit is assumed to be an acceptable method to account for reduced reactivity of SNF in criticality evaluations (CDA Key 009, Ref. 28). A list of 29 "Principal Isotopes" for long-term criticality control in SNF has been previously established (Ref. 8, p. 3-26). The concentrations of these isotopes as a function of time derived from the SAS2H/ORIGEN-S analysis of the MOX SNF is used in the criticality analysis discussed in Section 6.

\subsection{Waste Package Description}

Waste packages considered for MOX SNF are the 21 PWR Advanced Uncanistered Fuel (AUCF) waste package (WP) and the 12-PWR AUCF waste package which are the same as the standard designs for commercial LEU SNF (Ref. 9, Section 8 and Ref. 10, Section 8). These waste packages are illustrated in Figure 2.2-1 and in Figure 2.2-2, respectively. These illustrations depict the waste packages, their internals, and the material specifications. Both designs incorporate techniques to limit the maximum anticipated temperatures in the waste package and fuel cladding materials. The 21 PWR WP design also incorporates borated stainless steel (B-SS) plates in the basket assembly for criticality control. The absorber plates are needed because the MOX assemblies proposed for disposal in this waste package design have the lowest burnup levels and consequently greater fissile Pu content. The nominal 12 PWR WP design does not contain B-SS absorber plates since it is to be used only for high burnup assemblies and the analysis is more conservative by not considering such 
absorber plates. (Borated stainless steel absorber plates can be used in the 12 PWR WP but are not required for criticality control. Using of absorber plates in the 12PWR WP would decrease the criticality potential of the 12 PWR WP even further and, thus, were not considered in this analysis). In the uncanistered waste package design, SNF assemblies are placed directly into the steel basket assemblies enclosed within the corrosion resistant and corrosion allowance barriers. The design for the corrosion barrier includes a corrosion allowance outer barrier material and a corrosion resistant inner barrier material.

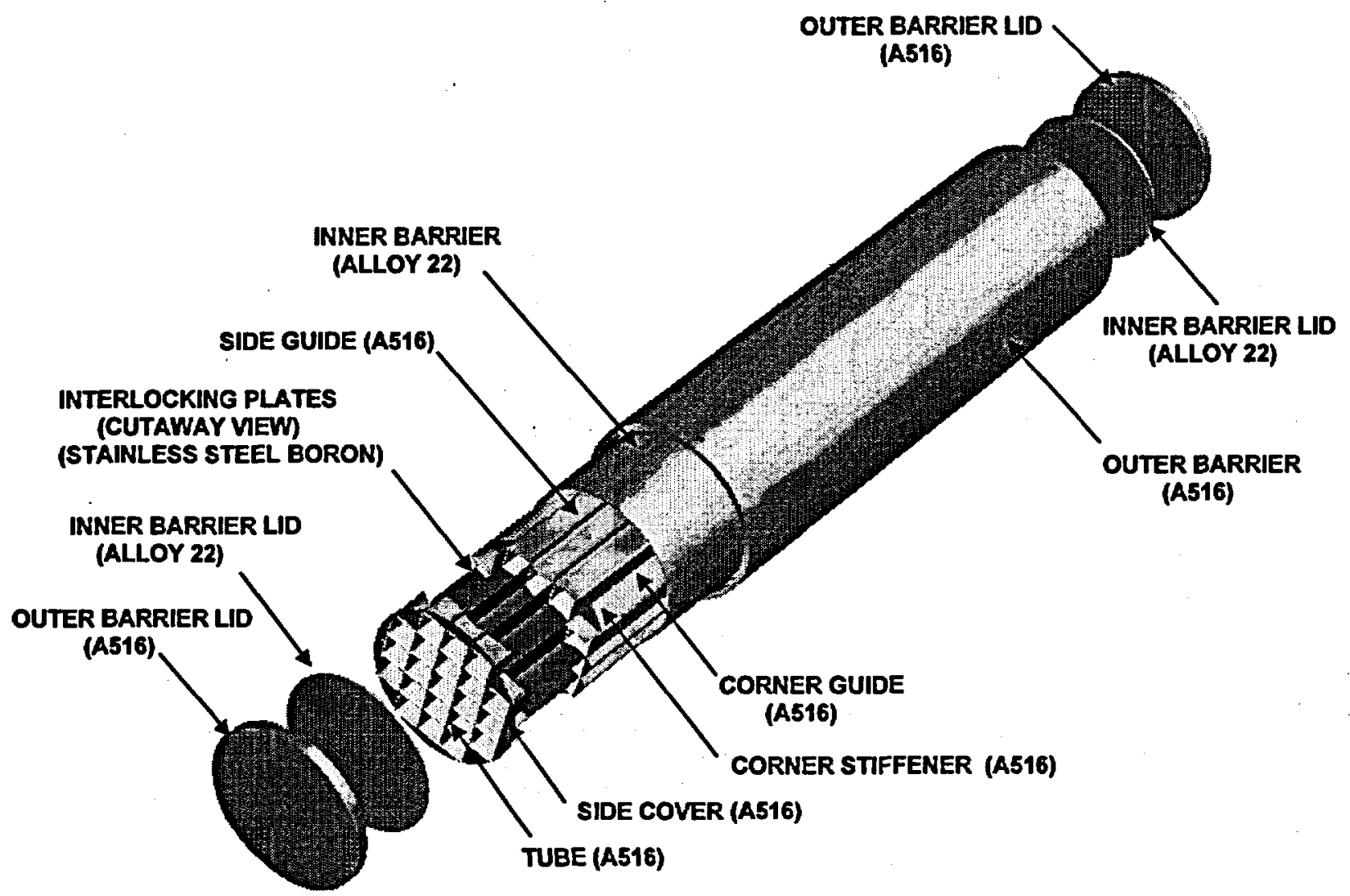

Figure 2.2-1. 21-PWR UCF Waste Package Assembly 


\section{Report on Intact and Degraded Criticality for Selected Plutonium Waste Forms in a Geologic Repository, Volume I: MOX SNF}

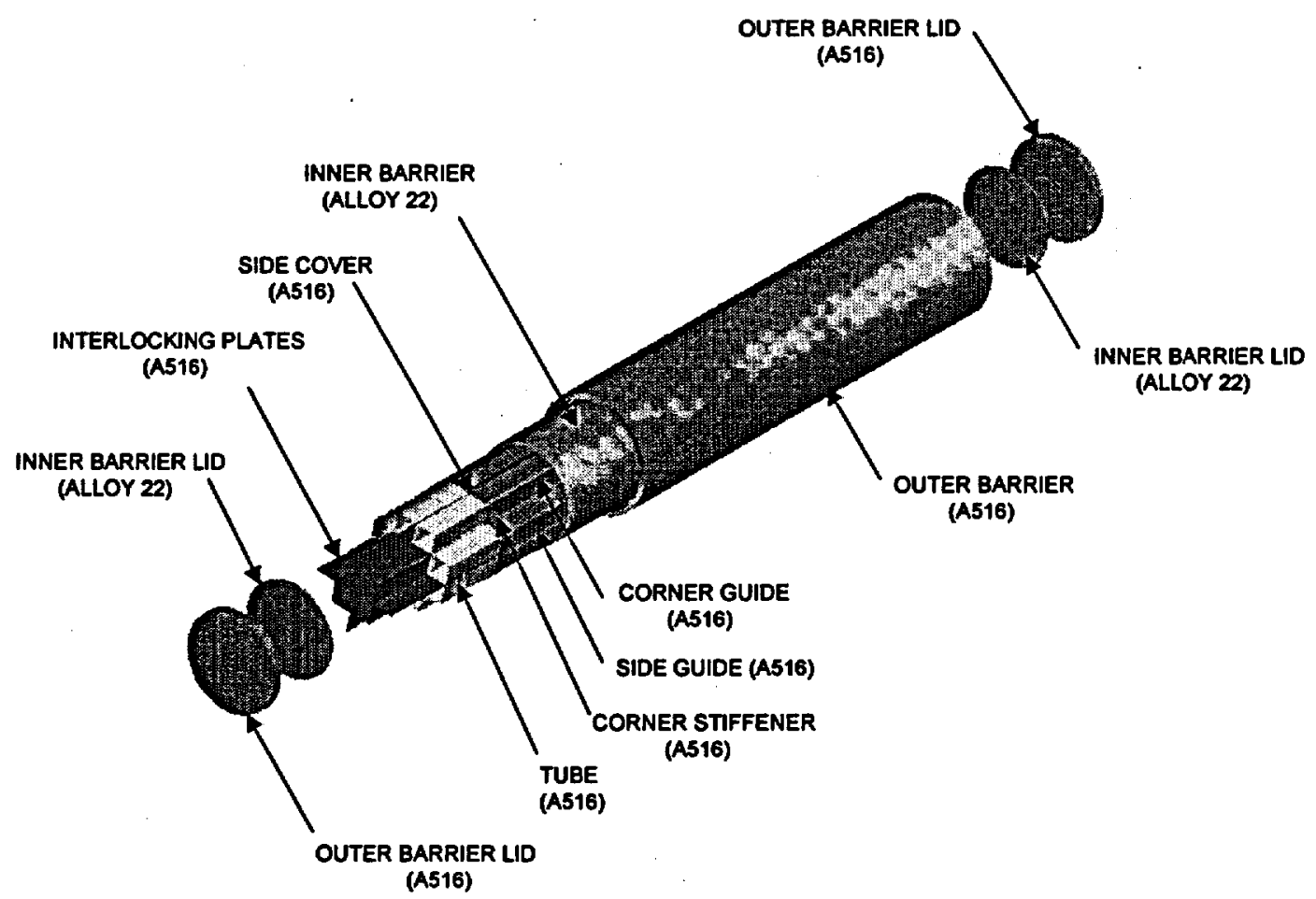

Figure 2.2-2. 12-PWR UCF Waste Package Assembly

All of the analyses were based on these 21 PWR and 12 PWR WP designs but taylored to the particular analysis as appropriate.

The intact waste package geometry parameters used in this analysis are listed in Reference 11, Section 5 . The general waste package assembly information was obtained from References 12 and 13. Since the analysis covers both intact and degraded waste forms, modeling the chemical behavior of these systems is necessary which requires the chemical compositions of the waste package materials, their masses, surface areas, and corrosion or degradation rates as input. Corrosion product volume information for the 21 PWR WP was calculated for the geochemistry analysis (Ref. 14) and is summarized in Section 2.2.1 with the material property data. Corrosion product volumes were calculated for the 12 PWR WP assuming only carbon steel in the basket structure with a mass of $4449.7 \mathrm{~kg}$. Calculating the corrosion product volume for the 12 PWR WP from carbon steel only is conservative since aluminum corrosion products (from thermal shunts) will displace a larger moderator volume than the carbon steel products. 


\section{Report on Intact and Degraded Criticality for Selected Plutonium Waste Forms in a Geologic Repository, Volume I: MOX SNF}

\subsubsection{Material Properties}

Material properties of the 21 PWR MOX SNF WP required for modeling the geochemical behavior of the waste package for the criticality analyses include the masses, surface areas, and average corrosion or degradation rates. Only the average values are listed since variation in the corrosion rate had very minimal effect on the amount of iron or aluminum retained in the WP as solids (Ref. 14, p. 32). These properties are listed in Table 2.2.1-1 (Ref. 14, p. 25). An exception is made, however, for the material of the inner corrosion resistant barrier which is assumed to react so slowly with the infiltrating water as to have negligible effect on the chemistry (Ref. 14, Assumption 3.7).

Table 2.2.1-1. Material Properties of 21 PWR WP Components

\begin{tabular}{|c|c|c|c|}
\hline Component Material & $\begin{array}{c}\text { Mass } \\
(\mathrm{kg})\end{array}$ & $\begin{array}{c}\text { Surface Area } \\
\left(\mathrm{m}^{2}\right)\end{array}$ & $\begin{array}{c}\text { Corrosion Rate } \\
\left(\mathrm{moles} / \mathrm{cm}^{2} / \mathrm{sec}\right)\end{array}$ \\
\hline A516 Gr 55Carbon Steel & 5443.2 & 229 & $1.573 \mathrm{e}-11$ \\
\hline $\begin{array}{c}\text { Borated Stainless Steel } \\
\text { (SS316B6A) }\end{array}$ & 1882.0 & 71 & $1.169 \mathrm{e}-13$ \\
\hline Aluminum (6061 T4) & 146.5 & 43 & $1.263 \mathrm{e}-11$ \\
\hline SNF & $11,054.0$ & 43774 & $4.419 \mathrm{e}-14$ \\
\hline
\end{tabular}

\subsection{Waste Stream Quantities}

Approximately 200 metric tons of fissile material (highly enriched uranium (HEU) and plutonium) have been declared surplus and withdrawn from the U. S. nuclear stockpile. The disposition of surplus HEU was addressed in a DOE 1996 Record of Decision (Ref. 15). In a 1997 Record of Decision (Ref. 16), the strategy adopted by the DOE for disposition of surplus weapons grade plutonium consists partly of direct geologic disposal of Pu immobilized in a ceramic matrix and partly of using the $\mathrm{Pu}$ as mixed oxide fuel (MOX) in one or more commercial reactors with disposal of the spent nuclear fuel (SNF) according to the Nuclear Waste Policy Act.

There are about 50 metric tons of plutonium in the surplus fissile material. Approximately 18 metric tons of this material contains significant quantities of impurities and is considered unsuitable for reactor fuel as MOX. This material has been designated for direct disposal by immobilization in a ceramic waste form. The remaining 32 metric tons of plutonium are suitable for incorporation into MOX assemblies for commercial reactors. The composition of possible MOX SNF assemblies at discharge from a reactor will be substantially different from standard commercial fuel, and, so, must be analyzed to identify potential impacts on the waste package designs and to provide guidance for potential MOX SNF disposal recommendations.

Approximately $1732 \mathrm{MOX}$ assemblies will be required to consume the 32 metric tons of $\mathrm{Pu}$. This translates into 19 core reloads of 92 assemblies per reload. The standard LEU 21 PWR and 12 PWR waste package design are proposed for disposal of the MOX SNF. The 21 PWR WP design will be used for assemblies with lower burnup values (and consequently more fissile Pu content) and the 12 PWR WP design will be used for assemblies with high burnup values and corresponding high thermal heating rates. The number of highly burned assemblies can be estimated from the discharge 
burnup distribution (Ref. 3, p. 2-39). This analysis shows that the MOX SNF burnup limit for the 21 PWR WP is approximately $46.5 \mathrm{GWd} / \mathrm{MTHM}$. This waste package loading criteria results in 43 of the 21 MOX PWR WPs and 72 of the 12 MOX PWR WPs required for the 1732 MOX assemblies.

\subsection{Waste Package Criticality Control Measures}

The criticality control requirement for emplacement and isolation of radioactive waste is that the system $\mathrm{k}_{\text {eff }}$ maintains a minimum $5 \%$ margin below unity after allowing for biases and uncertainties (Ref. 42, Section 2.1.1). To assure such conditions for long term emplacement of MOX SNF, reactivity control measures are necessary the same as for LEU SNF. Reactivity control in the waste packages while the system is intact is provided by borated stainless steel absorber plates in the assembly basket structure as shown in Figure 2.2-1. Insoluble corrosion products from the A516 carbon steel basket structure (notably hematite $\left[\mathrm{Fe}_{2} \mathrm{O}_{3}\right]$ ) may provide long term criticality control for breached but structurally intact waste packages because of moderator displacement. This study shows that only the 21 MOX SNF WPs with the larger fissile Pu content will require reactivity control. The 12 MOX PWR WPs remains subcritical under all degradation scenarios because of the smaller initial fissile Pu inventory and subsequent moderator displacement by waste package corrosion products. Thus, no supplemental absorber plates are necessary for reactivity control in this waste package. 


\section{Report on Intact and Degraded Criticality for Selected Plutonium Waste Forms in a Geologic Repository, Volume I: MOX SNF}

\section{STRUCTURAL ANALYSIS}

The structural design criteria for the waste package is that the waste form be capable of withstanding a two meter drop onto a flat essentially unyielding surface without breaching (EBDRD 3.7.1.1.F, Ref. 28, p. 4-40). The tipover accident produces the highest stresses in the waste package since the upper part of the waste package experiences a drop greater than the two meter criteria. Analyses were performed for the 21 PWR MOX WP (Ref. 17) and 12 PWR MOX WP (Ref. 18) to determine the structural response to a tipover accident design basis event (DBE) dynamic load (Ref. 19, p. 44).

\subsection{Structural Analysis Method}

A three-dimensional finite-element solution was performed by making use of the ANSYS V5.4 finite-element computer code (Ref. 20). A finite-element model of the waste package was developed to determine the effects of tipover accident DBE loads on the waste package structural components. The basket structure in the 21 PWR MOX WP was modeled with B-SS absorber plates and a combination of A516 carbon steel and aluminum in the basket structure. The aluminum serves as a heat conduit (thermal shunt) in the waste package and is not a structural material. The basket structure in the 12 PWR MOX WP was modeled in a similar manner as the 21 PWR MOX WP except that two calculations were conducted on the waste package, one with and one without B-SS absorber plates. The waste package is modeled with an initial orientation of $30^{\circ}$ from vertical in order to initiate tipping of the waste package, and gravitational acceleration is then applied to the system. The simulation is continued throughout the impact until the waste package begins to rebound, at which time the peak stresses have been obtained.

PWR SNF assemblies differ in total weight due to the variations in designs. However, the PWR MOX SNF assemblies have the same maximum weight $(685.9 \mathrm{~kg}$, allowing for variations about the average) as commercial LEU SNF assemblies of similar design (Ref. 6, p. 6). Weight changes due to burnup are negligible (less than $25 \mathrm{~g}$ at the maximum burnup). The structural analyses show that stresses from the tipover accident for both SNF waste forms are of similar magnitude.

\subsection{Structural Analysis Results}

The structural response of the waste package to tipover accident loads is given as maximum stress values obtained from the finite-element solutions to the problem. These solutions indicate that the maximum stress is located in the region of the inner and outer barrier lids in the vicinity of the impact region between the waste package and the target surface for both waste package designs. Linearized stress paths were defined in all of the waste package structural components passing through the nodes with the maximum stress intensity in order to determine the maximum membrane and membrane plus bending stresses. The results of the waste package tipover accident structural analysis are provided in Table 3.2-1 for the 21 PWR MOX WP. Maximum stresses from a similar analysis for the 21 PWR WP containing LEU SNF are also included in Table 3.2-1 (nonWestinghouse assembly, $773.4 \mathrm{~kg}$ assemblies) (Ref. 21, p. 11). Stress results from both cases (with and without absorber plates) calculated for the 12 PWR MOX WP are given in Table 3.2-2. As shown, maximum stress levels for both waste package designs are at least $15 \%$ below the respective 


\section{Report on Intact and Degraded Criticality for Selected Plutonium Waste Forms in a Geologic Repository, Volume I: MOX SNF}

ultimate tensile strength values and thus are within design limits (Ref. 22, Vol. 1, p. 13).

Table 3.2-1 shows that for some waste package components, linearized stresses are higher for the 21 PWR MOX WP than the stresses obtained from the 21 PWR WP containing LEU SNF. Considering the fact that structural analyses were performed using a finite element code and the solution is entirely transient dynamic with stress propagation and nonlinear material properties, the stress peaks of the two models do not necessarily occur at the same time step. Therefore, depending on the element and time discretization, a certain fluctuation in stress magnitudes is anticipated. However, the general trend of the results obtained for both MOX and commercial SNF waste package weights show that all stresses are below the ultimate tensile strength of the waste package component materials. 
Report on Intact and Degraded Criticality for Selected Plutonium Waste Forms in a Geologic Repository, Volume I: MOX SNF

Table 3.2-1. Finite-Element Structural Analysis Results for the 21 PWR WP

\begin{tabular}{|c|c|c|c|c|c|}
\hline WP Component & $\begin{array}{c}\text { Ultimate } \\
\text { Tensile } \\
\end{array}$ & $\begin{array}{c}\text { Strength } \\
(\mathrm{MPa})\end{array}$ & \multicolumn{2}{|c|}{$\begin{array}{c}\text { Maximum Membrane Stress } \\
\text { (Mpa) }\end{array}$} & \multicolumn{2}{c|}{$\begin{array}{c}\text { Maximum Membrane Plus Bending } \\
\text { Stress } \\
\text { (Mpa) }\end{array}$} \\
\cline { 3 - 6 } & 483 & 375 & 340 & 390 & 349 \\
\hline $\begin{array}{c}\text { Outer Barrier } \\
\text { and Outer } \\
\text { Barrier Lid }\end{array}$ & 48 LEU SNF & MOX SNF & LEU SNF \\
\hline $\begin{array}{c}\text { Inner Barrier } \\
\text { and Inner } \\
\text { Barrier Lid }\end{array}$ & 690 & 431 & 407 & 524 & 456 \\
\hline Guides & 483 & 401 & 242 & 413 & 340 \\
\hline Tubes & 483 & 283 & 289 & 302 & 294 \\
\hline $\begin{array}{c}\text { Criticality } \\
\text { Control Plates }\end{array}$ & 550 & 289 & 301 & 319 & 305 \\
\hline
\end{tabular}

Table 3.2-2. Finite-Element Structural Analysis Results for the 12 PWR MOX WP.

\begin{tabular}{|c|c|c|c|c|c|}
\hline & $\begin{array}{c}\text { Ultimate Tensile } \\
\text { Strength } \\
\text { (Mpa) }\end{array}$ & \multicolumn{2}{|c|}{$\begin{array}{c}\text { Maximum Membrane Stress } \\
\text { (Mpa) }\end{array}$} & $\begin{array}{c}\text { Maximum Membrane Plus Bending } \\
\text { Stress } \\
\text { (Mpa) }\end{array}$ \\
\cline { 2 - 6 } & $\begin{array}{c}\text { With Absorber } \\
\text { Plates }\end{array}$ & $\begin{array}{c}\text { Without } \\
\text { Absorber Plates }\end{array}$ & $\begin{array}{c}\text { With Absorber } \\
\text { Plates }\end{array}$ & $\begin{array}{c}\text { Without } \\
\text { Absorber Plates }\end{array}$ \\
\hline $\begin{array}{c}\text { Outer Barrier and } \\
\text { Outer Barrier Lid }\end{array}$ & 483 & 265 & 258 & 360 & 378 \\
\hline $\begin{array}{c}\text { Inner Barrier and } \\
\text { Inner Barrier Lid }\end{array}$ & 690 & 399 & 418 & 404 & 425 \\
\hline Guides & 483 & 220 & 148 & 300 & 285 \\
\hline Tubes & 483 & 326 & 326 & 333 & 347 \\
\hline $\begin{array}{c}\text { Carbon Steel } \\
\text { Plates }\end{array}$ & 483 & N/A & 315 & N/A & 321 \\
\hline Comer Stiffeners & 483 & 307 & 307 & 314 & 317 \\
\hline
\end{tabular}

Not Applicable. Absorber plates replace carbon steel plates. No structural credit taken for absorber plates. 


\section{Report on Intact and Degraded Criticality for Selected Plutonium Waste Forms in a Geologic Repository, Volume I: MOX SNF}

\section{THERMAL ANALYSIS}

Thermal analyses (Ref. 23) were performed under normal repository disposal conditions on the 21 PWR WP and the 12 PWR WP loaded with MOX SNF using the heating rates from Reference 44 (summarized in Table 2.1-4) to demonstrate that these waste packages can accommodate the entire MOX waste stream. The $46.5 \mathrm{GWd} / \mathrm{MTHM}$ heating rates were used in the $21 \mathrm{PWR}$ MOX WP and the $56.5 \mathrm{GWd} / \mathrm{MTHM}$ in the 12 PWR MOX WP. In both cases, the SNF assemblies were assumed to have had a 10 year cooling period prior to emplacement in the waste package (CDA Key 004 [Ref. 28] specifies that the initial SNF for the repository be at least 10 years old).

\subsection{Thermal Analysis Method}

A two-dimensional, time dependent finite-element calculation was performed by making use of the ANSYS V5.1 finite element computer code (Ref. 24). A two-dimensional (2-D) finite-element model was developed (Ref. 23, Section 5.4) for a midpoint cross section of the waste package. This represents the hottest portion of the waste package because of the non-uniform axial heat source distribution. Aluminum thermal shunts were included in the model for both the 21 PWR and 12 PWR WP designs to enhance the heat flow rate.

The SNF assembly, which produces a heat load in the waste package, was modeled as a lumped parameter solid material placed inside each tube in the basket assembly. The time-dependent volumetric heat loads were multiplied by an axial peaking factor of 1.25 (Ref. 25, p. 29) to approximate modeling the axial center of the waste package with a 2-D model. The peaking factor conservatively compensates for the lack of a detailed axially non-uniform assembly power shape. The initial heating rates for the MOX SNF were 798 watts/assembly for the 21 PWR WP and 1070 watts/assembly for the 12 PWR WP. The burnup levels for these assemblies were 46.5 $\mathrm{GWd} / \mathrm{MTHM}$ and $56.5 \mathrm{GWd} / \mathrm{MTHM}$, respectively. These values compared to 850 watts/assembly and 1500 watts/assembly for commercial PWR thermal design basis fuel assemblies (Ref. 25, p. 67) in the respective waste packages. The burnup level for the design basis commercial PWR assembly was $60 \mathrm{GWd} / \mathrm{MTU}$. The initial heating rate values for the commercial PWR SNF correspond to different cooling periods prior to inclusion in the repository waste stream.

Temperature boundary conditions at the exterior surfaces of the 21 and 12 PWR MOX WPs for the 2-D thermal calculations were derived from the time-dependent temperature boundary conditions resulting from the three-dimensional (3-D) multiple waste package calculation (Ref. 26). The waste package boundary surface temperatures were determined at thermal design basis loading of 85 MTU/acre which gives a constant center-to-center spacing for the 21 PWR WP with absorber plates of $15.4 \mathrm{~m}$ and $9.2 \mathrm{~m}$ for the 12 PWR WP with no absorber plates (Ref. 27, p. 17). This areal mass loading (AML) is within the AML range (80 to $100 \mathrm{MTU} / \mathrm{acre}$ ) given in the CDA (Ref. 28, Key 019) as the reference mass loading range. Thus the MOX SNF will pose no additional constraints on the waste package layout. The source for the thermal calculation was derived from the time-dependent radioactive decay heat sources (Ref. 45) documented in Reference 6, Section 6. The 2-D thermal analyses of the waste packages were carried out for a time period of 1000 years following a cooling period of 10 years after discharge from the reactor. 


\subsection{Thermal Analysis Results}

The temperature history containing the peak value in the fuel for 21 PWR MOX SNF WP is shown in Figure 4.2-1 and for the 12 PWR MOX SNF WP in Figure 4.2-2. The location of the peak node was at the center of the innermost assembly in both cases (Note that the fuel assemblies were modeled as a homogenized solid material). The peak values were $336^{\circ} \mathrm{C}$ for the $21 \mathrm{PWR}$ SNF WP and $302^{\circ} \mathrm{C}$ for the $12 \mathrm{PWR}$ WP. The outer surface boundary condition temperatures for the respective cases are also shown in the figures. The peak values for the waste package surface temperatures were $234^{\circ} \mathrm{C}$ for the 21 PWR SNF WP and $218^{\circ} \mathrm{C}$ for the 12 PWR WP. The time of occurrence of the peak waste package surface temperature was about 20 years after emplacement for both histories.

The fuel temperature (homogenized assembly material) peaks at approximately $336^{\circ} \mathrm{C}$ about 7 years after emplacement for the $21 \mathrm{PWR}$ MOX SNF WP and at approximately $302^{\circ} \mathrm{C}$ about 2 years after emplacement for the 12 PWR MOX WP. Both these peak temperatures are well below the maximum permissible waste package temperature of $350^{\circ} \mathrm{C}$ given in the CDA (Ref. 28, DCWP 001, p. 8-1).

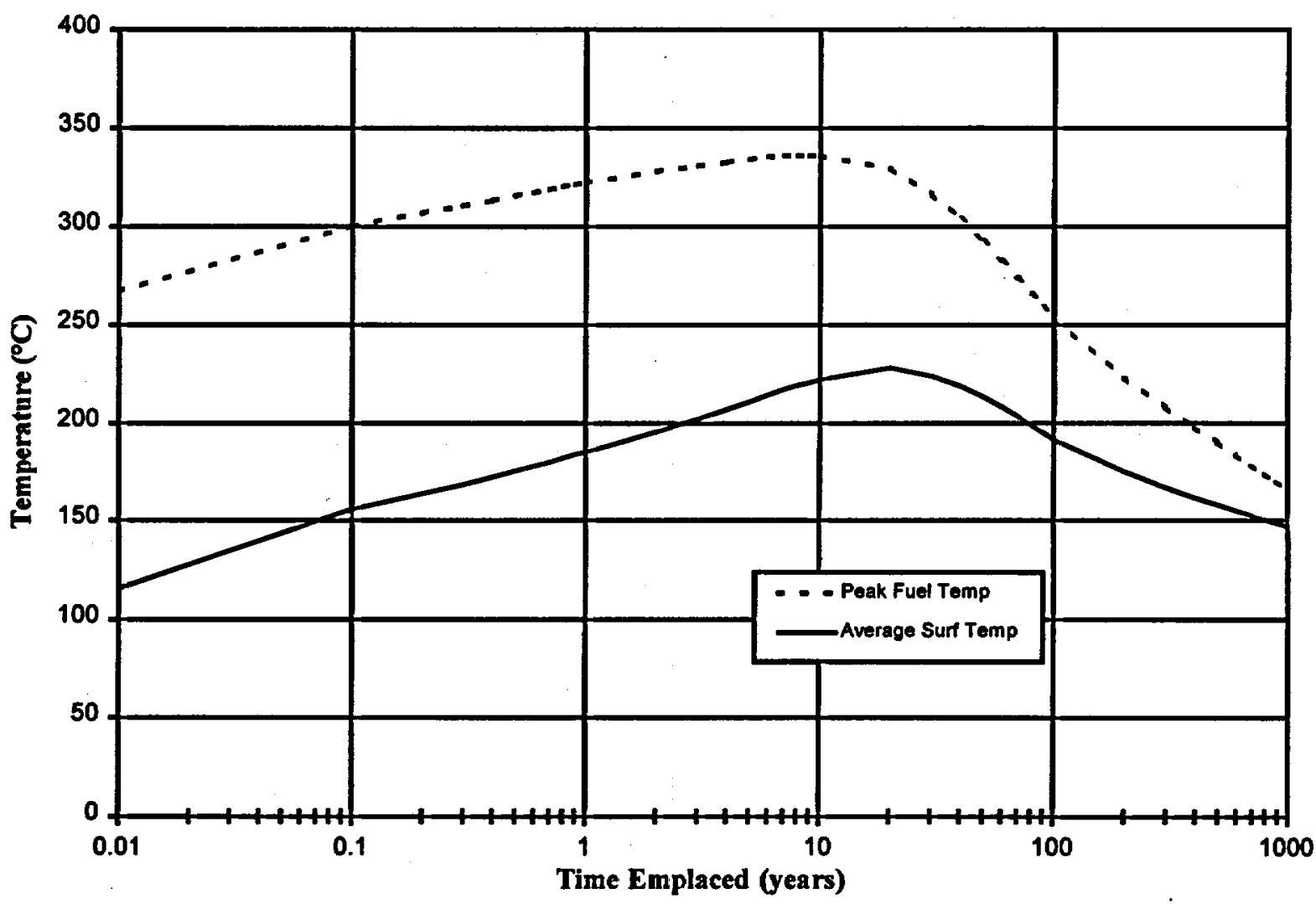

Figure 4.2-1. Temperature Histories for 21 PWR MOX WP 
Report on Intact and Degraded Criticality for Selected Plutonium Waste Forms in a Geologic Repository, Volume I: MOX SNF

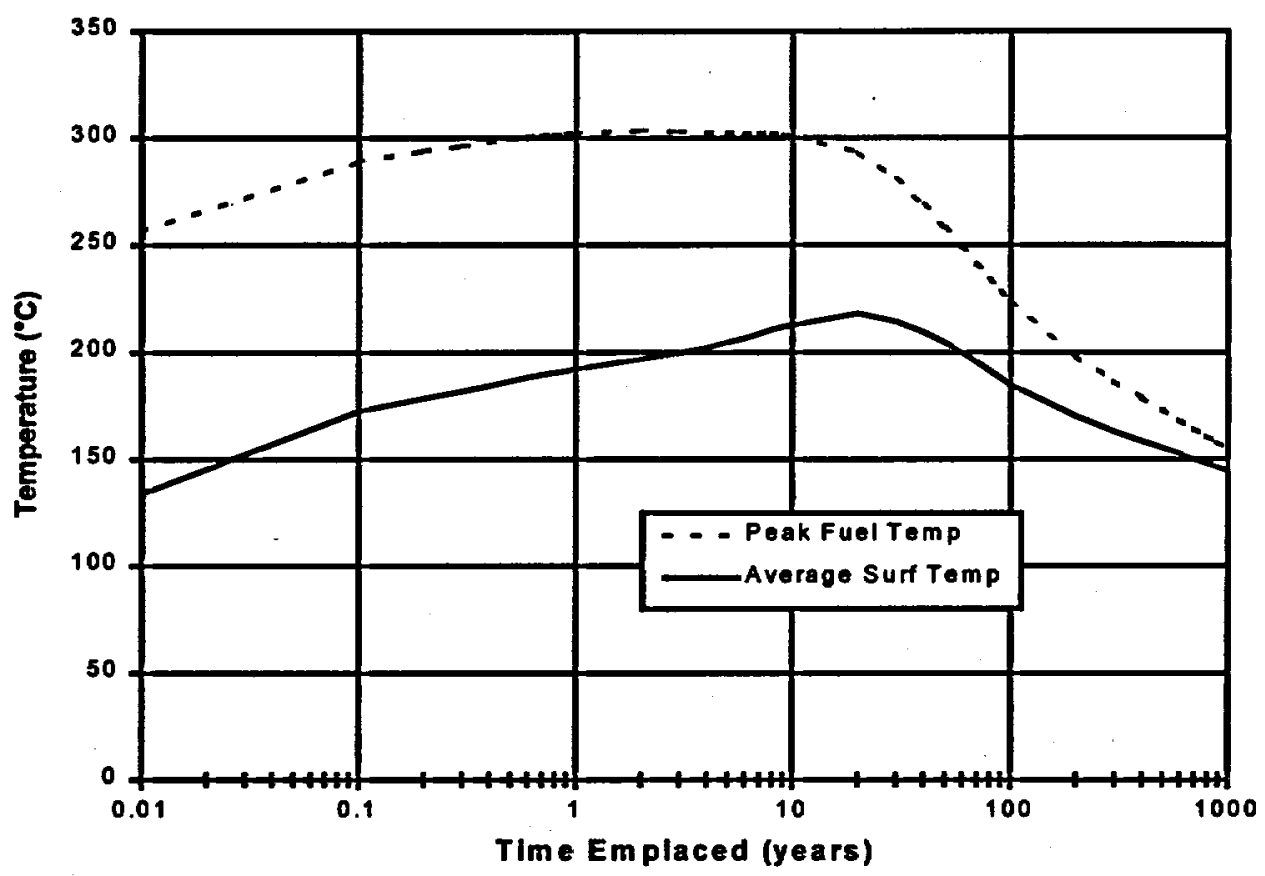

Figure 4.2-2. Temperature Histories for 12 PWR MOX SNF WP 


\section{Report on Intact and Degraded Criticality for Selected Plutonium Waste Forms in a Geologic Repository, Volume I: MOX SNF}

\section{SHIELDING ANALYSIS}

Shielding analyses were performed for the 21 PWR MOX WPs (Ref. 29) using the MOX SNF assembly producing the highest gamma-heating source following discharge from a hypothetical equilibrium PWR MOX reactor (Ref. 5). These analyses required a two step calculation procedure given by:

1) generation of the appropriate radiation source terms for $\mathrm{SNF}$ assemblies (primarily gamma intensity) as a function of time using the SAS2H/ORIGEN-S code sequence from SCALE 4.3 (Ref. 7), and

2) use of the calculated source terms as partial input to the MCNP4B2 code (Ref. 33) to calculate time-dependent dose rates in $\mathrm{rem} / \mathrm{h}$ on various surfaces and external near-field locations around the waste package.

Shielding requirements for AUCF waste packages as given in Key Assumption 031 from the Controlled Design Assumptions Document (CDA) (Ref. 28) states that waste package containment barriers will provide sufficient shielding for protection of waste package materials from radiation enhanced corrosion. Experiments on radiolytic corrosion reported in Reference 30, (Vol. III, p. 8-4) indicate that for iron based materials in an air/steam environment, a $100 \mathrm{rad} / \mathrm{h}$ dose rate at $250^{\circ} \mathrm{C}$ increased the corrosion rate by a factor of 5 but no change in rates were observed at $150^{\circ} \mathrm{C}$. Dose rates from the shielding analysis are given in rem $/ \mathrm{h}$. The factor for converting dose rates in rad/h to $\mathrm{rem} / \mathrm{h}$ for gamma radiation is unity and approximately 10 for neutron. Dose rates in $\mathrm{rad} / \mathrm{h}$ will always be less than or equal to the dose rate in $\mathrm{rem} / \mathrm{h}$.

Methods and results for the shielding calculation are discussed in detail to aid in the interpretation of the time history surface dose rate and to identify the differences between the MOX SNF dose rates and the LEU SNF dose rates.

\subsection{Shielding Analysis Method}

The source terms for the shielding configuration included activation of assembly hardware and were determined by taking the documented amount of hardware for the assembly (Ref. 31, p.2A-349 through 2A-354) and exposing it to the entire active fuel region via the light element option in SAS2H. To do this, the composition and mass of the hardware in each region of the assembly are determined from Reference 31 above. The masses of the hardware components were estimated from descriptions of the particular assembly, i.e., the bottom end fitting, fuel, plenum, or top end fitting region. The light element masses for these components were then adjusted by a scaling factor (Ref. 33, p. 9) to account for the location of the assembly hardware in various axial positions in the reactor. 


\section{Report on Intact and Degraded Criticality for Selected Plutonium Waste Forms in a Geologic Repository, Volume I: MOX SNF}

The PWR MOX WP source terms are generated from the data files (Ref. 44) developed during the analyses documented in Reference 6, Section 6 . The case chosen for the shielding analysis of the 21 PWR MOX WP from the set of analyses reported in this latter reference was the the 56.5 GWd/MTHM burnup case with $4.0 \mathrm{wt} \%$ initial fissile Pu in HM. Results of the shielding analysis will be conservative since this case produced the largest gamma heating source from the MOX analysis.

Shielding calculations have also been carried out for commercial SNF in the 21 PWR WP using a B\&W Mark B assembly having an initial enrichment of $5.05 \mathrm{wt} \%$ fissile uranium and a burnup of 75 GWd/MTU (Ref. 32, p. 4). This burnup level was used since it is the worst case situation for which shielding must be designed. The commercial SNF calculation provides a frame of reference for the MOX SNF shielding results.

The SAS2H/ORIGEN-S code is used to simulate the irradiation of the fuel and the light elements and to decay the radiation source. Time dependent gamma and neutron sources are generated for each time step requested in ORIGEN-S. To use this information as a source in MCNP4B2, the spectrum and group structure for the sources are entered and normalized by the code. The source strength is then entered in the form of a tally multiplier. This multiplier is calculated by multiplying the total source determined in SAS2H/ORIGEN-S analysis by the number of assemblies in the package and by an axial peaking factor of 1.25 . This factor is based on the axial gamma radiation profile from Reference 40, Figure 3-18. The peaking factor conservatively compensates for the lack of a detailed axially non-uniform assembly source profile.

The major isotopes contributing to the sources for the shielding calculations are given in Table 5.2-1 for the MOX PWR SNF and the commercial PWR SNF. The isotopic inventory in both cases was calculated for a 10 year cooling period following discharge from a reactor (CDA Key 004 [Ref. 28] specifies that the initial SNF for the repository be at least 10 years old). Contributions from the fuel region included actinides, fission products, and the light elements. Contributions from the lower end fittings, representative of the non-fueled regions, included only the light elements, Table 5.2-2. The following observations can be made concerning these radiation sources:

1. The MOX SNF actinide curie source was considerably higher than for the commercial SNF but the actinides decay mainly by alpha emission contributing little to the external dose rate.

2. The fission product isotopic distribution from the MOX SNF results in lower relative source contributions from Sr-90 and Y-90 than from the commercial SNF. This is due partly to the higher burnup in the LEU SNF and due partly to the different fission product inventory (curies) as shown in Table 5.2-1.

3. The major contributors to the radiation source in the non-fuel regions are ${ }^{60} \mathrm{Co}$ and ${ }^{125} \mathrm{Sb}$, with the commercial PWR SNF source much larger than the MOX SNF source (Table 5.2-2). The differences result from the end fitting composition differences, notably the greater amount of Inconel-718 in the LEU assembly hardware than in the MOX assembly hardware (Ref. 30, p. 10, Ref. 33, p. 8.

The variation in radiation sources between the MOX and LEU PWR assemblies results in higher calculated dose rates from the LEU assemblies compared to the MOX assemblies. 
Report on Intact and Degraded Criticality for Selected Plutonium Waste Forms in a Geologic Repository, Volume I: MOX SNF

Table 5.2-1. Major Isotopes Contributing to the Fuel Region Radiation Source

\begin{tabular}{|l|r|r|l|r|r|r|r|r|}
\hline \multicolumn{3}{|c|}{ Actinides } & \multicolumn{3}{c|}{ Fission Products } & \multicolumn{3}{c|}{ Light Elements } \\
\hline Isotope & $\begin{array}{c}\text { PWR } \\
\text { (curies) }\end{array}$ & $\begin{array}{c}\text { MOX } \\
\text { (curies) }\end{array}$ & Isotope & $\begin{array}{c}\text { PWR } \\
\text { (curies) }\end{array}$ & $\begin{array}{c}\text { MOX } \\
\text { (curies) }\end{array}$ & Isotope & $\begin{array}{c}\text { PWR } \\
\text { (curies) }\end{array}$ & $\begin{array}{c}\text { MOX } \\
\text { (curies) }\end{array}$ \\
\hline Pu238 & 6080 & 2720 & Kr 85 & 4080 & 1810 & Fe 55 & 56.4 & 28 \\
\hline Pu239 & 191 & 267 & Sr 90 & 55800 & 20600 & Co 60 & 2670 & \\
\hline Pu240 & 400 & 757 & Y 90 & 55800 & 20700 & Ni 63 & 288 & \\
\hline Pu241 & 63700 & 124000 & Cs134 & 6930 & 4520 & Nb 93m & 28.4 & \\
\hline Am241 & 1460 & 2950 & Cs137 & 87900 & 60900 & Sb125 & 67.4 & 146 \\
\hline Cm244 & 9230 & 8320 & Ba137m & 83000 & 57500 & Te125m & 16.5 & 36 \\
\hline & & & Pm147 & 6240 & 5700 & & & \\
\hline & & & Eu154 & 3940 & 3800 & & & \\
\hline Total & 81300 & 140000 & Total & 307000 & 179000 & Total & 3140 & 215 \\
\hline
\end{tabular}

Table 5.2-2. Major Isotopes Contributing to the End Fittings Region Radiation Source

\begin{tabular}{|l|r|r|}
\hline Isotope & PWR & MOX \\
\hline Fe 55 & 88 & 43 \\
\hline Co 60 & 223 & 109 \\
\hline Ni 63 & 56 & 20 \\
\hline Sb125 & 179 & \\
\hline Te125m & 44 & \\
\hline Total & 598 & 177 \\
\hline
\end{tabular}

Fuel assemblies and their hardware compositions are homogenized over the inside dimension of the waste package in the geometric model for the MCNP calculation with no shielding credit taken for the waste package basket and basket guide materials. This is a conservative approach for dose rate calculations since: (1) the internal basket structure would attenuate the neutron and gamma ray flux, and (2), homogenizing the assemblies inside the waste package in effect moves the source closer to the outer surface of the waste package, thereby allowing more particles to reach the outer surface. The corrosion allowance barrier in the waste package was assumed to begin degradation when the repository humidity reaches $\mathbf{7 5 \%}$ at approximately 700 years after emplacement, thus gradually reducing the original quantity of shielding material.

A different calculation was made for each of four gamma sources representative of four axial regions in the waste package (bottom end, fuel, upper plenum, and top end) and one fuel region neutron source to isolate the contribution from each. These contributions are then summed to yield a total dose. 


\section{Report on Intact and Degraded Criticality for Selected Plutonium Waste Forms in a Geologic Repository, Volume I: MOX SNF}

\subsection{Shielding Analysis Results}

Radiation dose rates were calculated at a number of locations both interior and exterior to the 21 PWR MOX. Dose rates were calculated in the radial direction on the inside and outside surfaces of the corrosion allowance and resistant shells, shown in Figure 5.2-1, and at the one and two meter distances from the outside surface of the waste package. Axially, the dose rate was determined on the exterior surface and 2 meters from the waste package. The maximum source strength is in the mid-region of the waste package and maximum dose rates occurred in the radial direction normal to the waste package central axis. The total dose rates, together with the neutron and gamma components, in the radial direction at 10 years following reactor discharge are given in Table 5.2-3 for the surfaces defined in Figure 5.2-1. The dose rates at these surfaces are calculated from contributions from all source regions. The dose rate in $\mathrm{rem} / \mathrm{h}$ at several radial positions in the waste package mid-region is shown in Figure 5.2-2 as a function of time. At locations interior to the waste package, the dose rate declines monotonically with time as the source decays. Exterior to the waste package, however, the dose rate rises slightly in the period between approximately 700 and 12,000 years but is always lower than at the initial time. This is primarily due to the loss of shielding

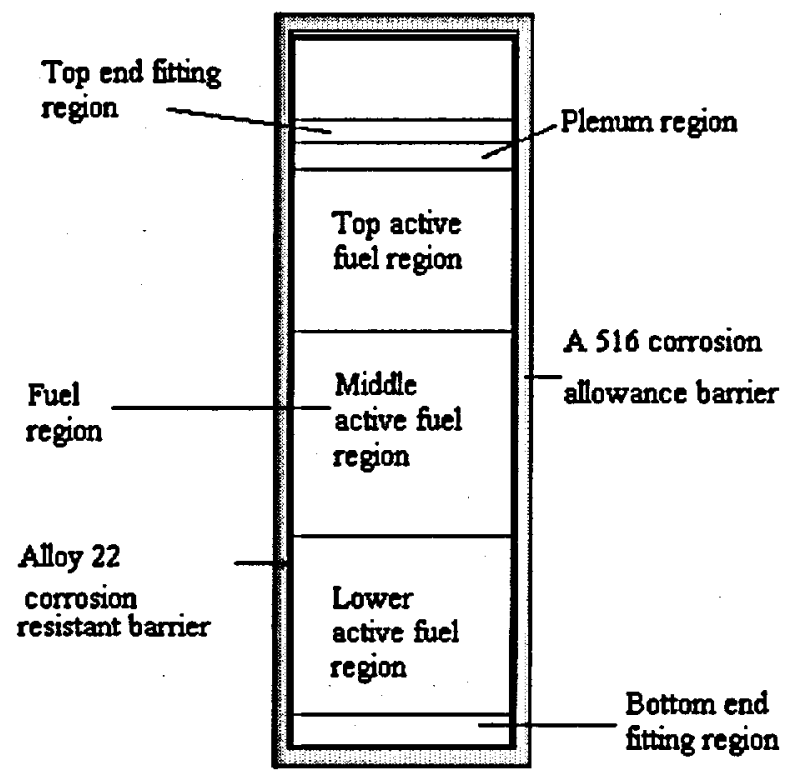

Figure 5.2-1. Waste Package Surfaces for Radial Dose Rate Calculation.

material as the corrosion allowance waste package material (A516 carbon steel) begins to degrade. Axial profiles of the radial dose rates at the waste package at the exterior surface of the waste package are shown in Figure 5.2-3 for various times following emplacement. The gamma dose from the end regions (see Table 5.2-3) results, in part, from ${ }^{60} \mathrm{Co}$ in the Inconel components as shown in Table 5.2-2. The spectrum of the gamma radiation from the fuel and end regions differs, resulting in the modest peaks near the assembly ends. These peaks are short-lived as shown in Figure 5.2-3.

Dose rates on the surface of the 21 PWR WP for commercial PWR SNF at 10 years following 


\section{Report on Intact and Degraded Criticality for Selected Plutonium Waste Forms in a Geologic Repository, Volume I: MOX SNF}

reactor discharge are shown in Table 5.2-4 (Ref. 32, Section 6.2). The commercial SNF used in the shielding calculation was a B\&W Mark B assembly having an initial enrichment of $5.05 \mathrm{wt} \%$ fissile uranium and a burnup of $75 \mathrm{GWd} / \mathrm{MTU}$. This burnup level was used since it is the worst case situation for which shielding must be designed. As shown, the dose rates at the waste package surface from Table 5.2-4 are considerably higher than for the MOX SNF WP consistent with the differences in the source values.

Table 5.2-3. 10 Year Dose Rates from 21 MOX PWR SNF at External Surface of Waste Package

\begin{tabular}{|c|c|c|c|}
\hline Region & Total $(\mathrm{rem} / \mathrm{h})$ & Neutron $(\mathrm{rem} / \mathrm{h})$ & Gamma $(\mathrm{rem} / \mathrm{h})$ \\
\hline Top end fitting region & $8.23 \mathrm{E}+01$ & $3.58 \mathrm{E}+00$ & $7.87 \mathrm{E}+01$ \\
\hline Plenum region & $1.12 \mathrm{E}+02$ & $5.08 \mathrm{E}+00$ & $1.07 \mathrm{E}+02$ \\
\hline Top active fuel region & $8.92 \mathrm{E}+01$ & $1.13 \mathrm{E}+01$ & $7.79 \mathrm{E}+01$ \\
\hline Middle active fuel region & $9.01 \mathrm{E}+01$ & $1.33 \mathrm{E}+01$ & $7.67 \mathrm{E}+01$ \\
\hline Lower active fuel region & $9.05 \mathrm{E}+01$ & $1.16 \mathrm{E}+01$ & $7.89 \mathrm{E}+01$ \\
\hline Bottom end fitting region & $9.53 \mathrm{E}+01$ & $5.50 \mathrm{E}+00$ & $8.98 \mathrm{E}+01$ \\
\hline
\end{tabular}

Table 5.2-4. 10 Year Dose Rates at the External Surface from Commercial LEU SNF in the 21 PWR Waste Package

\begin{tabular}{|c|c|c|c|}
\hline Region & Total $(\mathrm{rem} / \mathrm{h})$ & Neutron $(\mathrm{rem} / \mathrm{h})$ & Gamma $(\mathrm{rem} / \mathrm{h})$ \\
\hline Top end fitting region & $1.96 \mathrm{E}+02$ & $3.63 \mathrm{E}+00$ & $1.92 \mathrm{E}+02$ \\
\hline Plenum region & $2.93 \mathrm{E}+02$ & $5.30 \mathrm{E}+00$ & $2.88 \mathrm{E}+02$ \\
\hline Top active fuel region & $1.66 \mathrm{E}+02$ & $1.25 \mathrm{E}+01$ & $1.53 \mathrm{E}+02$ \\
\hline Middle active fuel region & $1.64 \mathrm{E}+02$ & $1.49 \mathrm{E}+01$ & $1.50 \mathrm{E}+02$ \\
\hline Lower active fuel region & $1.65 \mathrm{E}+02$ & $1.29 \mathrm{E}+01$ & $1.52 \mathrm{E}+02$ \\
\hline Bottom end fitting region & $1.76 \mathrm{E}+02$ & $6.05 \mathrm{E}+00$ & $1.70 \mathrm{E}+02$ \\
\hline
\end{tabular}




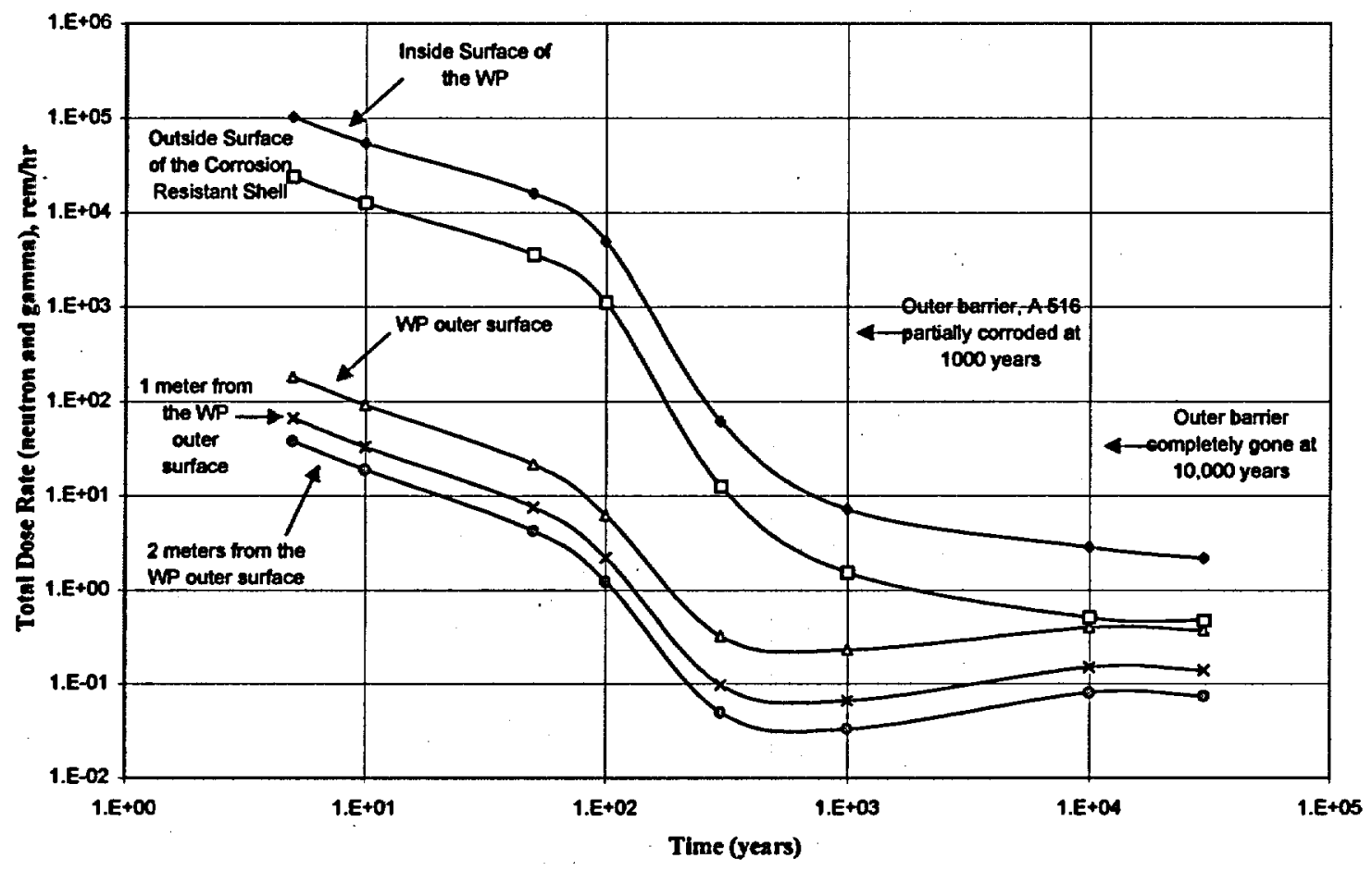

Figure 5.2-2. Radiation Dose Rate Over Time from the 21 MOX PWR WP Mid-Region

For the 21 MOX SNF WP, the dose rates shown in Figure 5.2-2 exceeded $10 \mathrm{rem} / \mathrm{h}$ only during the period prior to 100 years when the humidity of the external environment is assumed to be low. High humidity levels were assumed to occur only after approximately 700 years when the waste package surface temperatures are calculated to not exceed approximately $150^{\circ} \mathrm{C}$. Thus, it is concluded that there will not be any increase in the waste package barrier corrosion rate due to radiolysis. 
Report on Intact and Degraded Criticality for Selected Plutonium Waste Forms in a Geologic Repository, Volume I: MOX SNF

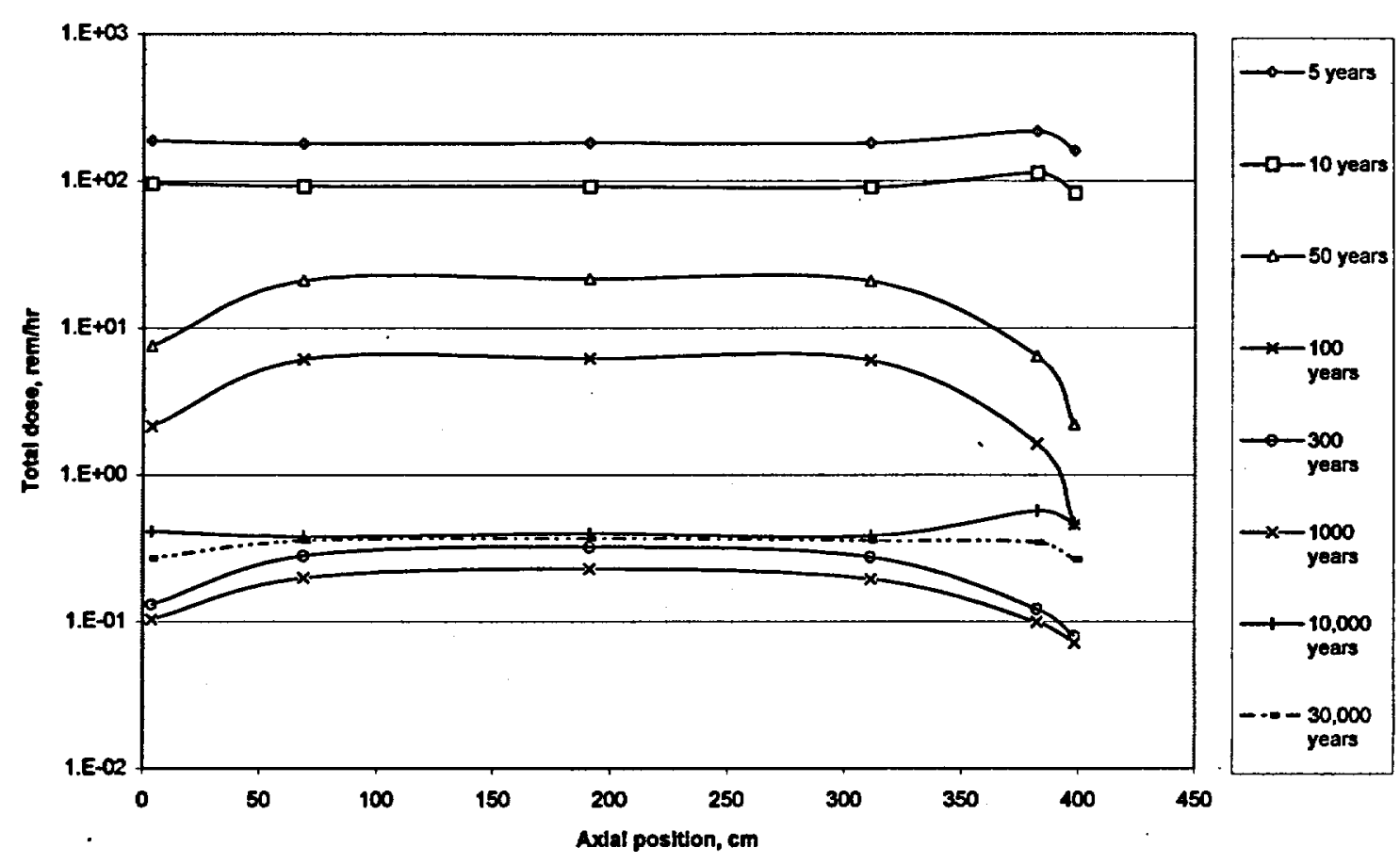

Figure 5.2-3. Axial Profile of Dose Rates at the Outside Surface of the 21 MOX PWR WP 


\section{Report on Intact and Degraded Criticality for Selected Plutonium Waste Forms in a Geologic Repository, Volume I: MOX SNF}

\section{DISPOSAL CRITICALITY ANALYSIS}

A series of criticality calculations were performed (Ref. 11) for both intact and degraded configurations of the MOX PWR assemblies described in Section 2 to evaluate the criticality potential of the MOX SNF WP configurations. Five wt\% fissile Pu in HM/burnup combinations were selected for analysis as given in Table 2.1-3. The cases which will be most important with respect to criticality are those having the lowest burnup for each initial wt\% fissile Pu in HM. For the 21 MOX PWR WP, these would be cases 4 and 5 from Table 2.1-3. However, the calculations for the 12 MOX PWR WP also considered a third and fourth wt\% fissile Pu in HM/burnup pairs (cases 2 and 3 from Table 2.1-3) as these are more representative of the higher burned fuel for which this package is intended. Isotopic compositions for each fuel in grams per assembly, for decay times from a few days, out to 1 million years are given in Reference 11, Section 6 . The compositions from Reference 12 tracked for the criticality calculations were limited to the PI burnup credit list as discussed in Section 2.1 .

The criticality analysis methodology for the SNF and waste package basket structure is discussed in Section 6.1 for both intact and degraded configurations. The methodology for the degraded configurations includes a brief discussion of the degradation sequences and composition definition for criticality calculations. The criticality evaluation of the intact SNF and basket structure is given first in Section 6.2. The degraded configurations and results of the criticality analyses of these configurations are discussed in Section 6.3. Results of the criticality analyses are summarized in Section 6.4.

\subsection{Disposal Criticality Analysis Methodology for both Intact and Degraded SNF}

In this study the methodology for computing $k_{\text {eff }}$ values (Ref. 11) for intact and various degraded waste package configurations uses the Monte Carlo N-Particle Code MCNP, Version 4B2 (Ref. 33). Fuel region number densities used in this criticality evaluation were calculated simply by homogenizing the isotopic concentrations from Reference 5 for a particular fuel and decay time throughout the volume of the active fuel region.

The degraded configurations to be considered are based on those evaluated for the commercial PWR waste package (Ref. 43, Section 7.1). Figure 6.1-1 shows a schematic view of the degradation sequence for the 21 PWR absorber plate waste package following breach of the package (Ref. 43, Section 7.1.1 provides a description of the degradation process and corrosion product generation). Since the waste package interior was inerted with $\mathrm{He}$ prior to time of breach, the initial configuration will be the as-built basket (Fig. 6.1-1A). Within a few hundred years following breach, the carbon steel and aluminum components will degrade to insoluble corrosion products as shown in Figure 6.11B (Ref. 14, Section 5.3). While structural calculations show that the absorber plates can support the load of the assemblies (Ref. 43, p. 27), localized corrosion in the crevice regions at the corners of each cell will likely cause collapse shortly after failure of the structural components. However, the majority of the B-SS absorber plates will be only minimally degraded and remain between the assemblies, with corrosion products from the degraded carbon steel tubes (Fig. 6.1-1C). Eventually, after thousands of years, general corrosion will also fully degrade the absorber plates, allowing the soluble boron neutron absorber to be flushed out of the package (Fig. 6.1-1D). The zircaloy 


\section{Report on Intact and Degraded Criticality for Selected Plutonium Waste Forms in a Geologic Repository, Volume I: MOX SNF}

cladding and spacers represent the most corrosion resistant material in the waste package, and thus will be the last to degrade. Collapse of the fuel rods at the bottom of the waste package will likely occur prior to complete cladding degradation (Fig. 6.1-1E), as the spacer grids are typically fabricated from strips of zircaloy that are thinner than the cladding. The final internal configuration (Fig 6.1-1F) is complete degradation of the entire waste package contents, with only the insoluble materials remaining. Similar configurations would also be expected to form during degradation of the 12 PWR WP, with the exception of configurations B and C, which cannot occur because the 12 PWR WP does not contain B-SS absorber plates.

This study summarizes calculations that considered configurations A, D, E, and F for both the 21 and 12 PWR WP. Chemical compositions of the remaining basket and fuel corrosion products were obtained from the geochemistry calculations reported in Reference 14, Section 5.3. As in Reference 11 , Section 5.4.3, both settled and uniform corrosion product distributions will be evaluated for configuration $\mathrm{D}$.

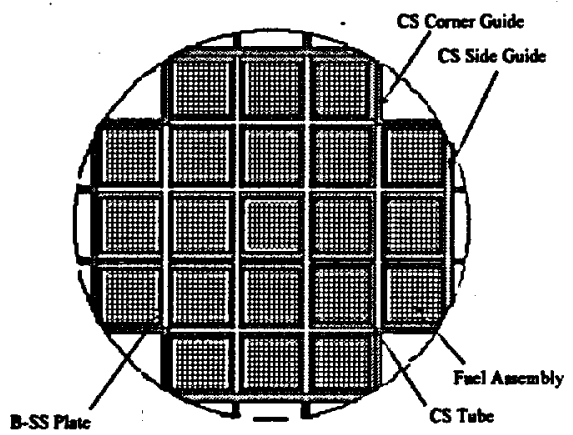

A) Initial Configuration

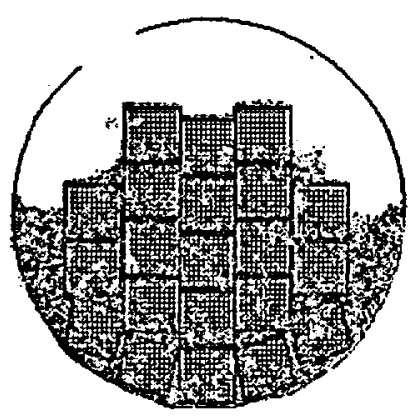

D) Fully Degraded Basket with Intact Assemblies

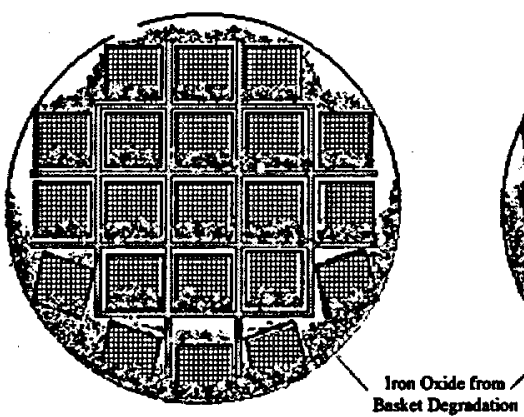

B) Side and Corner Guide Failure

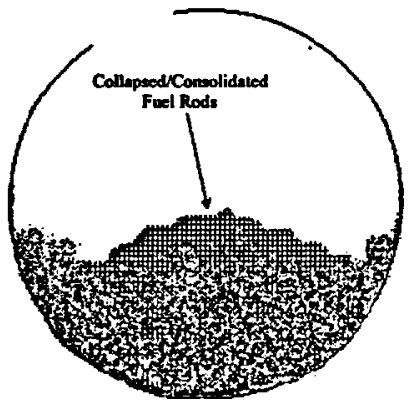

E) Fully Degraded Basket and Assembly Structure Intact Fuel Rods

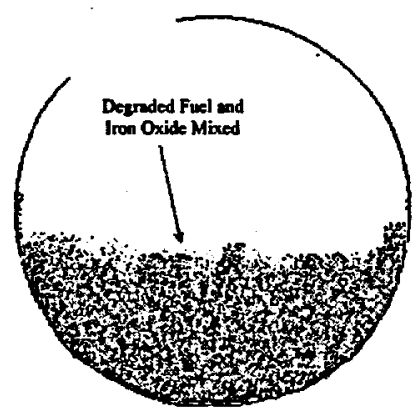

F) Fully Degraded Basket and Fuel

Figure 6.1-1. Degradation Sequence of the 21 PWR Basket Structure Following WP Breach 
Report on Intact and Degraded Criticality for Selected Plutonium Waste Forms in a Geologic Repository, Volume I: MOX SNF

\subsection{Criticality Evaluation of the Intact Configuration}

In keeping with the methodology described in Section 6.1, the criticality potential $\left(\mathrm{k}_{\mathrm{eff}}\right)$ of the intact MOX SNF WP configuration (Figure 6.1-1A) was evaluated for both the 21 and 12 PWR WP designs. The criticality control requirement for emplacement and isolation of radioactive waste is that the system $\mathrm{k}_{\text {eff }}$ maintains a minimum $5 \%$ margin below unity after allowing for biases and uncertainties (Ref. 42, Section 2.1.1). Benchmark calculations (Ref. 34, Section 3.1.4) with the MCNP4B2 code showed a maximum difference (or bias) of $3 \%$ between the calculated and experimental $\mathrm{k}_{\mathrm{eff}}$ 's. Statistical uncertainties at the $2 \sigma$ level in the $\mathrm{k}_{\text {eff }}$ calculations are normally of the order of $0.2 \%$ to $0.3 \%$. Thus the maximum $k_{\text {eff }}$ to assure subcriticality is $0.92=1.0-0.05-0.03$. This section describes the MCNP4B2 cases needed to evaluate the $\mathrm{k}_{\mathrm{eff}}$ of this configuration.

\subsubsection{Intact Fuel and Intact Basket Criticality Model}

The composition and dimensions of the containment barriers and basket components were modeled explicitly using the information in Section 2.2. Each Westinghouse 17x17 Vantage 5 fuel assembly was treated as a heterogeneous system with the fuel rods and control rod guide tubes modeled explicitly using the information contained in Section 2.1 . The fuel rods are conservatively modeled with water in the gap region simulating the effect of penetrated cladding (Zircaloy-4 is highly corrosion resistant but assumed to have sufficient penetration to allow water to fill the gap). Figure 6.2.1-1 shows the details of the MCNP4B2 model for the 21 PWR WP and Figure 6.2.1-2 shows the model details for the 12 PWR WP. In both models, the waste package is filled with water and there is a water reflector on the exterior. In addition to the base design discussed in Section 2.2, an additional case was evaluated with the central basket plates changed from A516 carbon steel to aluminum Alloy 6061 . This alternative was evaluated because it was being considered in the thermal analyses of the 12 PWR WP. Each of the intact designs was evaluated for the $4.0 \mathrm{wt} \%$ fissile Pu in H, 35.6 GWd/MTHM burnup fuel (fuel \#1) and the $4.5 \mathrm{wt} \%$ fissile Pu in $\mathrm{H}, 39.4$ GWd/MTHM burnup fuel (fuel \#2), for decay times from 10 years to 250,000 years. In addition, the intact 12 PWR WP designs were also evaluated for the $4.0 \mathrm{wt} \%$ fissile $\mathrm{Pu}$ in $\mathrm{H}, 50.1 \mathrm{GWd} / \mathrm{MTHM}$ burnup fuel (fuel \#3) and 4.5 wt\% fissile Pu in $\mathrm{H}, 46.5 \mathrm{GWd} / \mathrm{MTHM}$ burnup fuel (fuel \#4). 

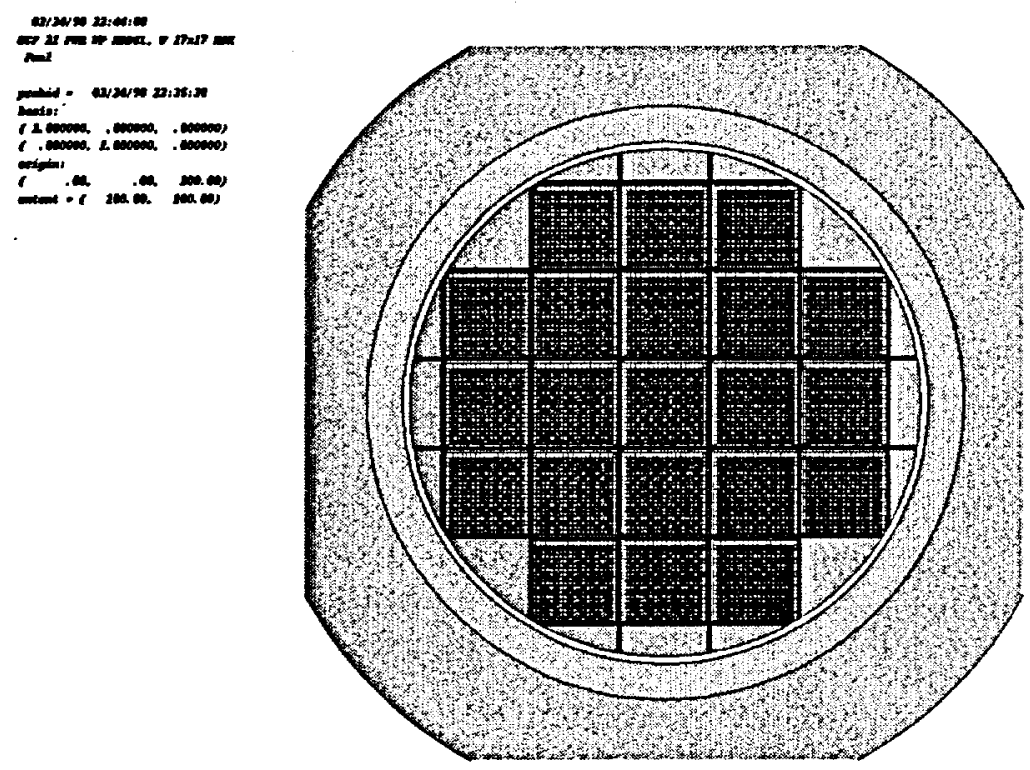

Figure 6.2.1-1. Intact 21 PWR MOX Fuel Waste Package

Principal isotopic compositions for the MOX SNF, summarized in Section 2.2, as obtained from the SAS2H/ORIGEN-S output (Ref. 44) are given in grams per assembly for decay times from a few days out to 1 million years. These were converted to number densities for the criticality calculations with MCNP using the fuel volume (Ref. 5, p. 10) and isotopic mass (Ref. 34, pp. 29-31).
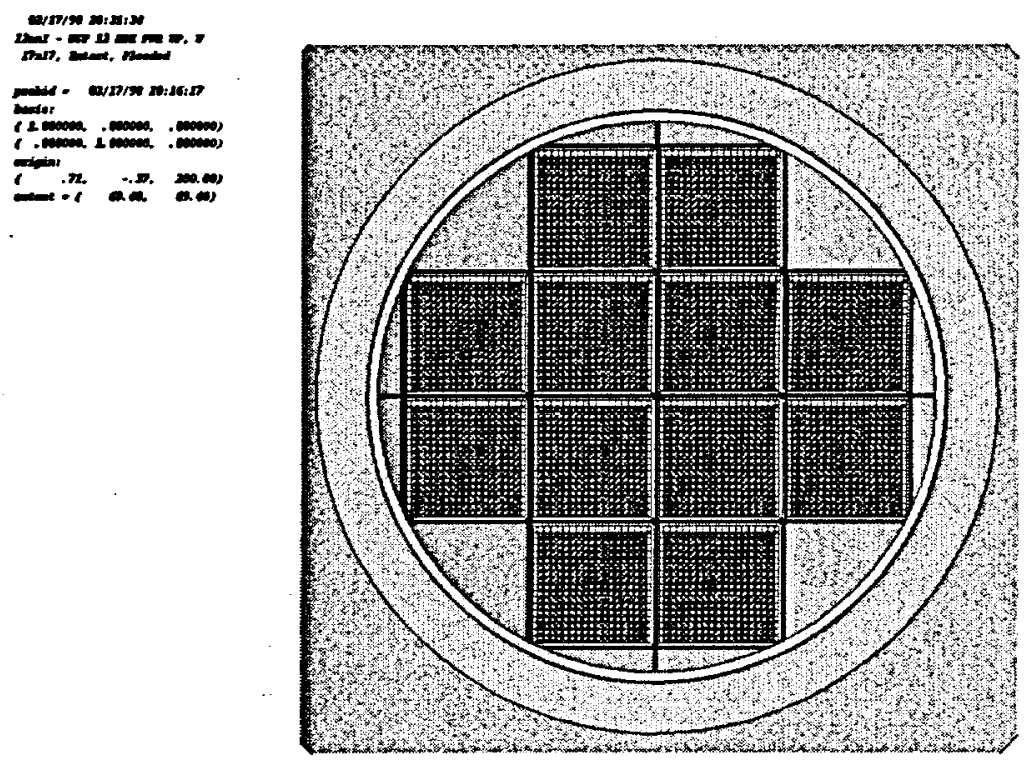

Figure 6.2.1-2. Intact 12 PWR MOX Fuel Waste Package 


\subsubsection{Intact Fuel and Intact Basket Criticality Evaluation Results}

Results of the criticality analyses of the intact 21 PWR WP and 12 PWR WP and basket are discussed below (Table 6.1-1 through Table 6.1-3 of Reference 11, pp. 25-30). The $\mathrm{k}_{\text {eff }}$ for all cases was well below the critical limit of 0.92 . For the first $\approx 100$ years after being discharged, the $k_{\text {eff }}$ of the MOX SNF decreases as the Pu-241 (13.2-year half-life) fissile material decays. From $\approx 100$ years out to $\approx 20,000$ years the $\mathrm{k}_{\text {eff }}$ increases as the quantity of Pu-240 (6580-year half-life) and other intermediate half-life neutron absorbers is reduced through radioactive decay. After the $\approx 20,000$ year local peak, the $\mathrm{k}_{\text {eff }}$ decreases again as the $\mathrm{Pu}-239$ (24,400-year half-life) fissile material decays into U-235 (still highly fissile material but generally at only $80 \%$ the efficiency of Pu-239). These effects on $k_{\text {eff }}$ are illustrated in Figures 6.2.2-1, 6.2.2-2, and 6.2.2-3 which show the $k_{\text {eff }} \pm 2 \sigma$ values as a function of time for the intact 21 PWR WP, 12 PWR WP, and 12 PWR WP with Al thermal shunts, respectively. Assemblies with higher burnup values than shown in the figures will have a lower $\mathrm{k}_{\text {eff }}$ profile.

The 12 PWR WP designs showed higher $k_{\text {eff }}$ values than the 21 PWR WP design for the same fuel type because these waste package designs do not include criticality control plates. The 12 PWR WP with Al thermal shunts showed an $\approx 1 \%$ increase in $\mathrm{k}_{\text {eff }}$ over the 12 PWR WP with the all carbon steel basket primarily because the $\mathrm{Al}$ has a much smaller neutron absorption cross section than the Fe that it replaces. The averáge energy of the neutron causing fission (defined as the average energy per particle lost to fission divided by the average particle weight lost to fission) was in the range of 0.18 to $0.26 \mathrm{MeV}$, and generally peaked at $\approx 100$ years. The $4.0 \mathrm{wt} \%$ fissile $\mathrm{Pu}$ in $\mathrm{HM}, 35.6$ GWd/MTU burnup fuel generally showed higher $\mathrm{k}_{\text {eff }}$ values than the $4.5 \mathrm{wt} \%$ fissile $\mathrm{Pu}$ in $\mathrm{HM}, 39.4$ GWd/MTU fuel for all cases evaluated.

No specific comparisons were made of the intact MOX SNF and intact basket criticality results with LEU criticality results since the MOX SNF $k_{\text {eff's }}$ ' were well below critical values. Thus, a criticality event for this configuration is virtually impossible. 
Report on Intact and Degraded Criticality for Selected Plutonium Waste Forms in a Geologic Repository, Volume I: MOX SNF

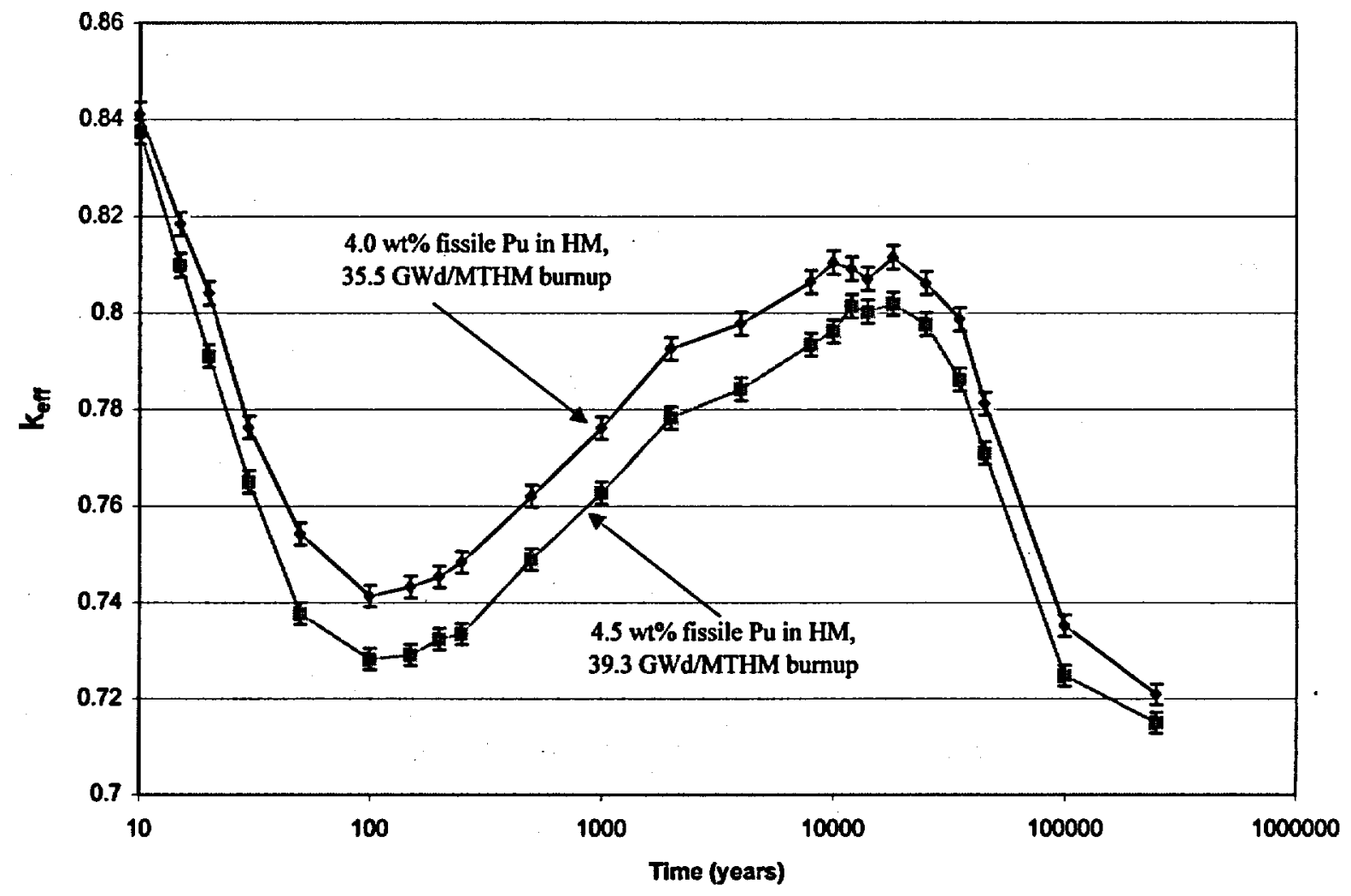

Figure 6.2.2-1. Time Effects on $\mathrm{k}_{\text {eff }}$ for Intact MOX SNF and Intact Baskets in a 21 PWR Absorber Plate WP 
Report on Intact and Degraded Criticality for Selected Plutonium Waste Forms in a Geologic Repository, Volume I: MOX SNF

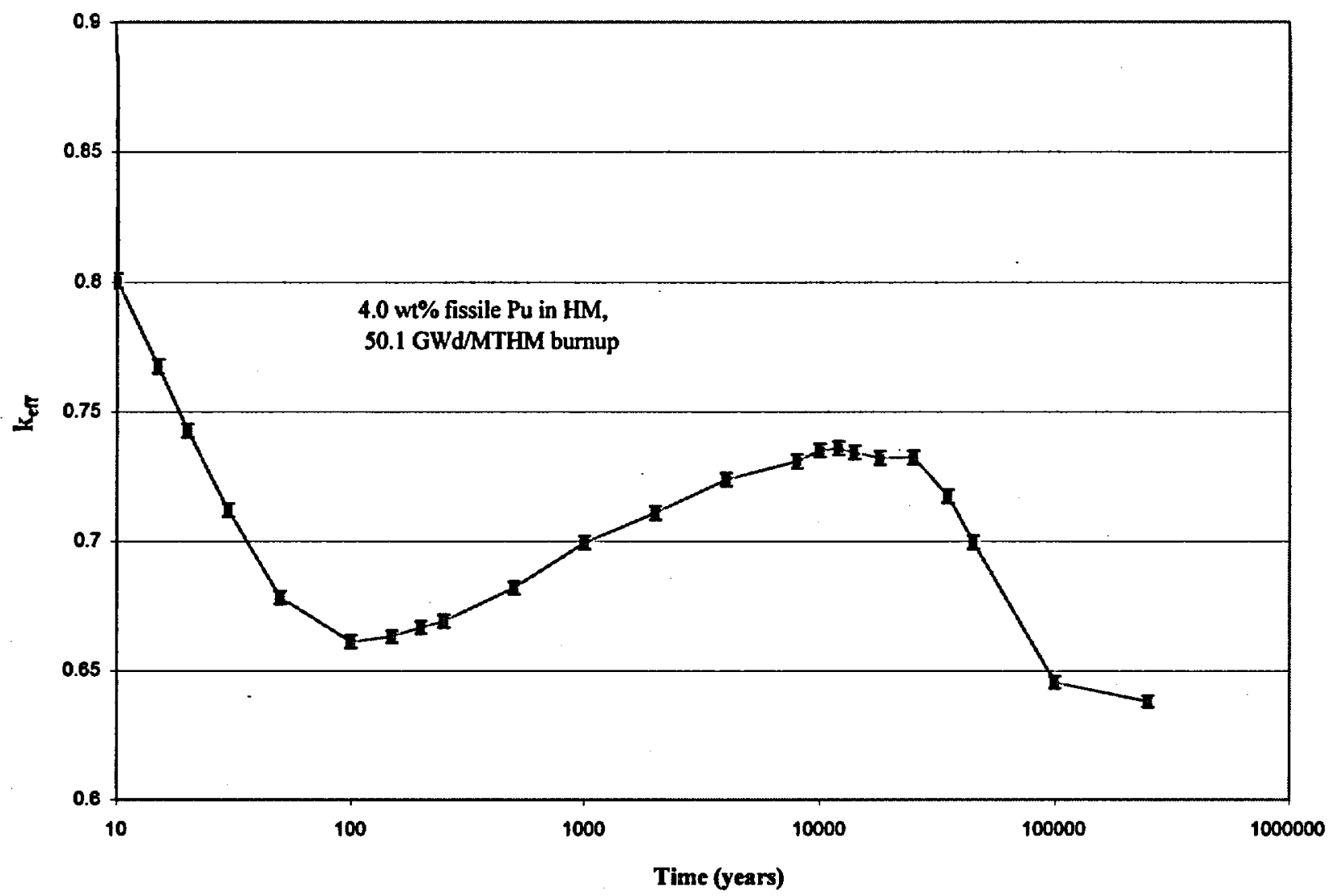

Figure 6.2.2-2. Time Effects on $\mathrm{k}_{\text {eff }}$ for Intact MOX SNF and Intact Baskets in a 12 PWR WP 


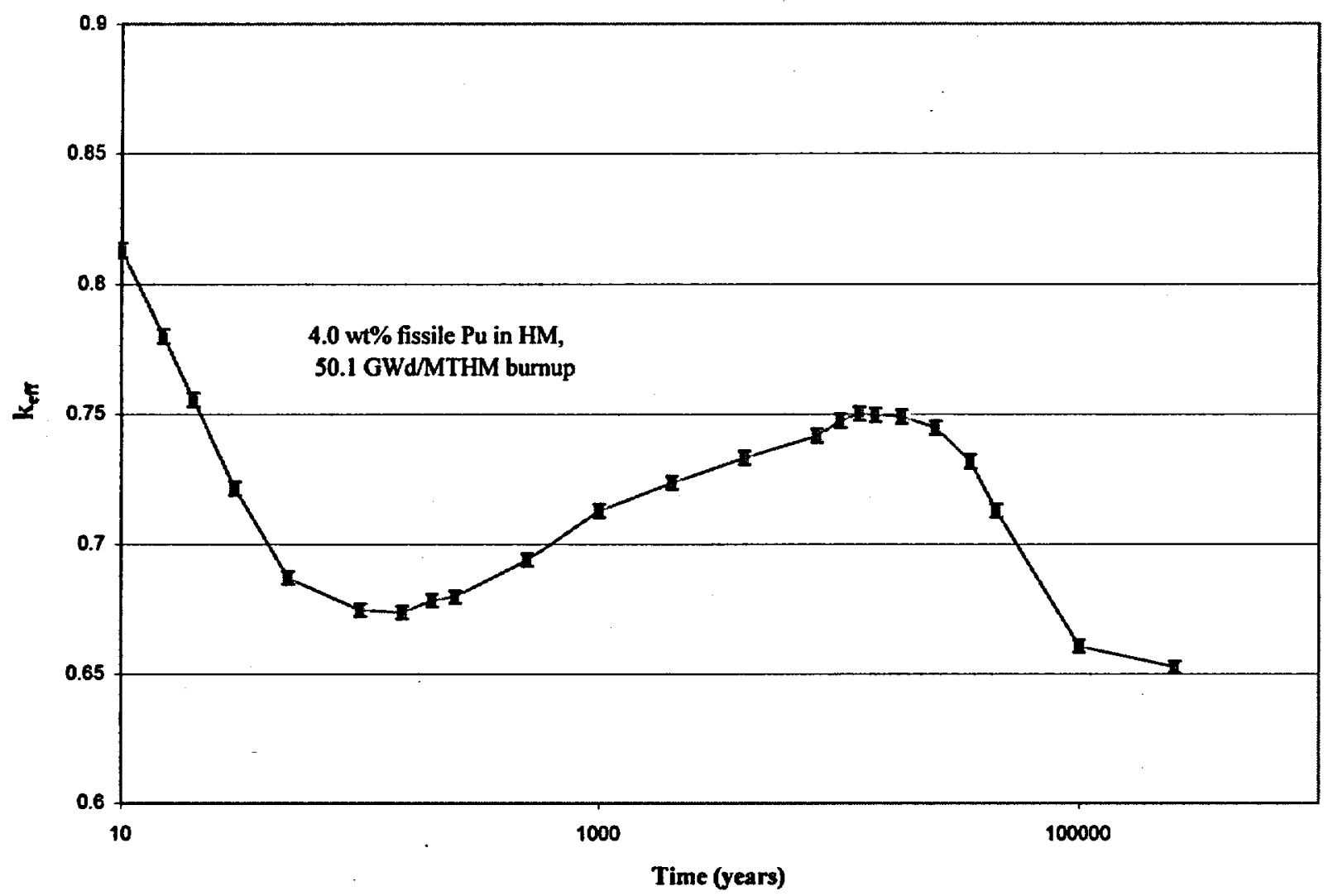

Figure 6.2.2-3. Time Effects on $\mathrm{k}_{\text {eff }}$ for Intact MOX SNF and Intact Baskets in a 12 PWR WP with Al Shunts

\subsection{Degraded Configurations for Criticality Analysis}

Analyses of the intact PWR MOX SNF evaluated the criticality potential of the water filled waste packages for the fissile and absorber nuclides in the waste package as a function of time. The analysis included radioactive decay of nuclides, geochemical degradation of materials, and removal of soluble compounds. The objectives of the geochemical analyses (Ref. 14, p. 5) were to determine the geochemical conditions under which:

1) Criticality control material suggested for this design will remain in the degraded waste package after the corrosion/dissolution of its initial form (such that it can be effective in preventing criticality), and

2) Fissile plutonium and uranium will be carried out of the degraded waste package by infiltrating water (such that internal criticality is no longer possible, but the possibility of external criticality may be enhanced).

Configurations of the SNF, as derived from the geochemical analyses, having a reasonable chance of 


\section{Report on Intact and Degraded Criticality for Selected Plutonium Waste Forms in a Geologic Repository, Volume I: MOX SNF}

occurring in those waste package's which experience degradation were discussed generally in Section 6.1.

Boron (B) in the form of B-SS was included in the analyses, as were various neutron absorbing fission products, notably Gd and Nd. These elements are important for inclusion in calculations of waste package internal criticality. The results of this analysis were used as input for the criticality evaluations of the degraded waste package configurations to ensure that the type and amount of criticality control material used in the waste package design will prevent criticality. These chemical compositions (and consequent criticality evaluations) were determined for time periods up to 100,000 years.

Geochemistry calculations were not performed for the 12 PWR MOX WP in Reference 14 since the results were expected to be similar to results from the 21 PWR WP adjusted for the differences in waste package volumes. The geochemistry results of the 21 MOX PWR WP indicated that all of the Fe from the carbon and stainless steel components was incorporated into $\mathrm{Fe}_{2} \mathrm{O}_{3}$, and remained in the package. Since the 12 PWR WP basket is fabricated entirely from carbon steel, it is expected that the corrosion product resulting from degradation of the basket components will also be $\mathrm{Fe}_{2} \mathrm{O}_{3}$. Since the criticality calculation considered only the initial configuration and fully degraded basket configurations (Figure 6.1-1), compositions for the 12 PWR WP can be calculated from the initial volumes.

\subsubsection{Methodology for Determining Degraded Configurations}

The following methodology was used for the degradation analysis (Ref. 15) of both basket materials and the waste form (MOX SNF). It is also used for the degradation analysis of the ceramic waste form documented in Volume II of this document. The geochemical analyses used the EQ3/6 software package (Ref. 35) whose major components include: EQ3NR, a speciation-solubility code; EQ6, a reaction path code which models water/rock interaction or fluid mixing in either a pure reaction progress mode or a time mode; EQPT, a data file preprocessor; EQLIB, a supporting software library; and several (>5) supporting thermodynamic data files. The software models thermodynamic equilibrium, thermodynamic disequilibrium, and reaction kinetics in chemical systems. EQ3NR is required to initialize an EQ6 calculation and is useful for analyzing groundwater chemistry data, calculating solubility limits, and determining whether certain reactions are in states of partial equilibrium or disequilibrium. EQ6 models the consequences of irreversibly reacting an aqueous solution with a set of reactants. It can also model fluid mixing and the consequences of changes in temperature.

The method used for the geochemical analysis of the PWR MOX SNF involves the following steps:

1) Use of basic EQ3/6 program for tracing the progress of reactions with evolution of the chemistry, including the estimation of the concentrations of minerals remaining in solution and the composition of the precipitated solids.

2) Evaluation of available data on the range of dissolution rates for the materials involved, to be used as material/species input for each time step. 


\section{Report on Intact and Degraded Criticality for Selected Plutonium Waste Forms in a Geologic Repository, Volume I: MOX SNF}

3) Use of the "pseudo flow-through" mode in which:

a) Water is added continuously to the waste package and builds up in the waste package over a sequence of time steps (typically 200 to 600 steps in the initial sequence, then 15 to 18 steps per sequence in the ensuing ones). The time period per sequence is constant and is determined from the selected drip rate, e.g., $0.15 \mathrm{~m}^{3} / \mathrm{yr}$ entering the waste package, and the percentage of added water selected. This percentage is set at $10 \%$ at the beginning of a set of runs, and typically increased to $100 \%$ to enable modeling of very long times after initial relatively rapid chemical changes have settled down to a quasisteady state. Individual EQ6 time steps range from 0.01 seconds to 1000 days as determined automatically by the program. EQ3/6 sequences extend over times up to or somewhat greater than 100,000 years.

b) Flushing action (removal of water added during one EQ6 sequence) is simulated by adjusting the amount of water and solutes for input to the next EQ6 sequence.

c) Determination of fissile material concentrations in solution as a function of time.

d) Calculation of the amount of fissile material released from the waste package as a function of time (which thereby reduces the chance of criticality within the waste package).

e) Determination of concentrations of neutron absorbers (criticality control materials), such as $\mathrm{B}$ and $\mathrm{Gd}$, in solution as a function of time.

f) Calculation of the amount of neutron absorbers retained within the waste package as a function of time.

\subsubsection{Degraded Configurations from Geochemistry Analysis}

The emphasis in the geochemical analyses was on the composition and composition reactivity, rather than on the physical configurations within different waste packages, although the geometric configurations were used for volume calculations to determine the chemical evolution. As shown in Figure 2.2-1, a 21 PWR MOX SNF WP consists of SNF assemblies held in a basket and placed inside a corrosion barrier. The design for the corrosion barrier itself specifies an outer corrosion allowance and an inner corrosion resistant metal. For modeling of the chemical behavior of this system, the chemical compositions of each of these materials, their masses, their surface areas, and their corrosion or degradation rates are required (Tables 5.2.3-2 and 5.2.3-3 of Reference 14; compositions are given in Reference 14, Section 5.1.1.1). Elemental compositions for the SNF assemblies were obtained from the output files (Ref. 44) from the SAS2H/ORIGEN-S analysis (Ref. 6) in gram-atoms/assembly. The compositions were decayed, following discharge from the reactor, to 10,000 and 25,000 years after emplacement. The resulting isotopic changes were used to adjust the geochemistry results since the EQ3/6 code package does not account for compositional changes due to radioactive decay. 


\section{Report on Intact and Degraded Criticality for Selected Plutonium Waste Forms in a Geologic Repository, Volume I: MOX SNF}

The geochemistry calculations determined the composition of the corrosion product mixture remaining in the 21 PWR waste package following complete basket degradation. Concentrations of insoluble corrosion products that remain after the basket has completely degraded are given in Section 5.3.2 of Reference 14 and Reference 14 indicates that this final composition remains fairly constant over the range of possible B-SS degradation rates and drip rates. The moles/WP column was calculated by multiplying the moles/liter $\mathrm{H}_{2} \mathrm{O}$ column by 4550 liters of $\mathrm{H}_{2} \mathrm{O}$, which is the amount of water considered to be in the waste package in Reference 45. (equivalent to the void space available in a loaded waste package with an undegraded basket). The corresponding corrosion product inventory remaining in the 12 PWR WP is derived from the 21 PWR WP values with the appropriate volume ratio.

Table 6.3.2-1. Corrosion Products Remaining Following Basket Degradation in the 21 PWR WP

\begin{tabular}{|c|c|c|c|}
\hline Basket Corrosion Product & Volume per WP $\left(\mathrm{m}^{3}\right)$ & Moles/liter $\mathrm{H}_{2} \mathrm{O}$ & moles/WP \\
\hline Diaspore $(\mathrm{AlOOH})$ & $1.8392 \mathrm{E}-01$ & 2.291 & 10424.05 \\
\hline Hematite $\left(\mathrm{Fe}_{2} \mathrm{O}_{3}\right)$ & $1.7707 \mathrm{E}+00$ & 12.77 & 58103.5 \\
\hline Pyrolusite $(\mathrm{MnO})$ & $2.7361 \mathrm{E}-02$ & 0.35 & 1592.5 \\
\hline $\mathrm{Ni}_{2} \mathrm{SiO}_{4}$ & $3.0867 \mathrm{E}-02$ & 0.1592 & 724.36 \\
\hline Nontronite-Ca $\left(\mathrm{Si}_{3.7} \mathrm{Ca}_{0.33} \mathrm{Al}_{0.33} \mathrm{Fe}_{2} \mathrm{H}_{2} \mathrm{O}_{12}\right)$ & $1.2874 \mathrm{E}-02$ & 0.0216 & 98.28 \\
\hline Nontronite- $\left.\mathrm{Si}_{3.7} \mathrm{~S}_{0.17} \mathrm{Al}_{0.33} \mathrm{Fe}_{2} \mathrm{H}_{2} \mathrm{O}_{12}\right)$ & $5.6325 \mathrm{E}-04$ & 0.0009151 & 4.163705 \\
\hline Nontronite- $\mathrm{Mg}\left(\mathrm{Si}_{3.7} \mathrm{Mg}_{0.2} \mathrm{Al}_{0.33} \mathrm{Fe}_{2} \mathrm{H}_{2} \mathrm{O}_{12}\right)$ & $8.9323 \mathrm{E}-03$ & 0.01513 & 68.8415 \\
\hline Nontronite- $\mathrm{Na}\left(\mathrm{Si}_{3.7} \mathrm{Na}_{0.33} \mathrm{Al}_{0.33} \mathrm{Fe}_{2} \mathrm{H}_{2} \mathrm{O}_{12}\right)$ & $9.0407 \mathrm{E}-04$ & 0.001504 & 6.8432 \\
\hline TOTAL & $2.0362 \mathrm{E}+00$ & & \\
\hline
\end{tabular}

An important part of the geochemistry results is the effects that fuel degradation will have on the principal isotope inventory since these isotopes are important for burnup credit. Two cases were studied:

1) fuel degradation concurrent with basket degradation, and

2) fuel degradation beginning after basket degradation is completed.

Figure 6.3.2-1 illustrates graphically the simulated history for these elements for the MOX case in which hematite forms showing the quantity in gram-atoms of selected elements of special interest for criticality computations remaining in the MOX PWR WP for the concurrent degradation case. Times are relative to the initial breach of the corrosion barrier. The assumed inflow rate of water into the waste package was $0.15 \mathrm{~m}^{3} / \mathrm{yr}$. Mo and Tc are effectively removed as soluble corrosion products from the waste package as the fuel degrades. Consequently, they will be absent from the waste package, except for very minor amounts of adsorbed species or minute traces left in solution, e.g., as a consequence of incomplete mixing of water within the waste package, soon after the SNF is fully degraded.

Figure 6.3.2-1 shows the rapid total removal of $\mathrm{Am}$, and the early flushing out of $\mathrm{Np}, \mathrm{Eu}, \mathrm{Sm}$, and Gd. However, these latter elements stabilize to a (approximately) constant fraction of their original inventory. The solubilities of all the lanthanides ( $\mathrm{Gd}, \mathrm{Nd}, \mathrm{Sm}$, and $\mathrm{Eu}$ ) are very similar; the different 


\section{Report on Intact and Degraded Criticality for Selected Plutonium Waste Forms in a Geologic Repository, Volume I: MOX SNF}

histories reflect differences in their initial inventories in the waste form compositions. Only a small percentage of Nd is removed and nearly all of the $U$ is retained. The inventories for $\mathrm{Pu}, \mathrm{Rh}$, and $\mathrm{Ru}$ are essentially unchanged.

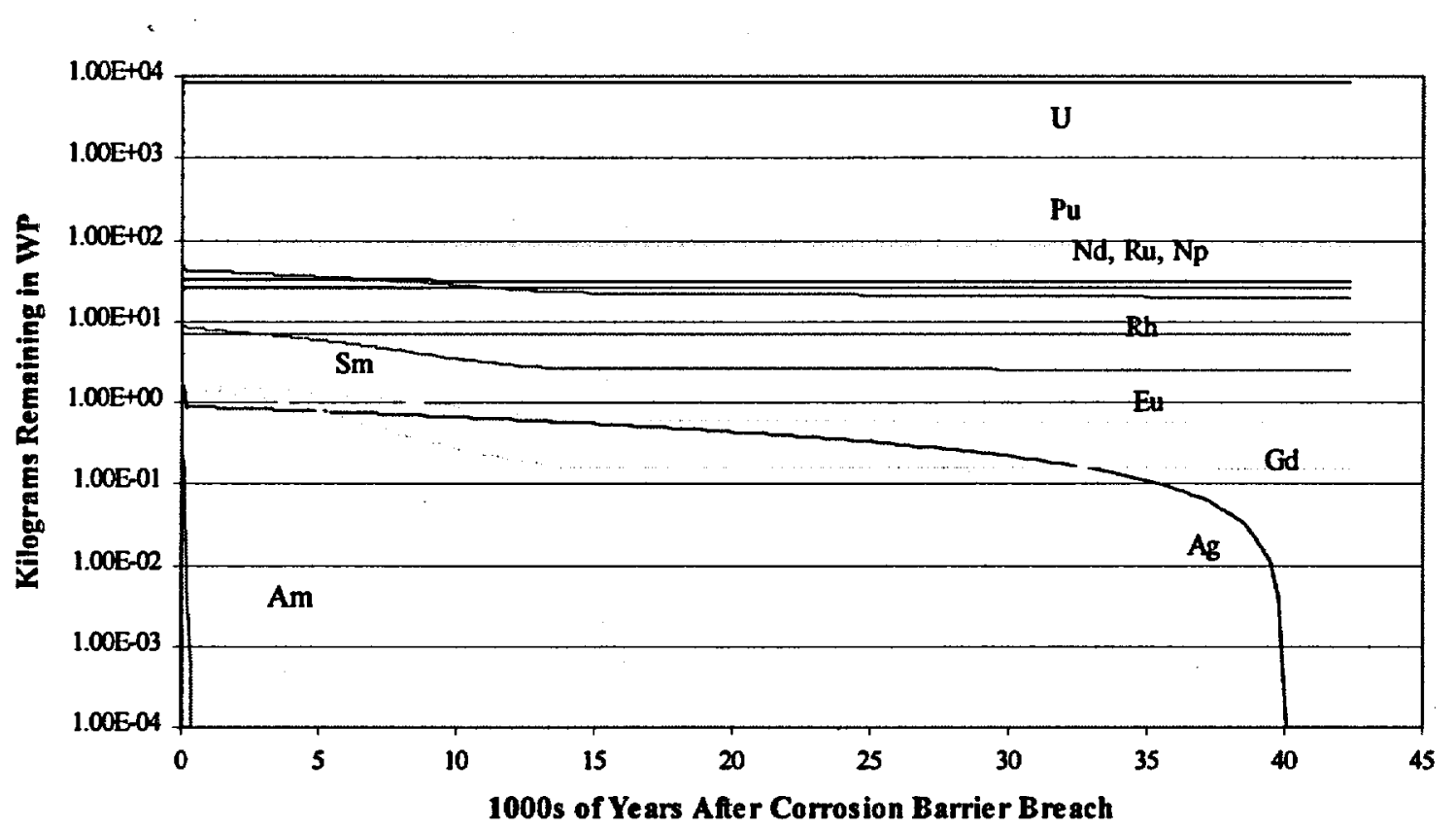

Figure 6.3.2-1. Retention History of Elements of Principal Interest for Criticality Remaining in WP

The case in which the fuel degradation was concurrent with the basket degradation resulted in more of the principal isotopes being lost due to lower $\mathrm{pH}$ conditions during degradation of the B-SS. This is the more conservative configuration and the results from this case are used in the degraded criticality analyses.

\subsubsection{Criticality Evaluation of Degraded Waste Package Configurations}

As discussed in Section 6.3.2, fuel degradation will lead to a reduced inventory of the soluble principal isotopes (summarized in Ref. 11, p. 15). Criticality calculations involving degraded fuel examined cases with the reduced principal isotope inventories, as well as a conservative case including only the $\mathrm{U}$ and $\mathrm{Pu}$ principal isotopes.

Number densities were calculated for the corrosion product and water mixtures in the waste package by dividing the moles of each element per waste package by the void space they occupied and multiplying by Avogadro's Number $\left(0.602252 \times 10^{24}\right.$ atoms $\left./ \mathrm{mole}\right)$. Based on the total volume of corrosion products remaining following full basket degradation, and the total volume contained within the inner barrier minus that occupied by the fuel assemblies (volume of the fuel rods), the 


\section{Report on Intact and Degraded Criticality for Selected Plutonium Waste Forms in a Geologic Repository, Volume I: MOX SNF}

corrosion products will occupy $36.8 \%$ of the interior void space of a 21 PWR WP. If the corrosion products settle to the bottom of the waste package, the physical geometry of packed solids will occupy $58 \%$ of the void space (maximum percent solid content of packed sand [Ref. 12, p.15]). At $58 \%$ dense packing, if all of the oxides settle to the bottom, they will completely cover the bottom three rows of the Westinghouse $17 \times 17$ Vantage 5 MOX SNF assembly stack, and cover more than $95 \%$ of the fourth assembly row. This analysis conservatively assumes $94 \%$ or 16 of the 17 fuel pin rows in the assembly are covered.

If all of the Fe from the $12 \mathrm{PWR}$ WP basket were converted to $\mathrm{Fe}_{2} \mathrm{O}_{3}$, as assumed, it would occupy $37.4 \%$ of the interior void space of a loaded waste package. If this material were settled to the bottom of the waste package at a $58 \%$ dense packing, it would cover all but the top two assemblies in a 12 PWR WP.

\subsubsection{Configurations for Intact Fuel with Fully Degraded Basket}

The MCNP4B2 cases needed to evaluate the $\mathrm{k}_{\mathrm{eff}}$ of the 21 PWR MOX SNF and 12 PWR MOX SNF waste package designs with intact fuel and fully degraded basket structures (configuration $D$ from Section 6.1) are described in this section. Both the uniformly distributed corrosion product and the settled corrosion product configurations were evaluated for each waste package. Each Westinghouse $17 \times 17$ Vantage 5 fuel assembly was treated as a heterogeneous system with the fuel rods and control rod guide tubes modeled explicitly. The fuel rods are conservatively modeled with water in the gap region and guide tubes, even when surrounded by water/corrosion product mixtures. The fuel rods are assumed to be breached but otherwise intact while the guide tubes are horizontal. There is no physical mechanism for getting basket corrosion products into these locations while the assembly remains intact. Figure 6.3.3.1-1 shows the geometry details of the MCNP4B2 model for the 21 PWR WP with a fully degraded basket and uniformly distributed corrosion products. Figure 6.3.3.12 shows the geometry details of the MCNP4B2 model for the 21 PWR WP with a fully degraded basket and settled corrosion products. Figure 6.3.3.1-3 shows the geometry details of the MCNP4B2 model for the base 12 PWR WP with a fully degraded basket and uniformly distributed corrosion products. Figure 6.3.3.1-4 shows the geometry details of the MCNP4B2 model for the base 12 PWR WP with a fully degraded basket and settled corrosion products. Each of these configurations were evaluated for the $4.0 \mathrm{wt} \%$ fissile Pu in HM, 35.6 GWd/MTU burnup fuel (fuel \#1), and the $4.5 \mathrm{wt} \%$ fissile Pu in HM, 39.4 GWd/MTU burnup fuel (fuel \#2), for decay times from 10 years to 250,000 years. In addition these configuration were evaluated for the $4.0 \mathrm{wt} \%$ fissile $\mathrm{Pu}$ in $\mathrm{HM}, 50.1$ GWd/MTHM (fuel \#4) and for $4.5 \mathrm{wt} \%$ fissile Pu in HM, 46.5 GWd/MTHM (fuel \#3).

Similar MCNP4B2 calculations were made to evaluate the $\mathrm{k}_{\text {eff }}$ for commercial LEU SNF in the 21 PWR WP design (Ref. 36, Section 6) with intact fuel and fully degraded basket structures (configuration D from Section 6.1). The commercial PWR assembly design was based on the Babcock and Wilcox (B\&W) 15x15 Mark B assembly (Ref. 37, p. II.6-6). Since this assembly type has one of the largest fuel loading, it is likely to provide a conservative bounding calculation for the degraded mode criticality analysis.

The criticality potential for the LEU SNF waste forms was evaluated over decay times from 10,000 to 45,000 years for a number of enrichment-burnup combinations to identify the time of peak $k_{\text {eff }}$ 

Repository, Volume I: MOX SNF

(Ref. 37, Section 6). The MCNP4B2 geometry for the LEU SNF calculations was similar to the MOX SNF geometry shown in Figures 6.3.3.1-1 and 6.3.3.1-2. Both the uniformly distributed corrosion product and the settled corrosion product configurations were evaluated for 21 LEU PWR WP. Results from a subset of the LEU enrichment-burnup combinations which are comparable to the MOX SNF wt\% fissile Pu in HM-burnup combinations are included with the MOX SNF results in this study to provide a frame of reference for the MOX SNF results. These cases are as follows: $4.0 \mathrm{wt} \%$ fissile Pu in HM, 35GWd/MTU and $4.5 \mathrm{wt} \%$ fissile Pu in HM, $40 \mathrm{GWd} / \mathrm{MTU}$. These results show that, for most configurations, the MOX SNF has a lower criticality potential $\left(k_{\text {eff }}\right)$ than B\&W LEU SNF waste form.

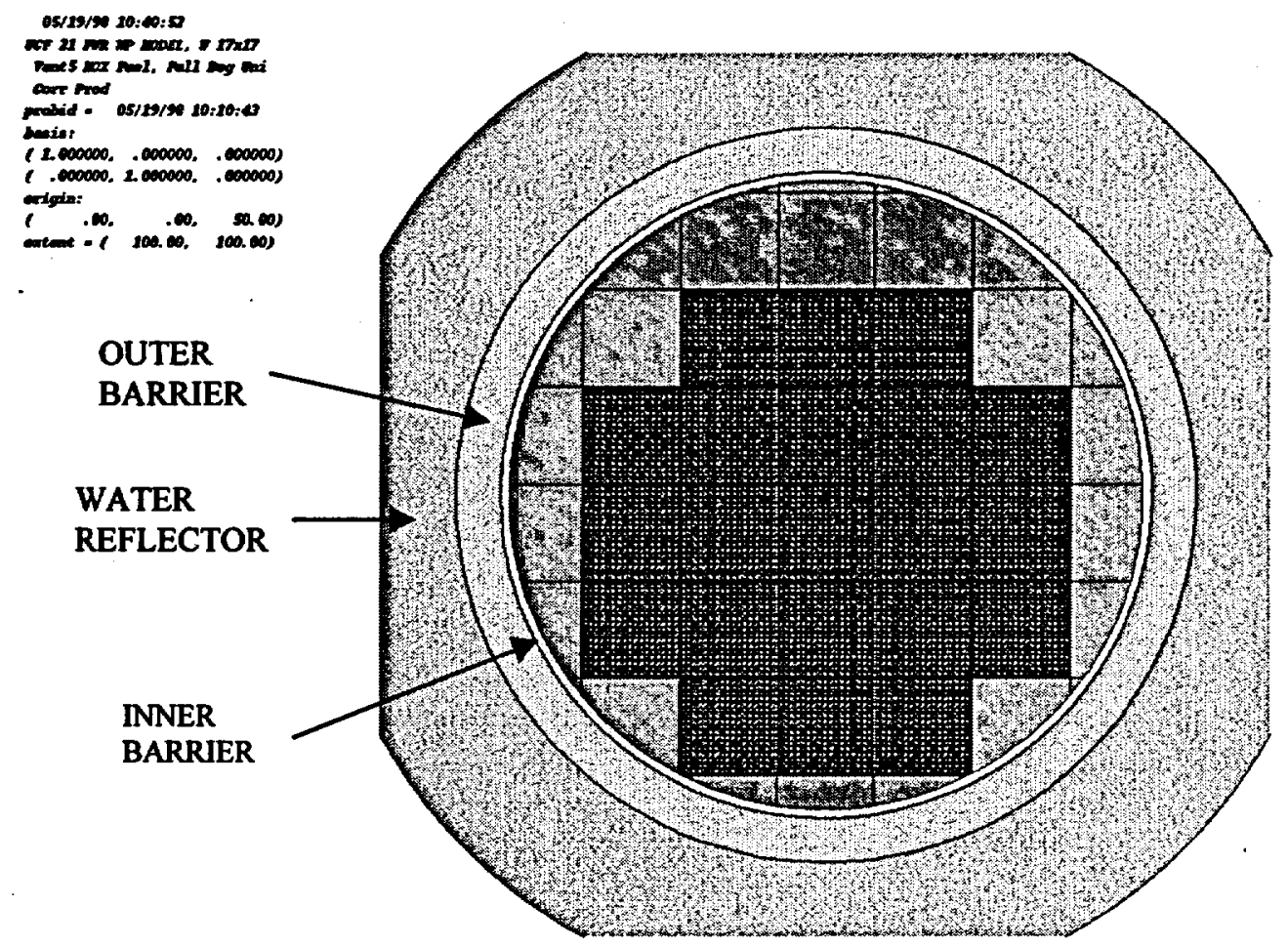

Figure 6.3.3.1-1. Degraded 21 PWR MOX Fuel Waste Package w/ Uniform Corrosion Product Distribution 

Repository, Volume I: MOX SNF

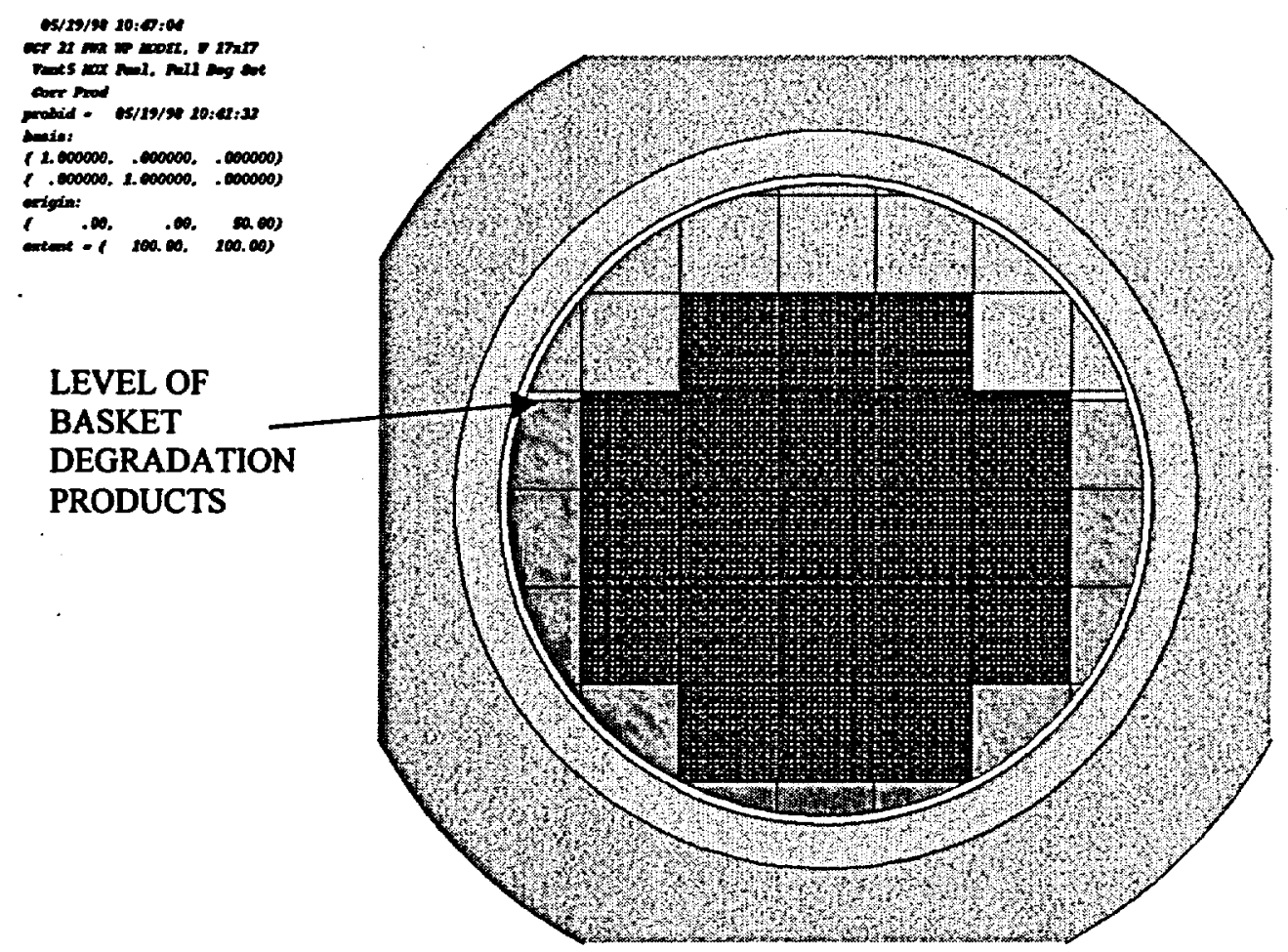

Figure 6.3.3.1-2. Degraded 21 PWR MOX Waste Package With Settled Corrosion Product Distribution (58\% solid content)

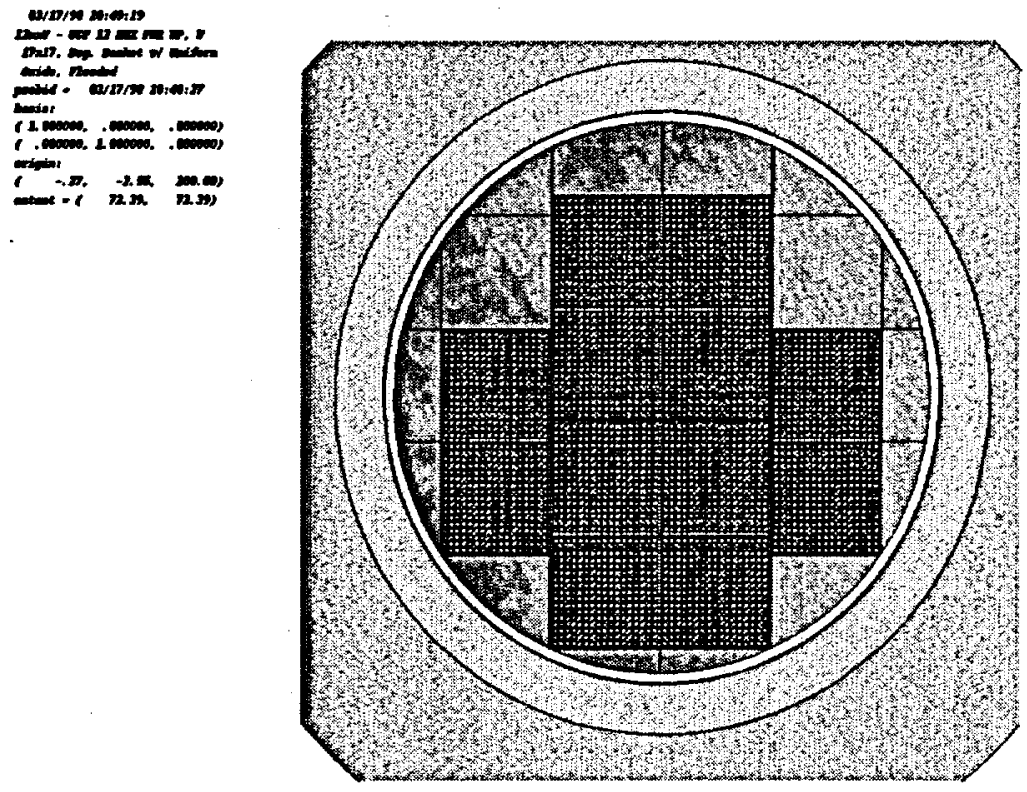

Figure 6.3.3.1-3. Degraded 12 PWR MOX Fuel Waste Package with Uniform Corrosion Product Distribution 

Repository, Volume I: MOX SNF

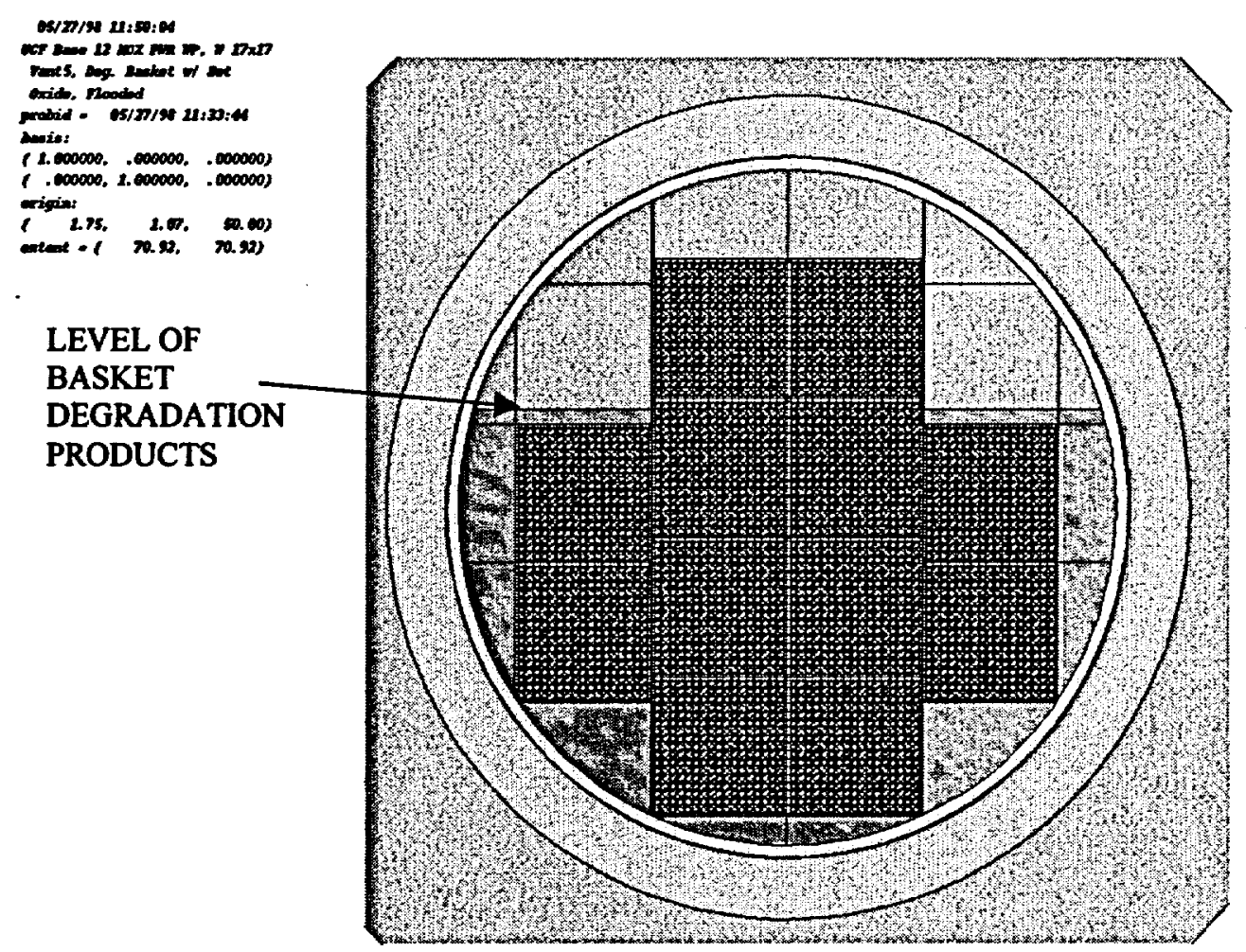

Figure 6.3.3.1-4. Degraded 12 PWR MOX Waste Package With Settled Corrosion Product Distribution (58\% solid content)

\subsubsection{Criticality Results for Intact Fuel with Fully Degraded Basket}

Results of the criticality analyses of the intact fuel and degraded basket for MOX SNF in the 21 PWR WP and in the 12 PWR WP are shown (Table 6.2-1 through Table 6.2-4 of Reference 11, pp. 33-39) in Figures 6.3.3.2-1, 6.3.3.2-2, 6.3.3.2-3, and 6.3.3.2-4. The figures show the nominal $k_{\text {eff }}$ with a $2 \sigma$ variance shown as error bars. The time effect behavior is essentially the same as for the intact configurations.

As with the intact results presented in Section 6.2.2, all of the degraded cases for the $4.0 \mathrm{wt} \%$ fissile $\mathrm{Pu}$ in $\mathrm{HM}, 35.6 \mathrm{GWd} / \mathrm{MTU}$ fuel consistently showed higher $\mathrm{k}_{\text {eff }}$ values than those for the $4.5 \mathrm{wt} \%$ fissile Pu in HM, 39.4 GWd/MTU fuel. The degraded basket cases for the 21 PWR WP showed increases in $\mathrm{k}_{\text {eff }}$ over the intact waste package for the same fuel and decay time due to the loss of boron absorber as the B-SS absorber plates degraded. This effect, together with the fissile material inventory, more than compensated for the increased effectiveness (due to volume increase displacing moderator) of the A516 degradation products in reducing the $\mathrm{k}_{\text {eff. }}$. The $58 \mathrm{vol} \%$ settled corrosion product case showed a $6.8 \%$ increase in $k_{\text {eff }}$ (measured at the post-closure peak for the $4.0 \mathrm{wt} \%$ fissile $\mathrm{Pu}$ in $\mathrm{HM}, 35.6 \mathrm{GWd} / \mathrm{MTU}$ fuel) from the intact configuration, while the uniform corrosion product case showed only a $4.1 \%$ increase.

Figures 6.3.3.2-1 and 6.3.3.2-2 also show the $\mathrm{k}_{\mathrm{eff}}$ results from the LEU SNF calculations of intact 


\section{Report on Intact and Degraded Criticality for Selected Plutonium Waste Forms in a Geologic Repository, Volume I: MOX SNF}

fuel and fully degraded baskets for decay times around the time ( 10,000 years) the $k_{\text {eff }}$ generally reaches a secondary peak. This secondary peak is always lower than the 10 year decay values. The $\mathrm{k}_{\text {eff }}$ values for the LEU SNF cases are up to $4 \%$ higher than for the corresponding MOX SNF cases. Therefore, it is concluded that MOX SNF does not pose any greater, and likely less, criticality concerns in the 21 PWR WP than does LEU SNF of similar burnup and fissile content.

The degraded basket cases for the 12 PWR WP actually showed decreases in $\mathrm{k}_{\text {eff }}$ over the intact waste package for the same fuel and decay time. This is due solely to the increased volume of the carbon steel degradation products displacing moderator. Unlike the 21 MOX PWR WP, there is no boron to be lost in the basket degradation process and, therefore, no compensating increase in $\mathrm{k}_{\mathrm{eff}}$. The $58 \mathrm{vol \%}$ settled corrosion product case showed a $4.3 \%$ decrease in $\mathrm{k}_{\text {eff }}$ (measured at the postclosure peak for the $4.0 \mathrm{wt} \%$ fissile Pu in HM, 35.6 GWd/MTU fuel) from the intact configuration, while the uniform corrosion product case showed a $6.8 \%$ decrease.

The $k_{\text {eff' }}$ 's were sufficiently far from critical values ( 0.75 max) that a criticality event is virtually impossible and no comparisons with LEU SNF were necessary.

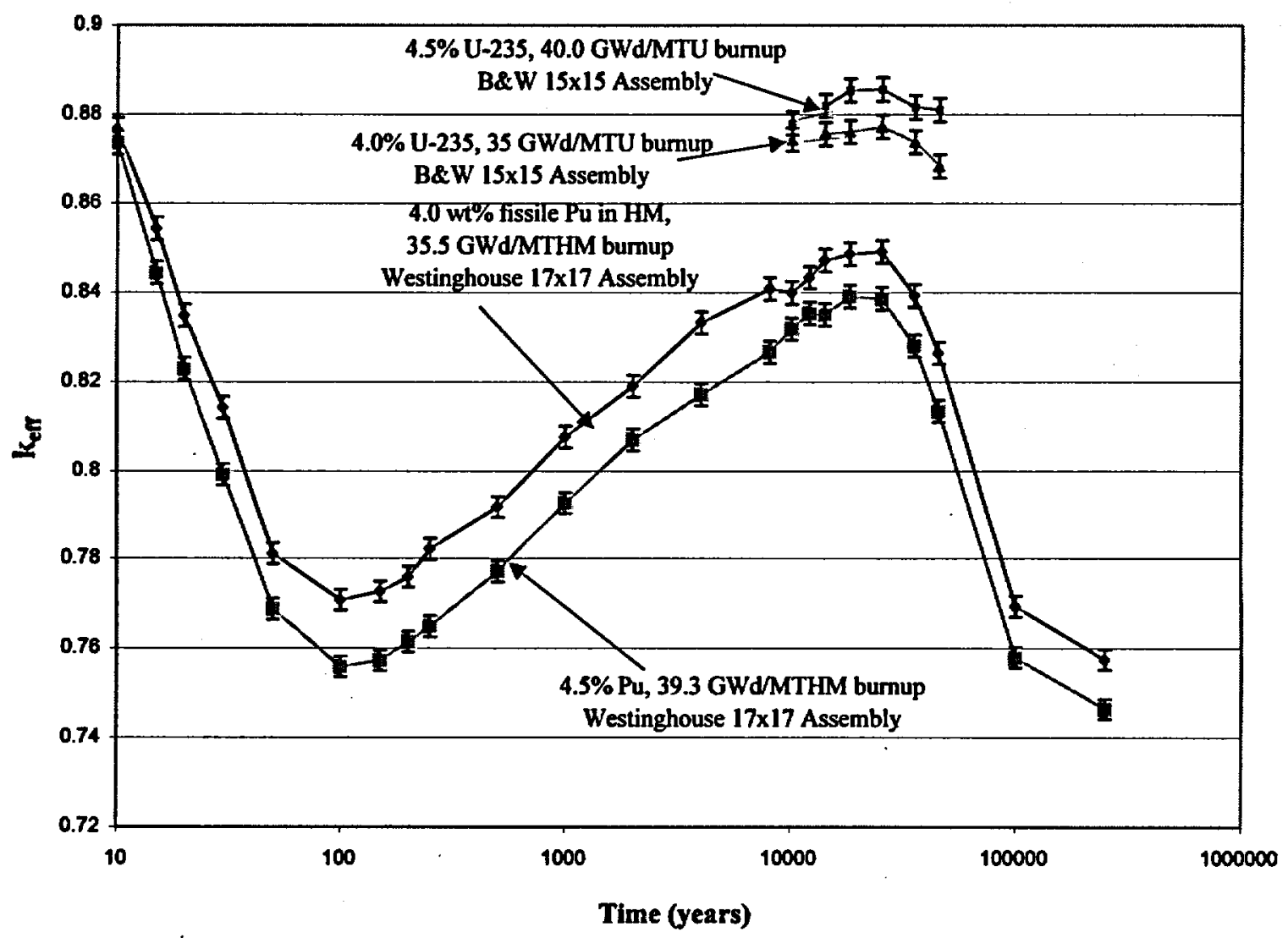

Figure 6.3.3.2-1. Time Effects on $\mathrm{k}_{\text {eff }}$ for Intact MOX and LEU SNF in a 21 PWR WP with a Fully Degraded Basket (No Boron Remaining) and Uniformly Distributed Corrosion Products 

Repository, Volume I: MOX SNF

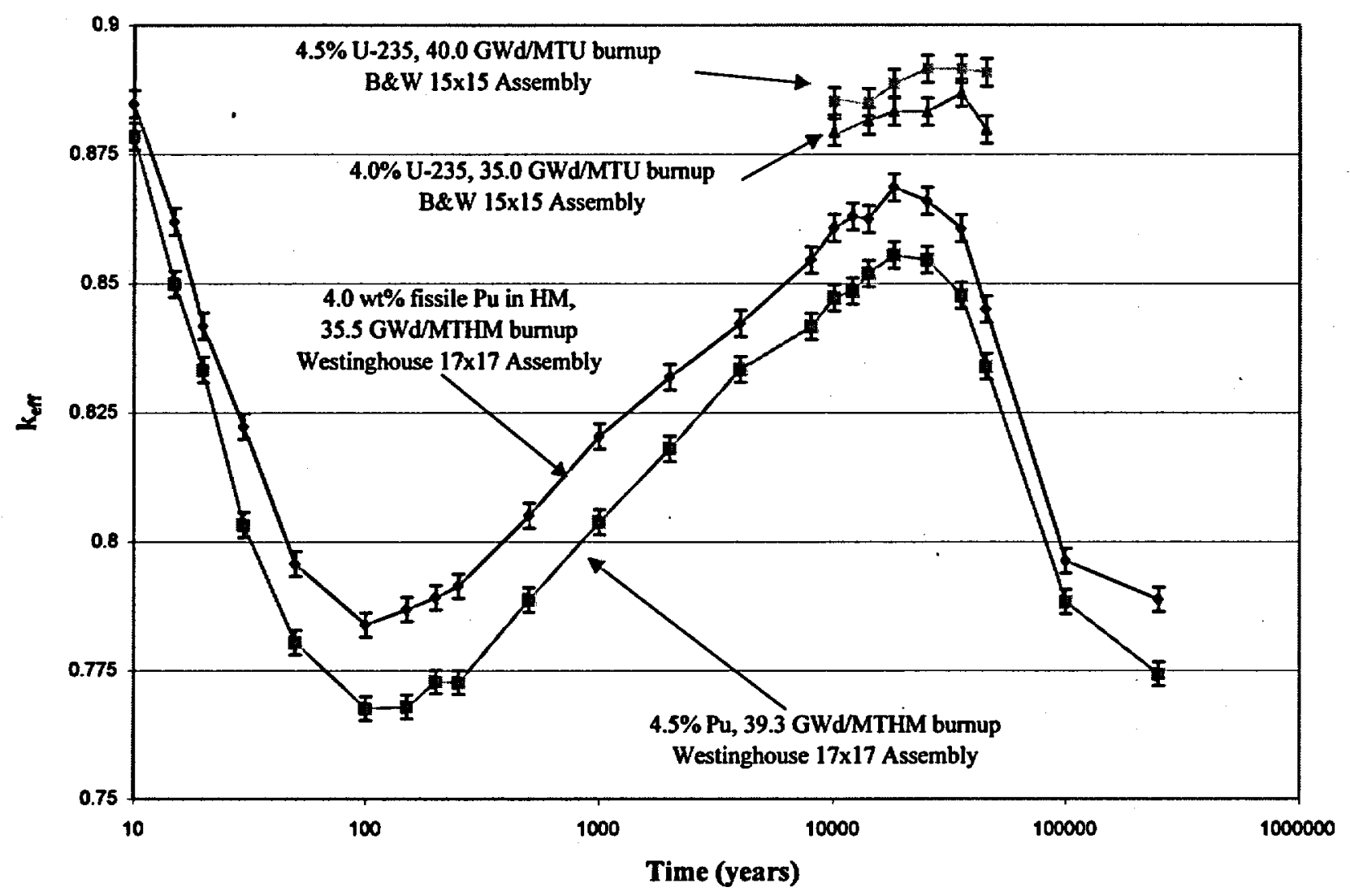

Figure 6.3.3.2-2. Time Effects on $k_{\text {eff }}$ for Intact MOX SNF in a 21 PWR WP with a Fully Degraded Basket (No Boron Remaining) and Settled Corrosion Products 
Report on Intact and Degraded Criticality for Selected Plutonium Waste Forms in a Geologic Repository, Volume I: MOX SNF

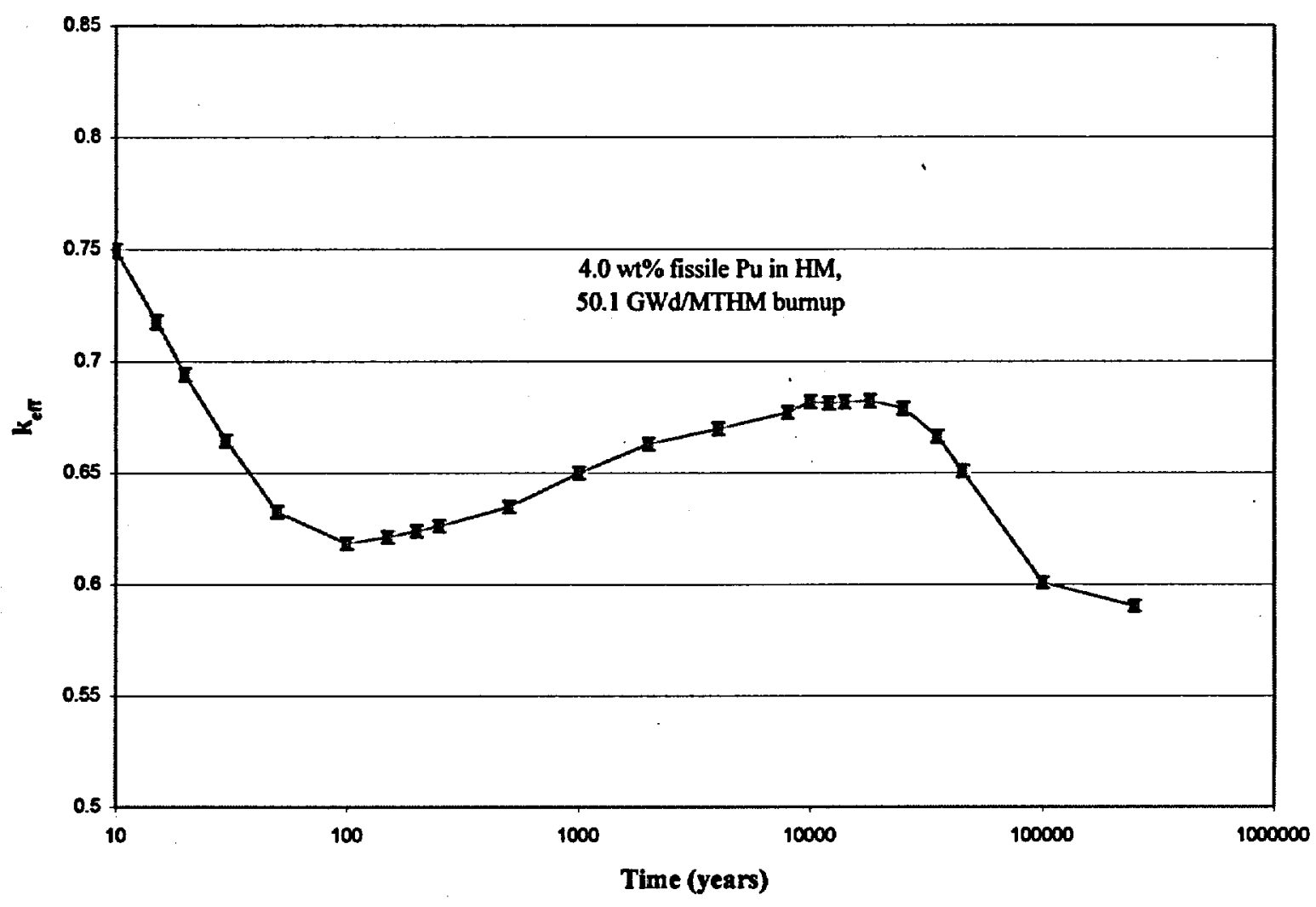

Figure 6.3.3.2-3. Time Effects on $\mathrm{k}_{\text {eff }}$ for Intact MOX SNF in a 12 PWR WP with a Fully Degraded Basket and Uniformly Distributed Corrosion Products 


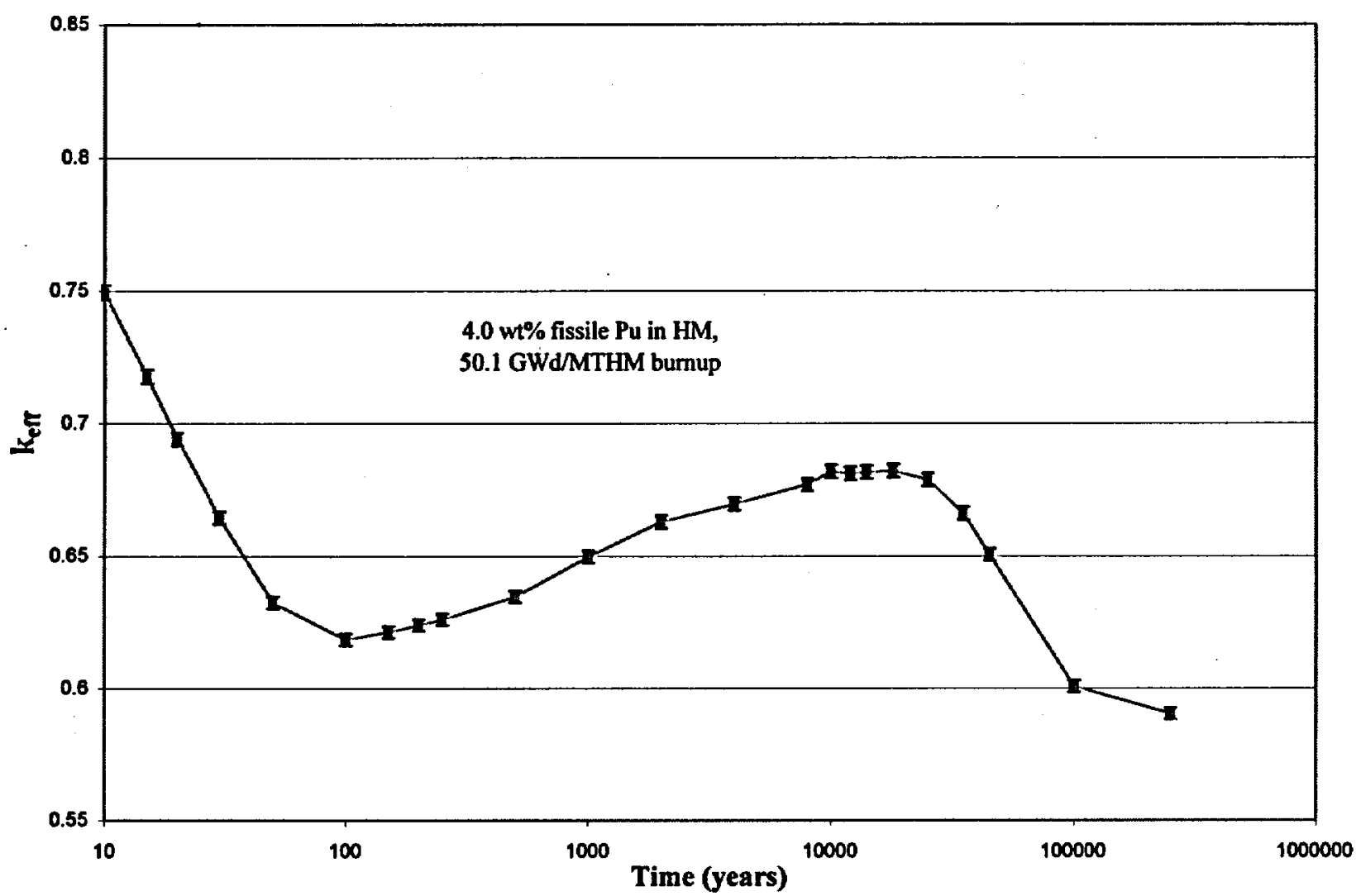

Figure 6.3.3.2-4. Time Effects on $\mathrm{k}_{\text {eff }}$ for Intact MOX SNF in a 12 PWR WP with a Fully Degraded Basket and Settled Corrosion Products

\subsubsection{Configurations for Degraded Fuel and Fully Degraded Basket}

The MCNP4B2 cases needed to evaluate the $\mathrm{k}_{\mathrm{eff}}$ of the 21 PWR MOX SNF waste package design with fully degraded basket structures and fuel that is partially (structurally intact but allows water to fill the gap region) or fully degraded (configurations $E$ and $F$ from Section 6.1) are described in this section. Configuration $\mathrm{E}$ was modeled by settling fuel rods into a cylinder segment at the bottom of the waste package in a square lattice arrangement, as is shown in Figure 6.3.3.3-1. The square lattice is the most conservative with respect to criticality since space is available for moderator in the lattice. A more likely arrangement such as a close packed one is less conservative because of greater moderator exclusion. The height of the cylinder segment was calculated to be that which would give a volume equal to 5544 fuel rods (264 rods/assembly x 21 assemblies) in a square lattice at a given pitch. Lattice pitches ranging from $0.9144 \mathrm{~cm}$ (rods touching) to $1.2598 \mathrm{~cm}$ (as-built fuel rod pitch) were evaluated (Ref. 12, Section 6.3) to represent the range of possible separations between collapsed rods which is expected to be less than the original pitch. The $\mathrm{k}_{\text {eff }}$ in this sensitivity study decreased as the pin pitch decreased. 


\section{Report on Intact and Degraded Criticality for Selected Plutonium Waste Forms in a Geologic Repository, Volume I: MOX SNF}

The fuel rods were modeled explicitly and contained water in the gap region. Only a uniform corrosion product distribution of $36.8 \mathrm{vol} \%$ (see Section 6.3.3) was evaluated. Cases were run with full isotope burnup credit, as well as for the reduced principal isotope conditions.

The fully degraded fuel and basket configuration (Configuration F) was modeled by homogenizing the remaining principal isotopes, zircaloy, and basket corrosion products in the waste package interior volume. The volume of degraded fuel material was assumed to be that which would occur if all of the initial $\mathrm{UO}_{2}$ degraded to soddyite $\left(\left[\mathrm{UO}_{2}\right]_{2} \mathrm{SiO}_{4}: 2 \mathrm{H}_{2} \mathrm{O}\right)$, as is indicated in the geochemistry calculations (Ref. 14, spreadsheet volmas2lc). Additional $\mathrm{Si}, \mathrm{H}$, and $\mathrm{O}$ were also added to the mixture to account for that which would be present if the fuel degraded to soddyite. The volume of zircaloy was equivalent to that contained in the cladding and guide tubes of 21 Vantage 5 SNF assemblies. All together, the degraded fuel, zircaloy, and basket corrosion products occupied $62.5 \%$ of the waste package interior volume. Water was assumed to fill the remaining void space. Figure 6.3.3.3-2 shows the geometry details of the MCNP4B2 model for the 21 PWR WP with fully degraded fuel and basket corrosion products uniformly distributed. Cases were run with reduced principal isotopes resulting from 17,500 years of radioactive decay and geochemical degradation. For comparison purposes only, a worst case was run for $\mathrm{U}$ and $\mathrm{Pu}$ isotopes only with all absorber isotopes removed.

Each of these configurations were evaluated for the $4.0 \mathrm{wt} \%$ fissile Pu in HM, 35.6 GWd/MTHM burnup fuel (fuel \#1) for decay times from 1000 years to 250,000 years.

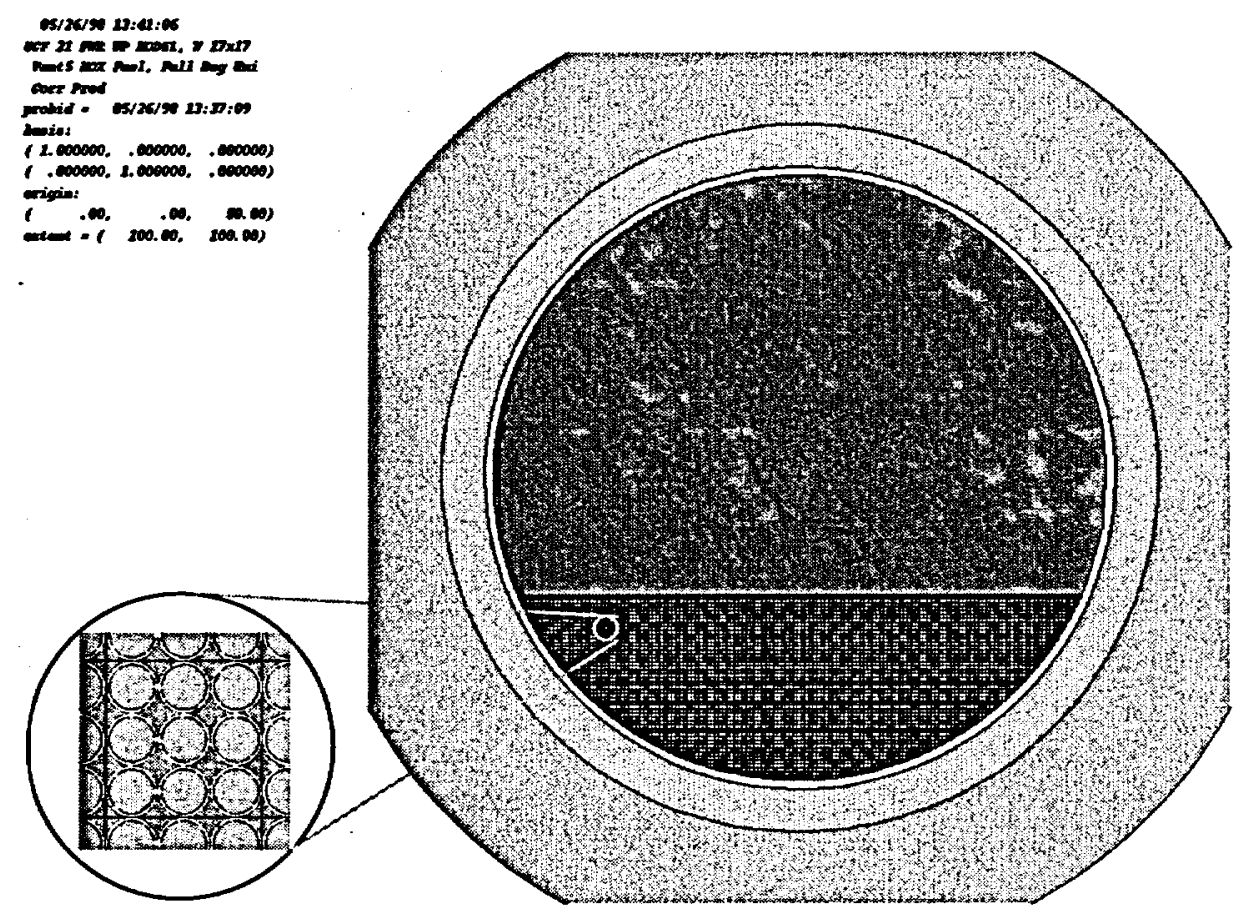

Figure 6.3.3.3-1. Degraded 21 PWR MOX WP with Fuel Rods Collapsed to Bottom of Package Surrounded by Uniformly Distributed Basket Corrosion Products 

Repository, Volume I: MOX SNF

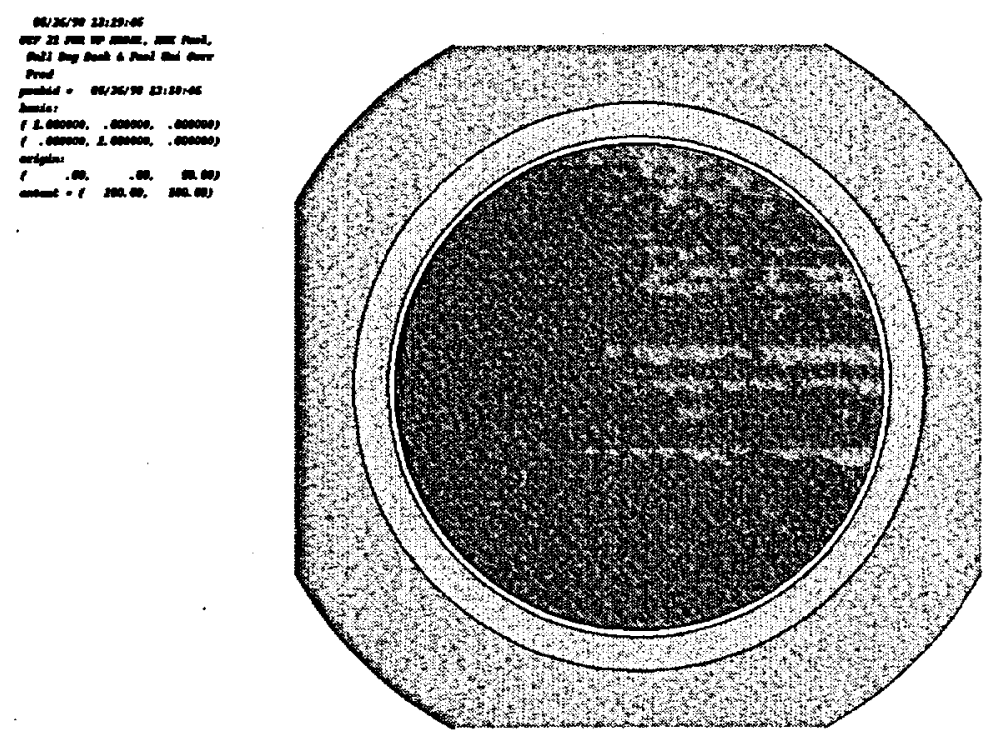

Figure 6.3.3.3-2. Fully Degraded Fuel and Basket Material Uniformly Distributed Throughout Interior Volume of 21 PWR WP

\subsubsection{Criticality Results for Degraded Fuel and Fully Degraded Basket}

Results of the criticality analyses of the 21 MOX PWR WP with a fully degraded basket, minimally spaced collapsed fuel rods $(0.9144 \mathrm{~cm})$, and a uniform corrosion product distribution are given in Table 6.3-1 of Reference 11, p. 46. The maximum $k_{\text {eff }}$ value was less than 0.675 for these cases, well below the critical limit of 0.92, as shown in Figure 6.3.3.4-1 (MOX labels). All values are for a rod center-to-center spacing of $0.9144 \mathrm{~cm}$ (rods touching in square lattice) representative of a nominal configuration. (Note: Nominal configuration; sensitivity to rod spacing is discussed below.) An extreme case in which all principal absorber isotopes are assumed to be lost leaving only the $U$ and $\mathrm{Pu}$ isotopes results in a $9 \%$ to $10 \%$ increase in $\mathrm{k}_{\text {eff. }}$ The ultra-conservative assumption (because of the low corrosion rate of zircaloy compared to carbon steel) that SNF degradation begins simultaneously with the baskets (see Section 6.3.2) is made in two of the analyses shown in Figure 6.3.3.4-1 (MOX Curves A and C). A more realistic SNF degradation assumption, where loss of the principal isotopes (PI) begins at 10,000 years after the start of basket degradation (MOX Curve B in Figure 6.3.3.4-1), shows a moderate increase in $k_{\text {eff }}$ over time relative to the early loss of the PI. Also of interest is the reduced peak-and-valley effect with time, and the movement of the peak $k_{\text {eff }}$ out to $\approx 45,000$ years. Both effects result from increased resonance absorption due to the harder spectrum of this configuration. The location of the peak shifts outward in time because the increased absorption in Pu-240 in a harder spectrum is not matched by an equal increase in Pu-239 fission. Thus, longer decay times are required to eliminate the absorption effect from Pu-240.

Results from a similar analysis for the 21 LEU PWR WP (fully degraded baskets, minimally spaced collapsed fuel rods, and uniform corrosion products) (Ref. 37, Section 6) are also shown in Figure 6.3.3.4-1 also with the LEU labels. This case utilized the $4.0 \mathrm{wt} \% \mathrm{u}-235,35.0 \mathrm{GWd} / \mathrm{MTU}$ LEU SNF with a $1.0922 \mathrm{~cm}$ square pitch (normal pitch is $1.44272 \mathrm{~cm}$ ). The MOX SNF $k_{\text {eff }}$ 's were less than those from the similar LEU SNF cases; the maximum LEU SNF $k_{\text {eff }}$ was approximately 0.7 . 


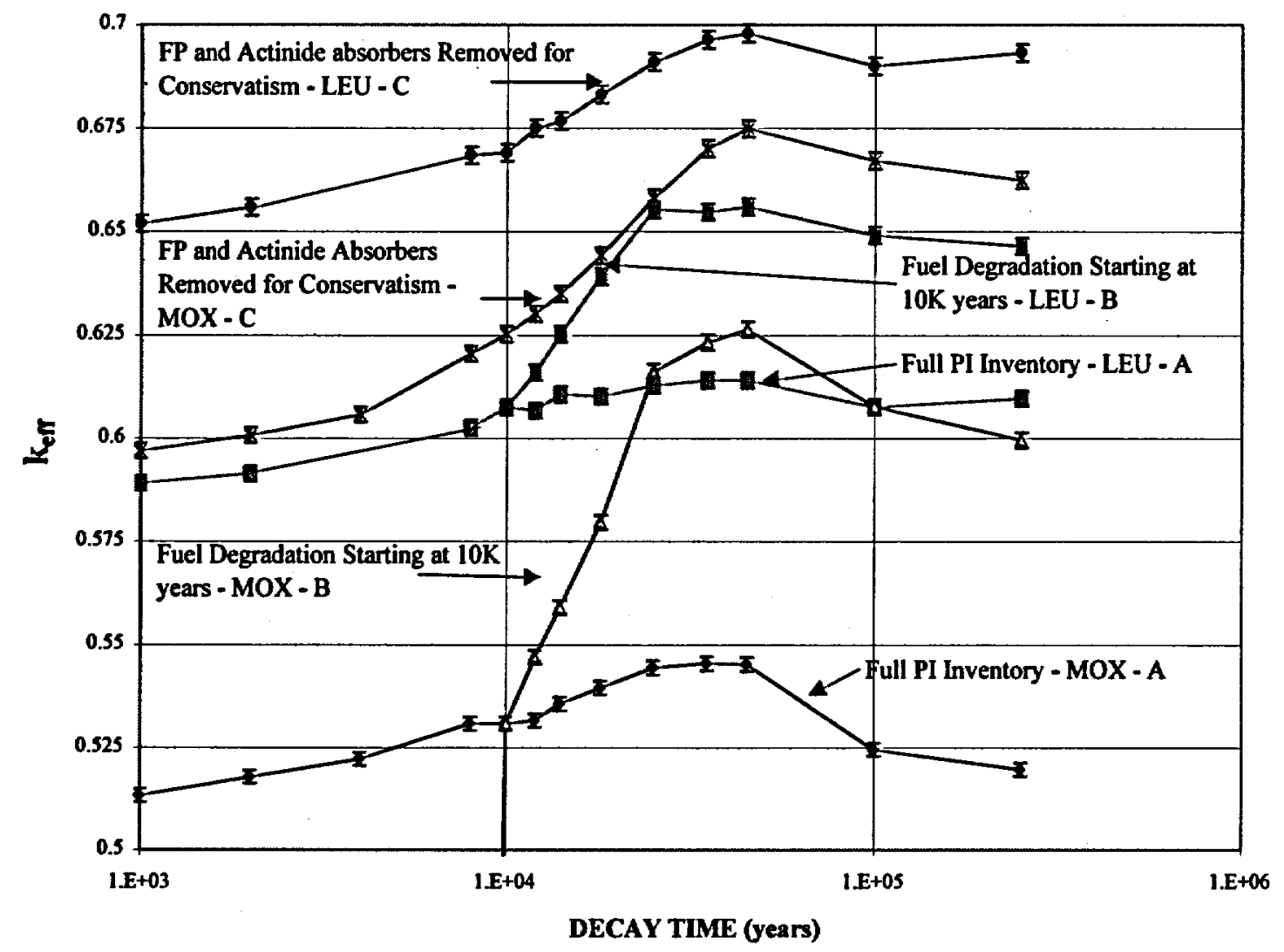

Figure 6.3.3.4-1. Time and Fuel Degradation Effects on $k_{\text {eff }}$ for 21 PWR WP with a Fully Degraded Basket, Square Lattice Collapsed Rods (MOX and LEU), and Uniformly Distributed Corrosion Products

Results of the 18,000 and 45,000 year MOX SNF cases run for various fuel rod spacing, up to the original pitch of $1.2598 \mathrm{~cm}$ showed that the optimum point of moderation occurs at the original assembly pitch. However, the $k_{\text {eff }}$ values only exceeded those of the 21 PWR WP in Configuration $\mathrm{D}$ with settled oxide (see Section 6.1) under the combination of extreme fuel degradation (U and $\mathrm{Pu}$ principal isotopes only) and rod spacing within $\approx 1 \mathrm{~mm}$ of the original pitch. This is not a likely situation, as the original rod geometry (much less the spacing) would not be expected to be retained at such a degree of fuel degradation.

Figure 6.3.3.4-2 shows the $k_{\text {eff }}$ results for the fully degraded fuel and basket configuration (Configuration F, Section 6.1 and Figure 6.3.3.3-2) for both the MOX SNF and the LEU SNF. Note that for this case, the peak $k_{\text {eff }}$ for the LEU SNF is approximately $4 \%$ less than the MOX SNF value of 0.845 . This is well below the critical value of 0.92 . 

Repository, Volume I: MOX SNF

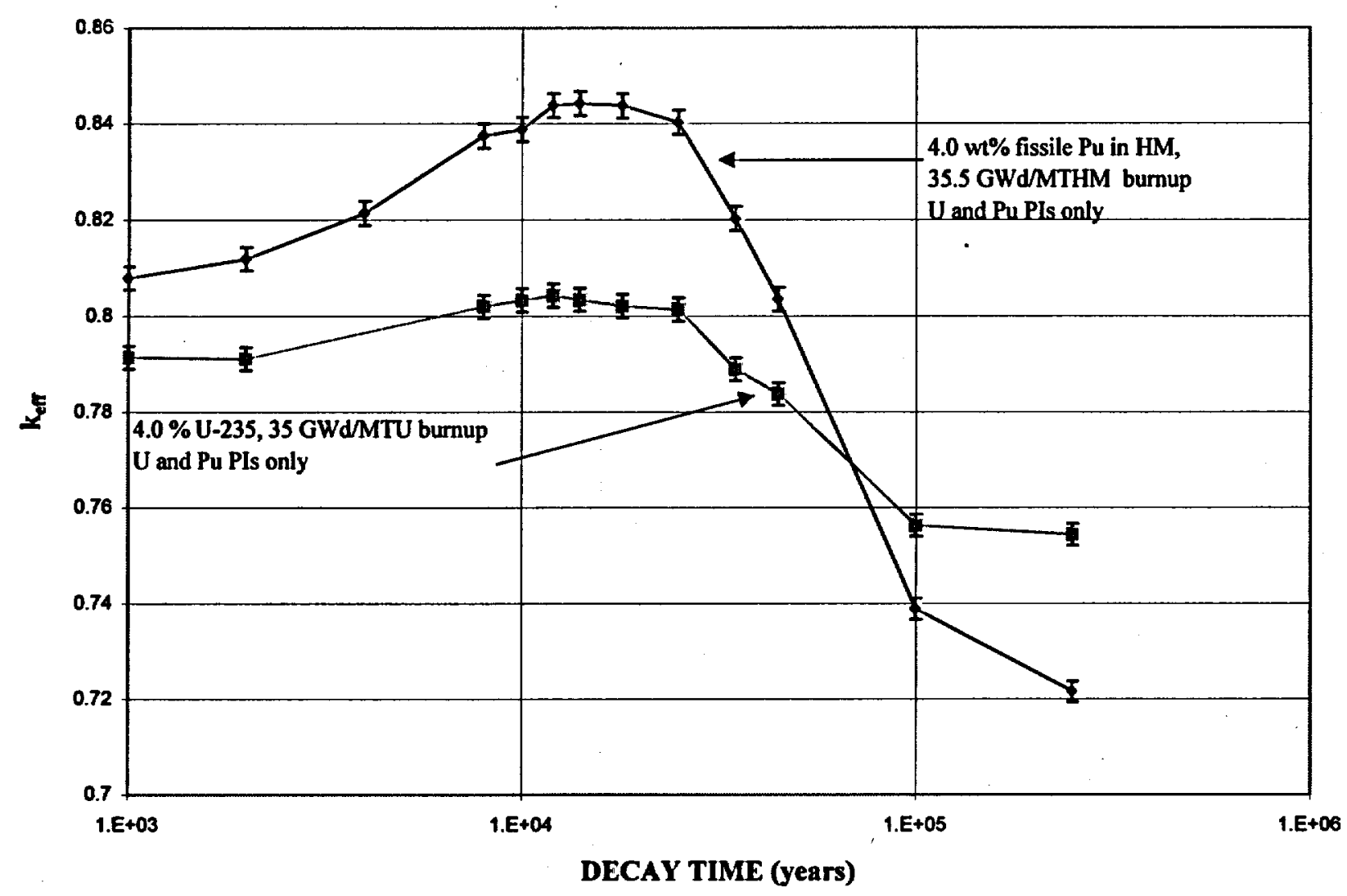

Figure 6.3.3.4-2. Time and Fuel Degradation Effects on $\mathrm{k}_{\text {eff }}$ for a 21 PWR WP with Fully Degraded Basket and Fuel, and Uniformly Distributed Corrosion Products

\subsection{Summary of Evaluation of Potential Critical Configurations}

Criticality evaluations were performed for the 21 PWR MOX SNF WP and the 12 PWR MOX SNF WP for conditions ranging from intact to fully degraded fuel and baskets. The peak $\mathrm{k}_{\text {eff' }}$ 's are shown in Table 6.3.3.5-1. The following observations on the criticality potential of the PWR MOX SNF can be made:

1) The worst case $k_{\text {eff }}$ is below the criticality limit of 0.92 for all waste package designs examined for any credible waste package internal configuration and thus a criticality event is virtually impossible.

2) The 12 PWR WP has a higher $k_{\text {eff }}$ than the 21 PWR WP for the flooded intact fuel and intact basket because this waste package has no neutron absorber plates.

3) The 12 PWR WP has a lower $k_{\text {eff }}$ than the 21 PWR WP for the flooded intact fuel and degraded basket because the iron oxide corrosion products displace moderator compensating, in part, for the absence of absorber plates. 
Report on Intact and Degraded Criticality for Selected Plutonium Waste Forms in a Geologic Repository, Volume I: MOX SNF

4) The MOX PWR SNF has a lower criticality potential ( $\left.k_{\text {eff }}\right)$ than the bounding LEU PWR SNF waste form for all configurations examined except for a highly unlikely configuration.

Table 6.3.3.5-1. Peak $k_{\text {eff }}$ for Degraded PWR MOX SNF

\begin{tabular}{|c|c|c|c|}
\hline SNF Configuration & \multicolumn{3}{|c|}{$\begin{array}{c}\text { Burnup } \\
\text { (GWd/MTHM) }\end{array}$} \\
\cline { 2 - 4 } & $\begin{array}{c}35.6(4.0 \mathrm{wt} \% \text { fissile } \\
\text { Pu in HM) }\end{array}$ & $\begin{array}{c}39.4(4.5 \mathrm{wt} \% \text { fissile Pu in } \\
\text { HM) }\end{array}$ & $\begin{array}{c}46.5(4.5 \mathrm{wt} \% \\
\text { fissile Pu in HM) }\end{array}$ \\
\cline { 2 - 4 } & 21 PWR WP & 21 PWR WP & 12 PWR WP \\
\hline Intact Fuel, Intact Basket & 0.84 & 0.84 & 0.86 \\
\hline $\begin{array}{c}\text { Intact Fuel, Degraded } \\
\text { Basket }\end{array}$ & 0.89 & 0.88 & 0.81 \\
\hline $\begin{array}{c}\text { Partially Collapsed and } \\
\text { Degraded SNF-Full Pls }\end{array}$ & 0.55 & NA & NA \\
\hline $\begin{array}{c}\text { Partially Collapsed and } \\
\text { Degraded SNF-Pu and U } \\
\text { PI }\end{array}$ & 0.67 & NA & NA \\
\hline $\begin{array}{c}\text { Fully Degraded Basket and } \\
\text { SNF }\end{array}$ & 0.84 & NA & NA \\
\hline
\end{tabular}

NA - Not Applicable; Case not run. 


\section{Report on Intact and Degraded Criticality for Selected Plutonium Waste Forms in a Geologic Repository, Volume I: MOX SNF}

\section{FINDINGS AND CONCLUSIONS}

\section{Structural}

The most severe structural design basis event is the waste package tipover accident. The finite element analyses of both the 21 PWR and the 12 PWR WPs for this postulated event show that the peak stress at any location in either of the waste packages will be at least $15 \%$ less than the ultimate material tensile strength and thus are within design limits. Calculated stresses in the MOX PWR WPs were of similar magnitude to stresses calculated for a tipover accident in similar waste packages containing commercial PWR SNF.

\section{Thermal}

The initial heating rates for MOX SNF were 798 watts/assembly for the 21 PWR WP loaded with the highest heat source MOX SNF to be placed in that package, i.e., assemblies having no greater burnup than $46.5 \mathrm{GWd} / \mathrm{MTHM}$. The initial heating rates were 1070 watts/assembly for the $12 \mathrm{PWR}$ WP loaded with the MOX SNF generating the highest heat source, i.e., assemblies with 56.5 GWd/MTHM burnup. For the 21 PWR waste package, the peak cladding temperature was approximately $234^{\circ} \mathrm{C}$. The peak cladding temperature for the $12 \mathrm{PWR}$ waste was approximately $218^{\circ} \mathrm{C}$. The fuel temperature (homogenized assemblies) peaks at approximately $336^{\circ} \mathrm{C}$ for the 21 PWR MOX SNF and at approximately $302^{\circ} \mathrm{C}$ for the 12 PWR MOX WP. Both of these peak temperatures are well below the maximum permissible waste package fuel temperature of $350^{\circ} \mathrm{C}$ given in the CDA (Ref. 28, p. 8-1).

The waste package surface temperatures were determined at the thermal design basis loading of 85 MTU/acre which is within the AML range (80 to 100 MTU/acre) given in the CDA (Ref. 28, Key 019) for the repository.

\section{Shielding}

Maximum dose rates at the waste package exterior surfaces were less than $110 \mathrm{rad} / \mathrm{h}$ for the $21 \mathrm{MOX}$ PWR WP loaded with the highest burnup MOX SNF at $56.5 \mathrm{GWd} / \mathrm{MTHM} 10$ years after reactor discharge. This is conservative since this configuration produces the largest radiation source, thus maximizing the surface dose rate. The 12 MOX PWR WP design has an equivalent amount of shielding with a smaller source which will result in smaller surface dose rates.

No significant increase in the waste package barrier corrosion rate from the radiolytic effects of high surface dose rates is likely since this requires a steam-air environment combined with a greater than $100 \mathrm{rad} / \mathrm{h}$ dose rate which is a very unlikely repository condition.

The radiation levels were shown to be much less than the values from commercial LEU PWR SNF of similar burnup which were calculated to be greater than $150 \mathrm{rem} / \mathrm{h}$. This is due primarily to the differences in the isotopic inventory in the two waste forms contributing to the radiation source. 


\section{Report on Intact and Degraded Criticality for Selected Plutonium Waste Forms in a Geologic Repository, Volume I: MOX SNF}

\section{Criticality}

The peak $k_{\text {eff }}$ 's for the MOX PWR SNF ranged from 0.55 to 0.90 where the 0.90 resulted from a worst case configuration. The $k_{\text {eff }}$ for the worst MOX PWR SNF case is below the criticality limit of 0.92 for any credible configuration and thus any criticality event is virtually impossible.

The worst case configuration was for intact MOX SNF fuel assemblies combined with fully degraded baskets. In this configuration, all boron was assumed to be removed from the waste package, so that the only criticality control was provided by the iron oxide left from the corrosion of the carbon steel basket. The iron oxide was assumed to be in the most conservative configuration, i.e., settled). The criticality calculation for the 21 PWR package (35.6 GWd/MTHM burnup and 4\% initial fissile $\mathrm{Pu}$ loading) resulted in a peak $\mathrm{k}_{\mathrm{eff}}=0.87$. For the $12 \mathrm{PWR}$ package, in which the most reactive MOX SNF is nominally $50 \mathrm{GWd} / \mathrm{MTHM}$ with $4 \%$ initial fissile Pu loading, the criticality calculation resulted in a peak $k_{\text {eff }}=0.70$.

A worst case can be defined for the degraded fuel and degraded basket configuration in which the neutron absorber fission products (particularly gadolinium) are leached from the SNF while the assemblies still retain sufficient cladding and spacer grids to maintain the intact SNF geometry. The criticality calculation for this configuration resulted in a peak $k_{\text {eff }}=0.92$. A much more likely configuration would have the SNF completely collapsed by the time the gadolinium had been leached, which leads to the much lower peak $k_{\text {eff }}=0.63$. In both these cases the rate of removal of gadolinium from the waste package is delayed by its low solubility, so that it remains as an effective criticality control material until after the time of peak $\mathrm{k}_{\text {eff. }}$ These worst cases have significant gadolinium removal because the degradation of the SNF is assumed to occur while the basket steel is not completely degraded so that there is still a possibility of the $\mathrm{pH}$ going below 6 where the gadolinium will be moderately soluble. It is more likely that the basket will have completely degraded before the zircaloy cladding degrades sufficiently to permit significant leaching of the SNF.

In summary, analysis of the effects of placing MOX SNF in the 21 and 12 PWR waste packages will not result in the design criteria for the waste packages being exceeded provided that:

1. burnup levels for assemblies placed in the 21 PWR WP be restricted to less than 46.5 GWd/MTHM, and

2. absorber plates be used in the 21 PWR WP basket design. 
Report on Intact and Degraded Criticality for Selected Plutonium Waste Forms in a Geologic Repository, Volume I: MOX SNF

\section{REFERENCES}

1. Civilian Radioactive Waste Management System (CRWMS) Management \& Operating Contractor (M\&O) 1998. Technical Document Preparation Plan for the Report on Intact \& Degraded Criticality for Selected Plutonium Waste Forms in a Geologic Repository. BBA000000-01717-4600-00011 REV 00. Las Vegas, NV. J.A. McClure. MOL.19980911.0307.

2. Westinghouse Electric Corporation 1994. Plutonium Disposition in Existing Pressurized Water Reactors. DOE/SF/19683-6. Pittsburgh, PA. TIC \#: 237140.

3. Westinghouse Electric Corporation 1996. Plutonium Disposition Study; Implementation of Weapons Grade MOX Fuel in Existing Pressurized Water Reactors. DOE/SF/19683-7. Pittsburgh, PA. TIC \#: 237139.

4. Oak Ridge National Laboratory 1992. Characteristics of Potential Repository Wastes. DOE/RW-0184-R1, Volume 1. Oak Ridge, TN. Lockheed Martin Energy Research Corporation. HQO.19920827.0001.

5. CRWMS M\&O 1998. Westinghouse MOX SNF Isotopic Source. BBA000000-01717-021000007 REV 00. Las Vegas, NV. J.A. McClure. MOL.19980818.0131.

6. CRWMS M\&O 1998. Estimation of the Westinghouse $17 \times 17$ MOX SNF Assembly Weight. A00000000-01717-0210-00001 REV 00. Las Vegas, NV. J.A. McClure. MOL.19980716.0557.

7. CRWMS M\&O 1997. Software Qualification Report for The SCALE Modular Code System Version 4.3. CSCI: 30011 V4.3. 30011-2002 REV 01. Las Vegas, NV. T.L. Lotz. MOL.19970731.0884.

8. CRWMS M\&O 1997. Disposal Criticality Analysis Methodology Technical Report. B00000000-01717-5705-00020 REV 01. Las Vegas, NV. D.A. Thomas. MOL.19980108.0700.

9. CRWMS M\&O. Waste Package Materials Selection Analysis. BBA000000-01717-020000020 REV 01. Las Vegas, NV. V. Pasupathi. MOL.19980324.0242.

10. CRWMS M\&O 1997. Determination of Waste Package Design Configurations. BBAA00000-01717-0200-00017 REV 00. Las Vegas, NV. T.L. Lotz. MOL.19970805.0310.

11. CRWMS M\&O 1998. Criticality Evaluation of Intact and Degraded PWR WPs Containing MOX SNF. A00000000-01717-0210-00002 REV 00. Las Vegas, NV. J.R. Massari. MOL.19980701.0482. 
Report on Intact and Degraded Criticality for Selected Plutonium Waste Forms in a Geologic Repository, Volume I: MOX SNF

12. CRWMS M\&O. 21-PWR Waste Package Disposal Container Assembly. BBAA0000001717-2700-15998 REV 00. Las Vegas, NV. MOL.19971222.0299.

13. CRWMS M\&O. 12-PWR Waste Package Disposal Container Assembly. BBAA0000001717-2700-16086 REV 00. Las Vegas, NV. MOL.19980199.0362.

14. CRWMS M\&O 1998. EQ6 Calculations for Chemical Degradation of PWR LEU and PWR MOX Spent Fuel Waste Packages. BBA000000-01717-0210-00009, REV 00. Las Vegas, NV. P.L. Cloke. MOL.19980701.0483.

15. United States Department of Energy 1996. Record of Decision for the Disposition of Surplus Highly Enriched Uranium Final Environmental Impact Statement. 61 Federal Register 40619. Washington, D.C. TIC \#: 231278.

16. United States Department of Energy 1997. Record of Decision for the Storage and Disposition of Weapons-Usable Fissile Materials Final Programmatic Environmental Impact Statement. Washington, D.C. TIC \#: 239425.

17. CRWMS M\&O 1998. 21 MOX PWR WP Tipover Calculations. BBAA00000-01717-021000003 REV 00. Las Vegas, NV. Z. Ceylan. MOL.19980716.0045.

18. CRWMS M\&O 1998. 12 PWR MOX Waste Package Tipover Calculations. BBAA0000001717-0210-00006 REV 00. Las Vegas, NV. Z. Ceylan. MOL.19880918.0085.

19. CRWMS M\&O 1997. Waste Package Design Basis Events. BBA000000-01717-0200-00037 REV 00. Las Vegas, NV. J.R. Massari and L.E. Booth. MOL.19971006.0075.

20. CRWMS M\&O 1998. Software Qualification Report for ANSYS V5.4. CSCI: 30040 V5.4. 30040-2003 REV 00. Las Vegas, NV. S.M. Bennett. MOL.19980609.0847.

21. CRWMS M\&O 1998. UCF WP Tipover Analysis. BBAAA0000-01717-0210-000001 REV 00. Las Vegas, NV. Z. Ceylan. MOL.19980625.0326.

22. CRWMS M\&O 1998. Uncanistered Spent Nuclear Fuel Disposal Container System Description Document. BBA000000-01717-1705-00004 REV 00. Las Vegas, NV. N.D. Sudan. MOL.19980515.0167 and MOL.19980518.0155.

23. CRWMS M\&O 1998. Thermal Evaluation of the PWR UCF Waste Package Loaded with MOX SNF. BBAA00000-01717-0210-00008 REV 00. Las Vegas, NV. M. Hinds. MOL.19980909.0155.

24. CRWMS M\&O 1995. Software Qualification Report for ANSYS V5.1HP. CSCI: 30003 V5.1HP. 30003-2006 REV 01. Las Vegas, NV. M.J. Plinski. MOL.19980908.0167. 
Report on Intact and Degraded Criticality for Selected Plutonium Waste Forms in a Geologic Repository, Volume I: MOX SNF

25. CRWMS M\&O 1997. Preliminary Design Basis for WP Thermal Analysis. BBAA0000001717-0200-00019 REV 00. Las Vegas, NV. R.H. Bahney. MOL.19980127.0719.

26. United States Department of Energy 1997. Temperature Results of the Emplacement Multiple Waste Packages Thermal Calculation. CRWMS Interoffice Correspondence LV.WP.HW.5/98-109. H. Wang to John H. Jones and David C. Copenhaver. MOL.19980730.0161.

27. CRWMS M\&O 1998. Multiple WP Emplacement Thermal Response-Suite 1. BBA00000001717-0210-00001 REV 00. Las Vegas, NV. MOL.19980807.0311.

28. CRWMS M\&O 1998. Controlled Design Assumptions Document. B0000000-01717-460000032 REV 05. Las Vegas, NV. MOL.19980804.0481.

29. CRWMS M\&O 1998. Time Dependent Source Term Generation and Shielding Analysis for MOX Fuel in the 21 PWR Waste Package. BBAC00000-01717-0210-00002 REV 00. Las Vegas, NV. K. Goluoglu. MOL.19980811.0596.

30. CRWMS M\&O 1996. Mined Geologic Disposal System Advanced Conceptual Design Report. B00000000-01717-5705-00027 REV 00. Las Vegas, NV. MOL.19960826.0094 and MOL.19960826.0097.

31. United States Department of Energy 1987. Characteristics of Spent Fuel, High Level Waste and Other Radioactive Wastes Which May Require Long-Term Isolation, Volume 3 of 6, Appendix 2A: Physical Descriptions of LWR Fuel Assemblies. DOE/RW-0184. TIC \#: 202243.

32. CRWMS M\&O 1998. Time Dependent Shielding Analysis for Commercial SNF in the 21 PWR Waste Package. BBAC00000-01717-0210-00003. Las Vegas, NV. K. Goluoglu. MOL.19980812.0238.

33. CRWMS M\&O 1998. Software Qualification Report for MCNP Version 4B2 CSCI: 30033 V4B2LV. 30033-2003 REV 01. Las Vegas, NV. S. Goluoglu and J.A. McClure. MOL.19980622.0637.

34. CRWMS M\&O 1996. Material Compositions and Number Densities for Neutronics Calculations. BBA000000-01717-0200-00002 REV 00. Las Vegas, NV: D.A. Thomas. MOL.19960624.0023.

35. Lawrence Livermore National Laboratory 1992. EQ3/6, A Software Package for Geochemical Modeling of Aqueous Systems: Package Overview and Installation Guide (Version 7.0). UCRL-MA-1 10662 PT I. T.J. Wolery. MOV.19980504.0006. 
36. CRWMS M\&O 1998. Supplemental Criticality Evaluation for Degraded Internal Configurations of a 21 PWR Waste Package. BBA000000-01717-0210-00022 REV 00. Las Vegas, NV. J.R. Massari. MOL.19980918.0086.

37. B\&W Fuel Company 1991. Final Design Package - Babcock \& Wilcox BR-100 - 100 Ton Rail/Barge Spent Fuel Shipping Cask. Document No. 51-1203400-01. MOL.19960802.0082 and MOL.19960802.0083.

38. Reserved.

39. Reserved.

40. Electric Power Research Institute 1989. Testing and Analysis of the TN-24P PWR Spent Fuel Dry Storage Cask Loaded with Consolidated Fuel. EPRI NP-6191. Richland, WA. NNA.19890428.0089.

41. Reserved.

42. CRWMS M\&O 1998. Disposal Criticality Analysis Methodology Topical Report. B00000000-01717-5705-00095 REV 00. Las Vegas, Nevada. MOL.19980918.0005.

43. CRWMS M\&O 1997. Criticality Evaluation of Degraded Internal Configurations for the PWR AUCF Waste Package Designs. BBA000000-01717-0200-00056 REV 00. Las Vegas, NV. J.R. Massari. MOL.19971231.0251.

44. CRWMS M\&O 1998. Electronic Attachments for: BBA000000-01717-0210-00007 REV00, Westinghouse MOX SNF Isotopic Source. Colorado Backup Tape. Las Vegas, NV. J. A. McClure. MOL.19980629.0795.

45. CRWMS M\&O 1998. Electronic Attachments for: BBA000000-01717-0210-00009 REV00, EQ6 Calculations for Chemical Degradation of PWR LEU and PWR MOX Spent Fuel Waste Packages. Colorado Backup Tape. Las Vegas, NV. P.L. Cloke. MOL.19980804.0100. 
WBS: 1.2.1.10

QA: N/A

Civilian Radioactive Waste Management System

Management \& Operating Contractor

Report on Intact and Degraded Criticality for Selected Plutonium Waste

Forms in a Geologic Repository, Volume II: Immobilized In Ceramic

Document Identifier: BBA000000-01717-5705-00020 REV 00

September 18, 1998

Prepared for:

U.S. Department of Energy

Office of Civilian Radioactive Waste Management

1000 Independence Avenue SW

Washington, D. C. 20585

Prepared By:

Civilian Radioactive Waste Management System

Management \& Operating Contractor

1261 Town Center Drive

Las Vegas, NV 89134

Under Contract Number

DE-AC08-91RW00134 
Report on Intact \& Degraded Criticality for Selected Plutonium Waste Forms in a

Geologic Repository, Volume II: Immobilized in Ceramic

\section{Civilian Radioactive Waste Management System \\ Management \& Operating Contractor}

\section{Report on Intact and Degraded Criticality for Selected Plutonium Waste} Forms in a Geologic Repository, Volume II: Immobilized In Ceramic

Document Identifier: BBA000000-01717-5705-00020 REV 00

\section{September 18, 1998}

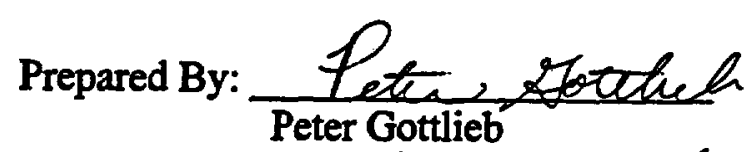

Concurrence:

Approved By:

Peter Gottlieb, Manager

Degraded and External Criticality

Approved By: Wuigh A. Benta

Hugh A. Benton, Manager

Waste Package Operations
Date: $\quad 9 / 18 / 98$

Date: $\quad 9 / 18 / 98$

Date: $\quad 9 / 18 / 98$

Date: $\quad 9 / 21 / 98$ 


\section{Report on Intact \& Degraded Criticality for Selected Plutonium Waste Forms in a}

Geologic Repository, Volume II: Immobilized in Ceramic

History of Change Page

Rev/Change Number Description and Reason for Change

REV $00 \quad$ Initial Issue 


\section{Report on Intact \& Degraded Criticality for Selected Plutonium Waste Forms in a Geologic Repository, Volume II: Immobilized in Ceramic}

\section{EXECUTIVE SUMMARY}

As part of the plutonium waste form development and down-select process, repository analyses have been conducted to evaluate the long-term performance of these forms for repository acceptance. Intact and degraded mode criticality analysis of the mixed oxide (MOX) spent fuel is presented in Volume I, while Volume II presents the evaluations of the waste form containing plutonium immobilized in a ceramic matrix.

Although the ceramic immobilization development program is ongoing, and refinements are still being developed and evaluated, this analysis provides value through quick feed-back to this development process, and as preparation for the analysis that will be conducted starting in fiscal year (FY) 1999 in support of the License Application.

While no MOX fuel has been generated in the United States using weapons-usable plutonium, Oak Ridge National Laboratory (ORNL) has conducted calculations on Westinghouse-type reactors to determine the expected characteristics of such a fuel. These spent nuclear fuel (SNF) characteristics have been used to determine the long-term potential for criticality in a repository environment.

In all instances the methodology and scenarios used in these analyses are compatible with those developed and used for Commercial Spent Nuclear Fuel (CSNF) and Defense High Level Waste (DHLW), as tailored for the particular characteristics of the waste forms. This provides a common basis for comparison of the results.

This analysis utilizes dissolution, solubility, and thermodynamic data that are currently available. Additional data on long-term behavior is being developed, and later analyses (FY 99) to support the License Application will use the very latest information that has been generated. Ranges of parameter values are considered to reflect sensitivity to uncertainty. Most of the analysis is focused on those parameter values that produce the worst case results, so that potential licensing issues can be identified.

\section{MOX (Volume I)}

This study is concerned with evaluating the criticality potential of the intact and degraded forms of the MOX SNF in waste packages (WPs). Current designs for both the 21 PWR WP and the 12 PWR WP are analyzed. Aluminum thermal shunts were used in both designs to enhance the heat flow rate.

This study also includes an evaluation of the structural, thermal, and shielding impacts of the MOX SNF WP's. Although previous analyses showed these impacts to be within regulatory and safety requirements, a more comprehensive evaluation is appropriate at this time to reflect the current MOX design and to prepare for the License Application analysis phase.

Since the MOX WP's will have criticality performance very similar to the waste packages 
Report on Intact \& Degraded Criticality for Selected Plutonium Waste Forms in a Geologic Repository, Volume II: Immobilized in Ceramic

containing commercial low enriched uranium (LEU) SNF, the criticality evaluations follow the same methodology of initial analysis with the following steps:

1. Criticality evaluation of the intact configuration to demonstrate the effectiveness of the criticality control measures,

2. Criticality evaluation of the same degraded basket configurations that have been used for the commercial LEU SNF,

3. Determination of the configurations having both degraded basket and degraded MOX SNF, using the geochemistry code, EQ6, as has also been done for the commercial LEU SNF, and

4. Criticality evaluation of the combined degraded basket and degraded SNF configurations.

\section{Major Findings, MOX (Volume I)}

Based on the current available data and designs for the MOX fuel, we find the following:

1. Assuming that the MOX SNF will be emplaced at least 10 years following discharge, those assemblies having low burnup ( $\leq 46 \mathrm{GWd} / \mathrm{MTHM}$ ) can be loaded into the standard commercial 21 PWR WP, and those assemblies having high burnup ( $>46 \mathrm{GWd} / \mathrm{MTHM}$ ) can be loaded into the standard commercial 12 PWR WP. With the expected distribution of burnups in the MOX SNF, this strategy will result in approximately half the MOX assemblies being placed in each of the two types of waste package. This emplacement strategy will also have the following performance aspects:

- The MOX SNF waste packages meet all regulatory requirements.

- There is no credible intact or degradation scenario leading to an internal criticality in the waste packages.

- Structural, thermal, and shielding impacts are no greater (and may be less) than those of the corresponding commercial SNF waste packages.

2. The most severe structural hazard to the waste package is modeled by a finite element analysis of a tipover accident. It is found that the peak stress in the waste package, resulting from such an event, will be at least $15 \%$ less than the ultimate material tensile strength of the material. This shows that the structural behavior of both the 21 PWR WP and the 12 PWR WP will be within design limits. The MOX SNF WP stress values are very similar to values calculated for commercial SNF WP's, as would be expected, since both fuel types have similar SNF assembly weights.

3. Assuming that the MOX SNF will be emplaced at least 10 years following discharge, the maximum initial heating rates for the MOX SNF were 798 watts/assembly for the 21 PWR WP and 1070 watts/assembly for the 12 PWR WP. These values are less than the 850 watts/assembly and 1500 watts/assembly used as the thermal design basis for commercial 


\section{Report on Intact \& Degraded Criticality for Selected Plutonium Waste Forms in a Geologic Repository, Volume II: Immobilized in Ceramic}

LEU PWR SNF, indicating that the MOX assemblies are well within the design envelope of the commercial SNF WP. The peak fuel temperature calculated for the 21 MOX PWR WP was approximately $336^{\circ} \mathrm{C}$, and that for the $12 \mathrm{MOX} \mathrm{PWR}$ was approximately $302^{\circ} \mathrm{C}$. These temperatures are well below the established design limit of $350^{\circ} \mathrm{C}$.

4. Dose rates from both neutron and gamma radiation were calculated for the 21 PWR WP loaded with the highest burnup MOX SNF and the shortest cooling period after reactor discharge (10 years) to serve as a worst case that would give the highest dose rates. Maximum dose values at the exterior surfaces of the waste package were less than 110 $\mathrm{rad} / \mathrm{hr}$. Maximum dose rates from the MOX SNF were much less than from commercial . LEU PWR SNF of similar burnup which were calculated to be greater than $150 \mathrm{rad} / \mathrm{hr}$. The 12 MOX PWR WP design has an equivalent amount of shielding with a smaller radiation source, which should result in smaller surface dose rates.

The design limit of $100 \mathrm{rad} / \mathrm{h}$ on the surface rate was specified so that no significant increase could occur in the corrosion rate of the waste package barrier due to any radiolytic compounds synthesized from moist air. For both waste packages, the SNF surface dose rate exceeded the design limit only during the period immediately following emplacement when humidity in the external environment is expected to be low. It is concluded, therefore, that no increase in corrosion rates from radiolysis will occur.

5. Criticality evaluations were performed for the 21 PWR MOX SNF WP and the 12 PWR MOX SNF WP for conditions ranging from intact to fully degraded fuel and basket. The peak $k_{\text {eff }}$ 's ranged from 0.55 to 0.90 where the 0.90 resulted from a worst case configuration. The following observations on the criticality potential of the PWR MOX SNF can be made:

- The 12 PWR WP has a higher $k_{\text {eff }}$ than the 21 PWR WP for the flooded conditions with intact fuel and basket because the 12 PWR WP has no neutron absorber plates.

- The 12 PWR WP has a lower $k_{\text {eff }}$ than the 21 PWR WP for the flooded conditions with intact fuel, but with degraded basket, because the iron oxide corrosion products displace moderator compensating, in part, for the absence of absorber plates.

- The worst case $\mathrm{k}_{\text {eff }}$ is below the criticality limit of 0.92 for any credible configuration and thus a criticality event internal to the waste package is virtually impossible.

\section{Ceramic (Volume II)}

For the ceramic waste form the principal criticality control measure is the incorporation of neutron absorbing material in the waste form itself. The potential for criticality is determined primarily by the amount of such neutron absorber material remaining in the waste package if, and when, the waste package is breached, and its contents are thereby exposed to aqueous corrosion. Under such conditions the waste form can be corroded; the fissile material in the waste form (either plutonium or its decay product uranium) will remain in the waste package for hundreds of thousands of years, because it is very insoluble under most water chemistry conditions. The neutron absorber hafnium is even less soluble than the fissile material so it will 


\section{Report on Intact \& Degraded Criticality for Selected Plutonium Waste Forms in a Geologic Repository, Volume II: Immobilized in Ceramic}

remain in the WP. However, the more neutronically efficient absorber, gadolinium, could become more soluble under some conditions and could eventually be flushed from the waste package.

This study is concerned with evaluating the potential for criticality of the currently defined ceramic waste form. After a few criticality calculations to demonstrate that the intact configuration is safely below the critical limit, the study is focused on identifying those degraded configurations that are most reactive (result in the highest values of the neutron multiplication factor, $\left.k_{\text {eff }}\right)$. The degraded configurations having the greatest potential for criticality are selected out of the range of configurations arising from the set of degradation scenarios analyzed.with the geochemistry code, EQ6. The degradation scenarios examined with the geochemistry code are those most likely to lead to a loss of a major fraction of the neutron absorber material, by virtue of an increase in the solubility of that material.

Shielding, thermal, and structural evaluations were not performed explicitly for immobilized Pu waste package because the comparison cases with the DWPF WP had not yet been completely evaluated. Nevertheless, conservative comparison with previous evaluations of a similar WP concept does support a finding that inclusion of the immobilized plutonium has a negligible repository impacts.

\section{Major Findings, Ceramic (Volume II)}

Based on the data presently available, and the current canister loading of the current ceramic formulation (28.7 $\mathrm{kg}$ of Pu per canister), we find the following:

1. The ceramic plutonium waste form can be emplaced in the repository at a loading of 5 plutonium containing canisters per waste package; this permits the disposal of immobilized plutonium in the same disposal container/waste package as will be used for the disposal of high level waste (HLW) glass.

- The ceramic plutonium waste package meets all regulatory requirements.

- There is no credible degradation scenario leading to criticality internal to the waste package.

- Thermal and shielding impacts are comparable to, or less than, those of the corresponding HLW waste package.

2. The completely intact configuration has virtually no potential for criticality, since the calculated $\mathrm{k}_{\text {eff }}=0.12$ for the unbreached wasted package, and $\mathrm{k}_{\text {eff }}=0.11$ when all of the void space in the waste package is filled with water.

3. The processes in the expected degradation scenarios will generally have the following sequence:

- breach of the waste package by aqueous corrosion, and wetting of all interior surfaces, 


\section{Report on Intact \& Degraded Criticality for Selected Plutonium Waste Forms in a Geologic Repository, Volume II: Immobilized in Ceramic}

- breach of the stainless steel canisters containing the HLW filler glass and the plutonium ceramic waste form,

- dissolution of the filler glass,

- breach of the inner cans that actually contain the plutonium ceramic disks,

- corrosion of the stainless steel of the canisters and cans, and

- dissolution of the ceramic waste form.

Many of these processes will overlap in time. In fact, the overlap of the last two processes (corrosion of the stainless steel and dissolution of the ceramic waste form) is what gives rise to the possibility of gadolinium removal.

4. The degraded configurations are divided into two types:

- intermediate-level degraded, in which the ceramic disks remain intact, while all the other components of the waste package have been degraded or fragmented (and the soluble degradation products are removed from the waste package), and

- fully collapsed, in which the ceramic disks are also degraded and/or fragmented and all the fragments and insoluble degradation products mixed into a homogeneous layer at the bottom of the waste package.

5. The following are the principal criticality $\left(\mathrm{k}_{\mathrm{eff}}\right)$ results for the worst cases of these two configuration types:

- For the intermediate degraded configurations there will be no significant loss of the principal neutron absorber, gadolinium, and: $\mathrm{k}_{\text {eff }}<0.38$.

- For the fully collapsed configurations there could be as much as a $13 \%$ loss of the neutron absorbing gadolinium, but the more dominating effect is the geometry being less favorable to criticality than the intermediate degraded configurations, so that $k_{\text {eff }}<0.33$, which is less than 0.38 for the intermediate degraded configurations. 


\section{Report on Intact \& Degraded Criticality for Selected Plutonium Waste Forms in a Geologic Repository, Volume II: Immobilized in Ceramic}

\section{ACRONYMS}

CDA Controlled Design Assumptions

CRWMS Civilian Radioactive Waste Management System

CSNF Commercial Spent Nuclear Fuel

DHLW Defense High Level Waste

DOE

DWPF

FY 99

Department of Energy

Defense Waste Processing Facility

HLW

Fiscal Year 1998

LEU

High Level Waste

LLNL Low Enriched Uranium (used in nuclear fuel)

MOX

Lawrence Livermore National Laboratory

MT

Mixed Oxide Fuel

SNF

Metric Ton

WF

Spent Nuclear Fuel

WP

Waste Form

Waste Package 


\section{Report on Intact \& Degraded Criticality for Selected Plutonium Waste Forms in a Geologic Repository, Volume II: Immobilized in Ceramic}

\section{Table of Contents}

Item

Page

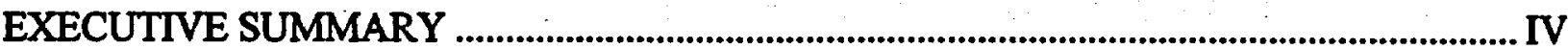

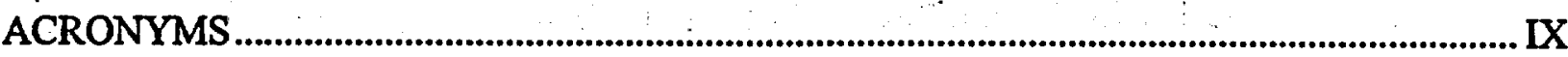

1. INTRODUCTION AND BACKGROUND

2. WASTE PACKAGE MATERIAL AND COMPONENTS: DESCRIPTIONS AND

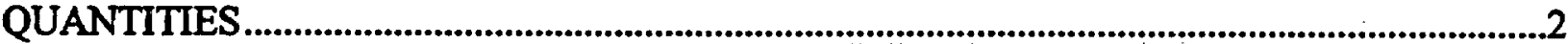

2.1 Waste Stream Quantities................................................................................................. 2

2.2 Waste Form Description ........................................................................................ 2

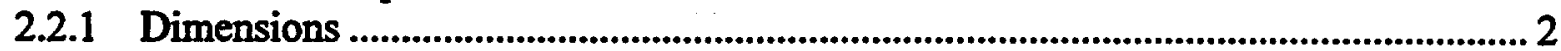

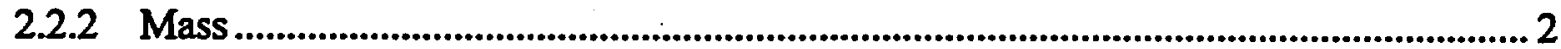

2.2.3 Chemical//sotopic Composition of the Ceramic Waste Form ...................................... 4

2.2.4 Composition of HLW Filler Glass................................................................................ 6

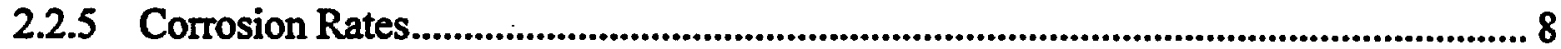

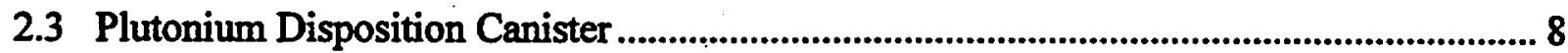

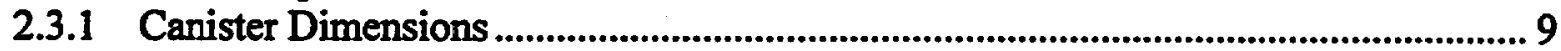

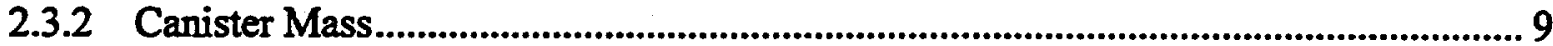

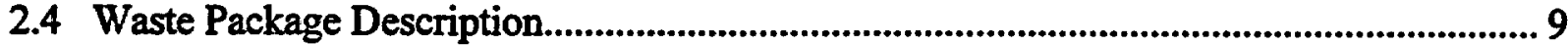

2.5 Waste Package and Canister Quantities............................................................................. 11

2.6 Properties and Behavior Not Related to Criticality ....................................................... 11

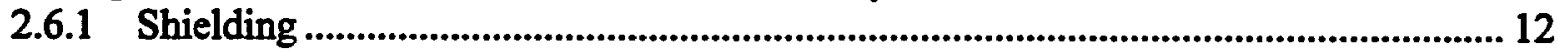

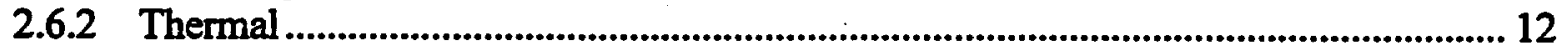

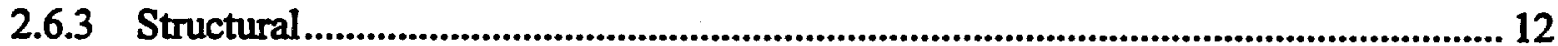

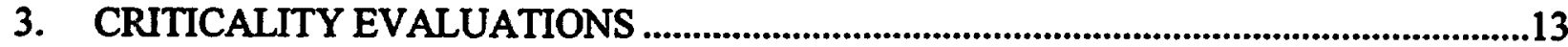

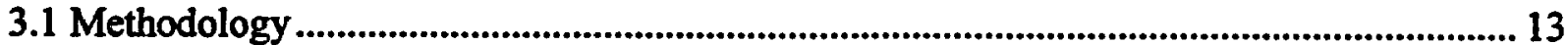

3.1.1 Methodology for Specifying Degradation Processes and Configurations .................. 13

3.1.2 Methodology for Evaluating Criticality................................................................. 14

3.2 Criticality Evaluations Relating to Intact Configurations................................................... 15

3.2.1 Description of Intact Configuration ................................................................... 15

3.2.2 Criticality Calculations for Intact Configurations...................................................... 15

3.3 Criticality Evaluations Relating to Degraded Configurations ........................................... 15

3.3.1 Degradation Processes, Scenarios, and Chemical Descriptions of Final

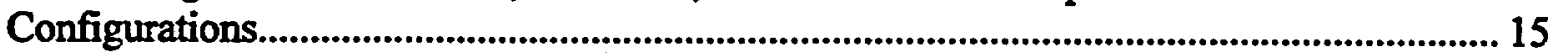

3.3.2 Physical Description of Degraded Configurations (Geometry).................................. 24

3.3.2.1 Intermediate-Level Degradation Configurations ................................................. 25

3.3.2.1.1 Square Geometry, Square Lattice Arrangement of Can Containing Tubes.. 25

3.3.2.1.2 Pseudo-Cylindrical Segment Geometry, Locally Square Lattice Arrangement of Tubes 
Report on Intact \& Degraded Criticality for Seleeted Plutonium Waste Forms in a Geologic Repository, Volume II: Immobilized in Ceramic

3.3.2.1.3 Pseudo-Cylindrical Segment Geometry, Square Lattice Arrangement of Ceramic Disks. 28

3.3.2.2 Fully Collapsed Configuration.................................................................................. 28

3.3.3 Criticality Evaluations of Degraded Configurations....................................................... 30

3.3.3.1 Criticality Evaluation Results for the Intermediate-Level Degradation Configurations................................................................................................................... 30

3.3.3.2 Criticality Evaluation Results for the Fully Degraded Configurations................. 32

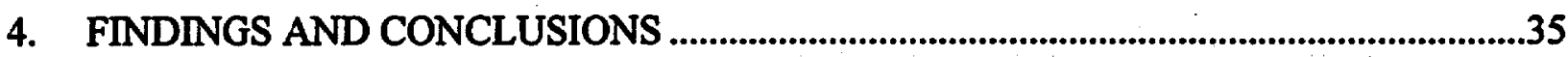

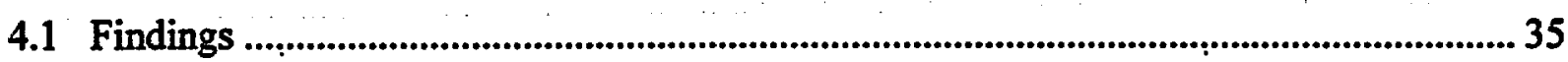

4.2 Conclusions......................................................................................................................... 36

5. REFERENCES 


\section{Report on Intact \& Degraded Criticality for Selected Plutonium Waste Forms in a}

Geologic Repository, Volume II: Immobilized in Ceramic

\section{$\underline{\text { Figures }}$}

Item

Page

Figure 2.2-1. Can-in-Canister sketch from SRS showing cross section with 4 cans in a tube and

7 tubes in a DWPF canister 3

Figure 2.4-1. Five Canister Waste Package for Plutonium Immobilized in Ceramic................... 10

Figure 3.3.1-1. Gd concentration in solution and $\mathrm{pH}$ as a Function of Time (Scenario \#6)........ 18 Figure 3.3.2.1-1. Cross-section of a Horizontally Emplaced Waste Package Showing a Square

Lattice Arrangement of Tubes in a "Square" Geometry .......................................................... 26

Figure 3.3.2.1-2. Cross-section of a Horizontally Emplaced Waste Package Showing a Stacking of 35 Tubes in a Pseudo-Cylindrical Segment Geometry .................................................... 28

Figure 3.3.2.2-1. A Cross-sectional View of a Horizontally Emplaced Waste Package for the Full Degradation Configuration 
Tables

Item

Table 2.2.3-1. Principal chemical components of the ceramic waste form .....................................4

Table 2.2.3-2. Impurities in the Pu process input stream..................................................................5 5

Table 2.2.3-3. Average wt\% isotopic composition of the Pu feed in 2010 ...................................... 6

Table 2.2.3-4. Curies per kg of total Plutonium plus Americium.....................................................6 6

Table 2.2.4-1. HLW Filler Glass Composition........................................................................................ 7

Table 2.2.5-1. Corrosion Rates Used for EQ6 Analyses ................................................................... 8

Table 2.4-1. The Physical Characteristics of the Main Components of the Five High-Level

Waste Canister Waste Package .............................................................................................. 10

Table 2.5-1. Canisters Required for Immobilized Plutonium Disposal.......................................... 11

Table 3.3.1-1. Key Parameters of Typical Degradation Scenarios................................................. 17

Table 3.3.1-2. Total WP Kilograms of the Principal Elements Remaining as Solids ${ }^{(6)}$ Scenario \#2 (From Ref. 6, Table 5.3.2-2) ..................................................................................... 22

Table 3.3.1-3. Total WP Kilograms of Principal Elements Remaining as Solids ${ }^{(7)}$, Scenario \# 6

(From Ref. 6, Table 5.3.3-2) .................................................................................................. 23

Table 3.3.2.2-1. Principal Elements or Isotopes in the Sludge Estimated by the EQ6 Code ...... 30

Table 3.3.3.1-1. $\mathrm{k}_{\text {eff }}$ Estimates for Intermediate-Level Degradation Configuration: Square Arrangement ${ }^{*}$

Table 3.3.3.1-2. $\mathrm{k}_{\mathrm{eff}}$ Estimates for Intermediate-Level Degradation Configuration: PseudoCylindrical Segment Geometry*

Table 3.3.3.2-1. $k_{\text {eff }}$ Estimates for the Full Degradation Configurations with Partial Gd Lossł. 32

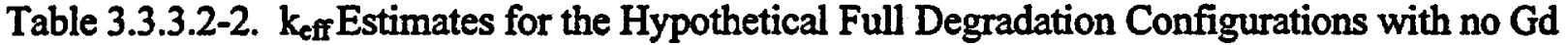
Present (for comparison purposes only, since complete removal is non-physical)* 


\section{Report on Intact \& Degraded Criticality for Selected Plutonium Waste Forms in a Geologic Repository, Volume II: Immobilized in Ceramic}

\section{INTRODUCTION AND BACKGROUND}

As part of the plutonium waste form development and down-select process, repository analyses have been conducted to evaluate the long-term performance of these waste forms for repository acceptance. This Volume assesses the intact and degraded mode criticality of the waste form containing plutonium immobilized in a ceramic matrix. Volume I presents a similar assessment for the plutonium in the form of a mixed oxide (MOX) spent fuel.

Although the ceramic immobilization development program is ongoing, and refinements are still being developed and evaluated, this analysis provides value through quick feed-back to this development process, and to the continuing analysis in support of the License Application.

In all instances the methodology and scenarios used in these analyses are compatible with those developed and used for the Commercial Spent Nuclear Fuel (CSNF) and Defense High Level Waste (DHLW), as tailored for the particular characteristics of the immobilized plutonium waste forms. This provides a common basis for comparison of the results.

This analysis utilizes dissolution, solubility, and thermodynamic data that are currently available. Long-term data are being developed and later analyses (FY 99) to support the License Application will use the very latest information that has been generated. Where applicable, ranges of values are used to bound the results.

The content of this report is organized as follows:

- Section 2 provides a brief description of the waste package and its contents, particularly the immobilized plutonium waste form. These descriptions include dimensions, masses, chemical compositions, and degradation rates. Summaries of evaluations showing negligible repository impacts for issues not related to criticality (shielding, thermal, and structural) are also given.

- Section 3 describes the analyses used to evaluate criticality. For the intact configuration, only the results of the $k_{\text {eff }}$ calculation are given. For the degraded configurations the $k_{\text {eff }}$ calculations are supported by descriptions of the degraded configurations, including the geochemistry calculations used to develop the chemical compositions of the material remaining in the waste package after degradation.

- Section 4 summarizes the major findings from this study.

The specific activities involved with the production and review of this document have been performed according to an approved Technical Document Preparation Plan (Ref. 3). 


\section{Report on Intact \& Degraded Criticality for Selected Plutonium Waste Forms in a Geologic Repository, Volume II: Immobilized in Ceramic}

\section{WASTE PACKAGE MATERIAL AND COMPONENTS: DESCRIPTIONS AND QUANTITIES}

\subsection{Waste Stream Quantities}

Of the $\mathbf{2 0 0}$ metric tons of fissile material declared surplus, about $\mathbf{5 0}$ metric tons are plutonium. Approximately 18 metric tons of this material contains impurities considered unsuitable for MOX reactor fuel and have been designated for immobilization in ceramic for disposal. In addition, the Department of Energy (DOE) has reserved the option of using the immobilization approach for disposal of all the $\mathbf{5 0}$ metric tons of surplus plutonium. The proposed immobilization and disposal methods must be analyzed to identify suitable waste package designs and to demonstrate compliance with criticality requirements.

\subsection{Waste Form Description}

The waste form for immobilized plutonium will be a ceramic containing approximately 10.5 $w t \%$ plutonium in the +4 valence state, nominally expressed as $\mathrm{PuO}_{2}$. The dominant mineral phase is a titania-based pyrochlore. The basic waste form unit will be a cold-pressed disk. This section provides the current dimensions and composition. The final values will be available as the waste form development project, presently in progress at Lawrence Livermore National Laboratory (LLNL), is completed.

The disks are stacked in cans, 20 disks per can. The stainless steel cans are stacked 4 deep in very light tubes, of a material to be specified; there will also be a mechanism to space and separate the cans within these tubes. The weight, volume, and composition of these light tubes and their supports have been neglected in this analysis.

There will be seven of these tubes fastened at the inside wall of a Defense Waste Processing Facility (DWPF) canister. While the final design has not yet been specified, a sketch of a likely arrangement is given in Figure 2.2-1. This results in a total of 28 cans, or 560 disks, per canister.

\subsubsection{Dimensions}

Ceramic Disk: 1 inch thick and 2.625 inches in diameter, yielding a volume of 5.412 cubic inches, or $88.69 \mathrm{~cm}^{3}$. The 20 disks per can will occupy a volume of 108.24 cubic inches, or $1773.7 \mathrm{~cm}^{3}$

Can: Cylindrical shell 21 inches length by 3 inches outside diameter $x 0.125$ inch thick. The can will displace a volume of 148.4 cubic inches, or $2432.5 \mathrm{~cm}^{3}$.

\subsubsection{Mass}

The WF mass is determined from the above dimensions and an approximate density of the ceramic material, $\rho=5.5 \mathrm{~g} / \mathrm{cm}^{3}$, resulting in $9.755 \mathrm{~kg}$ of ceramic per can. 


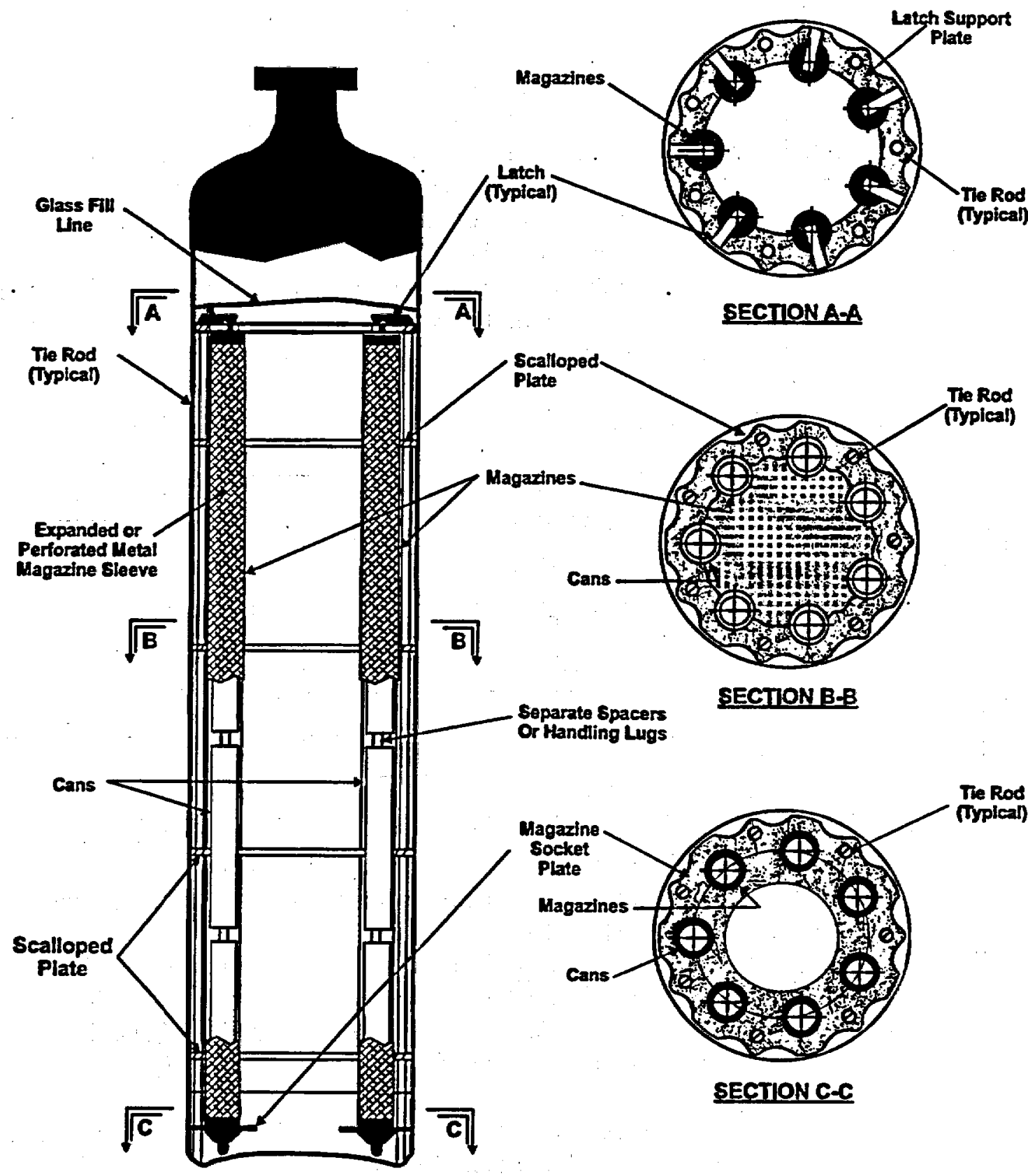

Figure 2.2-1. Can-in-Canister sketch from SRS showing cross section with 4 cans in a tube and 7 tubes in a DWPF canister 


\section{Report on Intact \& Degraded Criticality for Selected Plutonium Waste Forms in a Geologic Repository, Volume II: Immobilized in Ceramic}

\subsubsection{Chemical/sotopic Composition of the Ceramic Waste Form}

The principal chemical components of the waste form are specified in Table 2.2.3-1, below. The average concentration of impurities in the $\mathrm{Pu}$ stream that will be in the final ceramic (i.e., that survive the ceramic formation process) is specified in Table 2.2.3-2. The impurities, plus oxygen, are $27.2 \mathrm{wt} \%$ of the total Pu feed, with $72.8 \mathrm{wt} \%$ of the feed being Pu. Since the amount of feed is always adjusted so the Pu will be $10.5 \mathrm{wt} \%$ of the total ceramic, the impurities in the $\mathrm{Pu}$ feed will constitute $3.92 \mathrm{wt} \%$ of the total ceramic weight $(=27.2 \times 10.5 / 72.8)$, for the 18 metric ton (MT) case. Note that the value of the Pu wt\% (10.5) is used in this calculation, rather than the value of $\mathrm{PuO}_{2}$ wt\% (11.9) to be consistent with the oxygen of $\mathrm{PuO}_{2}$ already having been included in the non-Pu component of the feed.

Table 2.2.3-1. Principal chemical components of the ceramic waste form

\begin{tabular}{|l|l|l|l|}
\hline Component & Raw Wt \% & Wt\% adjusted(18 MT) & Wt\% adjusted(50 MT) \\
\hline $\mathrm{CaO}$ & 10.0 & 9.6 & 9.8 \\
\hline $\mathrm{HfO}_{2}$ & 10.6 & 10.1 & 10.4 \\
\hline $\mathrm{UO}_{2} \ddagger$ & 23.7 & 22.6 & 23.3 \\
\hline $\mathrm{PuO}_{2}$ & 11.9 & 11.9 & 11.9 \\
\hline $\mathrm{Gd}_{2} \mathrm{O}_{3}$ & 7.9 & 7.5 & 7.8 \\
\hline $\mathrm{TiO}_{2}$ & 35.9 & 34.3 & 35.3 \\
\hline Impurities & N/A & 3.92 & 1.43 \\
\hline
\end{tabular}

Represents total fissile oxide; enriched uranium may be substituted for plutonium, which will increase the uranium oxide percent above that given in the table.

* Nominal weight percents of the principal components without correction for the impurities in the plutonium feed (Ref. 13, p. 8).

${ }^{\dagger}$ Weights of the non-fissile components are adjusted for the impurities (including oxygen) which are $27.2 \mathrm{wt} \%$ of the Pu feed, or $3.92 \mathrm{wt} \%$ of the total ceramic. Therefore, the adjustment factor for each non-fissile component is (100-11.9-3.92)/(100-11.9). \# Consists of depleted uranium with ${ }^{235} \mathrm{U}$ enrichment of $0.2 \%$, which is included in the criticality calculation.

*** In the 50 MT immobilized case, the principal impurities will come from the 18.2 MT of the non-weapons grade $\mathrm{Pu}$, and will, therefore be diluted by the weapons grade $\mathrm{Pu}$ to $1.43 \%$ of the total ceramic $(=3.92 \times 18.2 / 50)$. [The weapons grade Pu actually has some gallium impurity not found in the non-weapons grade Pu, but the amount is uncertain, and gallium is not a neutronically significant element.] 
Report on Intact \& Degraded Criticality for Selected Plutonium Waste Forms in a Geologic Repository, Volume II: Immobilized in Ceramic

Table 2.2.3-2. Impurities in the Pu process input stream

\begin{tabular}{|c|c|c|}
\hline Element & Wt\% of Pu stream & Wt $\%$ of total ceramic \\
\hline $\mathrm{Al}$ & 1.86 & 0.268 \\
\hline$\overline{\mathrm{Am}}$ & 1.58 & 0.228 \\
\hline $\mathbf{B}$ & 0.09 & 0.013 \\
\hline$\overline{\mathbf{B a}}$ & 0.21 & 0.030 \\
\hline$\overline{\mathrm{Ce}}$ & 0.09 & 0.013 \\
\hline $\mathrm{Cr}$ & 0.14 & 0.020 \\
\hline$\overline{\mathbf{C u}}$ & 0.09 & 0.014 \\
\hline $\mathrm{Fe}$ & 0.62 & 0.090 \\
\hline $\mathrm{Ga}$ & 0.50 & 0.071 \\
\hline $\mathbf{K}$ & 0.71 & 0.103 \\
\hline La & 0.03 & 0.004 \\
\hline $\mathrm{Mg}$ & 1.14 & 0.165 \\
\hline Mo & 0.62 & 0.090 \\
\hline $\mathrm{Na}$ & 0.36 & 0.052 \\
\hline $\mathrm{Ni}$ & 0.29 & 0.042 \\
\hline$\overline{N d}$ & 0.58 & 0.084 \\
\hline $\mathrm{Np}$ & 0.05 & 0.008 \\
\hline Ot & 15.42 & 2.223 \\
\hline $\mathrm{Pb}$ & 0.01 & 0.001 \\
\hline$\overline{\mathrm{Si}}$ & 1.05 & 0.152 \\
\hline Sn & 0.00 & 0.000 \\
\hline $\mathrm{Ta}$ & 0.96 & 0.139 \\
\hline $\bar{W}$ & 0.02 & 0.003 \\
\hline $\mathrm{Zn}$ & 0.09 & 0.013 \\
\hline Unknown & 0.67 & 0.096 \\
\hline Total & 27.18 & 3.919 \\
\hline
\end{tabular}

* From Ref 13; percent of total ceramic has one more significant figure than percent of $\mathrm{Pu}$ feed because the Pu feed is approximately $10 \mathrm{wt} \%$ of the total ceramic (actually $10.5 \%$ ) so the $\mathrm{Pu}$ feed weight percents are shifted right by approximately one decimal place to make up the total ceramic weight percents. Wt\% Total Ceramic = (wt\% Pu stream) x (wt\% Pu Total Ceramic)/(wt\% Pu in feed).

+ Includes oxygen of $\mathrm{PuO}_{2}$.

The average initial Pu-related isotopic composition of the feed stream is given in Table 2.2.3-3. The data are taken from Table 4.3 of the LLNL report (Ref. 13, p. 15). It should be noted that by the time of any potential criticality, much of the ${ }^{239} \mathrm{Pu}$ will have decayed into ${ }^{235} \mathrm{U}$. A conservative estimate of this decay at the time of potential criticality is given in with the description of the configurations which are likely to have criticality potential (Section 3.3.1). 


\section{Report on Intact \& Degraded Criticality for Selected Plutonium Waste Forms in a Geologic Repository, Volume II: Immobilized in Ceramic}

Table 2.2.3-3. Average wt\% isotopic composition of the $\mathrm{Pu}$ feed in 2010

\begin{tabular}{|l|l|l|}
\hline Isotope & $18 \mathrm{MT}$ case & 50 MT case \\
\hline${ }^{258} \mathrm{Pu}$ & 0.02 & 0.01 \\
\hline${ }^{259} \mathrm{Pu}$ & 90.59 & 92.84 \\
${ }^{240} \mathrm{Pu}$ & 8.41 & 6.57 \\
\hline${ }^{241}(\mathrm{Pu}+\mathrm{Am})^{*}$ & 0.89 & 0.54 \\
\hline${ }^{242} \mathrm{Pu}$ & 0.09 & 0.04 \\
\hline
\end{tabular}

* Since ${ }^{241} \mathrm{Pu}$ has a half-life of only 14 years, all the ${ }^{241} \mathrm{Pu}$ will have decayed into ${ }^{241} \mathrm{Am}$ by the time there is any possibility of criticality (upwards of 10,000 years).

For the canister containing immobilized plutonium, the principal source of radiation during preclosure (up to 300 years) is the high level waste (HLW) glass in which the plutonium cans are embedded; there is approximately $1478 \mathrm{~kg}$ of $\mathrm{HLW}$ per canister. Any shielding requirements will, therefore, be less than, or approximately the same as, what is already required for the DWPF glass waste package (as explained further in Section 2.6.1).

The only significant radioactivity in the waste form itself derives from the Pu feed, and will have approximately the distribution indicated in Table 2.2.3-4 in the year 2010. This table lists Curies per $\mathrm{kg}$ of $(\mathrm{Pu}+\mathrm{Am})$ in the feed. This table is taken from Table 4.4 of the LLNL report (Ref. 13, p. 15)

Table 2.2.3-4. Curies per $\mathrm{kg}$ of total Plutonium plus Americium

\begin{tabular}{|l|l|l|}
\hline & \multicolumn{3}{|l|}{ Activity (Ci per kg of Pu+Am) } \\
\hline Isotope & 50 -MetricTon Case & 18 -Metric Ton Case \\
\hline${ }^{258} \mathrm{Pu}$ & 2.1 & 4.2 \\
\hline${ }^{209} \mathrm{Pu}$ & 57.7 & 56.3 \\
\hline${ }^{240} \mathrm{Pu}$ & 15.0 & 19.2 \\
\hline${ }^{241} \mathrm{Pu}$ & 99.3 & 165. \\
\hline${ }^{241} \mathrm{Am}$ & 15.1 & 25.0 \\
\hline${ }^{242} \mathrm{Pu}$ & 0.00161 & 0.0034 \\
\hline Total & 189. & 270. \\
\hline
\end{tabular}

\subsubsection{Composition of HLW Filler Glass}

The chemical composition of the HLW filler glass used for the degradation calculations is given in Table 2.2.4-1. 


\section{Report on Intact \& Degraded Criticality for Selected Plutonium Waste Forms in a Geologic Repository, Volume II: Immobilized in Ceramic}

Table 2.2.4-1. HLW Filler Glass Composition

\begin{tabular}{|c|c|}
\hline Component & Weight \% \\
\hline$\overline{\mathrm{Ag}}$ & 0.05 \\
\hline $\mathrm{Al}_{2} \mathrm{O}_{3}$ & 3.96 \\
\hline $\mathrm{B}_{2} \mathrm{O}_{3}$ & 10.28 \\
\hline $\mathrm{BaSO}_{4}$ & 0.14 \\
\hline $\mathrm{Ca}_{3}\left(\mathrm{PO}_{4}\right)_{2}$ & 0.07 \\
\hline $\mathrm{CaO}$ & 0.85 \\
\hline $\mathrm{CaSO}_{4}$ & 0.08 \\
\hline $\mathrm{C}_{2} \mathrm{O}_{3}$ & 0.12 \\
\hline $\mathrm{Cs}_{2} \mathrm{O}^{2}$ & 0.08 \\
\hline $\mathrm{CuO}$ & 0.19 \\
\hline $\mathrm{Fe}_{2} \mathrm{O}_{3}$ & 7.04 \\
\hline FeO & 3.12 \\
\hline $\mathrm{K}_{2} \mathrm{O}$ & 3.58 \\
\hline $\mathrm{Li}_{2} \mathrm{O}$ & 3.16 \\
\hline$\overline{\mathrm{MgO}}$ & 1.36 \\
\hline $\mathrm{MnO}$ & 2.00 \\
\hline $\mathrm{Na}_{2} \mathrm{O}$ & 11.00 \\
\hline $\mathrm{Na}_{2} \mathrm{SO}_{4}$ & 0.36 \\
\hline $\mathrm{NaCl}$ & 0.19 \\
\hline $\mathrm{NaF}$ & 0.07 \\
\hline$\overline{\mathrm{NiO}}$ & 0.93 \\
\hline $\mathrm{PbS}$ & 0.07 \\
\hline$\overline{\mathrm{SiO}_{2}}$ & 45.57 \\
\hline $\mathrm{ThO}_{2}{ }^{\mathrm{T}}$ & 0.21 \\
\hline $\mathrm{TiO}_{2}{ }^{2}$ & 0.99 \\
\hline $\mathrm{U}_{3} \mathrm{O}_{3}{ }^{3}$ & 2.20 \\
\hline Zeolite ${ }^{3}$ & 1.67 \\
\hline $\mathrm{ZnO}^{2}$ & 0.08 \\
\hline${ }^{W} \mathrm{~Np}{ }^{4}$ & 0.000751 \\
\hline${ }^{20} \mathrm{Pu}^{4}$ & 0.012342 \\
\hline $\mathrm{TC}^{4}$ & 0.010797 \\
\hline & 0.026415 \\
\hline
\end{tabular}

1. Ref. 14 (Attachment I, Table 3.3.8, except as explained in note 4 below).

2. Not carried through EQ6 calculation, due to small amount relative to other WP components, or judgement of little significance.

3. Assumed to be analcime, due to high pour temperature of glass and high Na content.

4. Obtained by taking the "Grams/canister" entry of Ref. 14 (Attachment I, Table 3.3.3), multiplying by $100 \%$ and dividing by the presumed mass/canister of $1682 \mathrm{~kg}$ (Ref. 14, Attachment I, footnote to Table 3.3.3). All Tc presumed to be ${ }^{99} \mathrm{Tc}$; all $\mathrm{Zr}$ presumed to be ${ }^{93} \mathrm{Zr}$.

5. Contains approximately $0.5 \%{ }^{235} \mathrm{U}$ 


\section{Report on Intact \& Degraded Criticality for Selected Plutonium Waste Forms in a Geologic Repository, Volume II: Immobilized in Ceramic}

\subsubsection{Corrosion Rates}

The range of corrosion rates for the waste package solid components used in the EQ6 runs are summarized in Table 2.2.5-1; these rates were taken from Table 5.1.1.6-1 of Ref. 6. The values actually used in the geochemistry calculations are identified, and justified, in Section 3.3.1.

Table 2.2.5-1. Corrosion Rates Used for EQ6 Analyses

\begin{tabular}{|c|c|}
\hline Material & Rate \\
\hline \multicolumn{2}{|l|}{ Pu-ceramic:* } \\
\hline Very high $\left(\mathrm{pH} 4,50^{\circ} \mathrm{C}\right)$ & $0.4 \mathrm{~g} / \mathrm{m}^{2} /$ day \\
\hline High $\left(\mathrm{pH} 6,50^{\circ} \mathrm{C}\right)$ & $4 \times 10^{-2} \mathrm{~g} / \mathrm{m}^{2} /$ day \\
\hline Average $\left(\mathrm{pH} \geq 7,25^{\circ} \mathrm{C}\right)$ & $2 \times 10^{-3} \mathrm{~g} / \mathrm{m}^{2} /$ day \\
\hline \multicolumn{2}{|l|}{ Stainless Steel (316L, 304L):† } \\
\hline High & $1 \mu \mathrm{m} / \mathrm{yr} \ddagger$ \\
\hline Average & $0.1 \mu \mathrm{m} / \mathrm{yr} \ddagger$ \\
\hline HLW Glass: † & 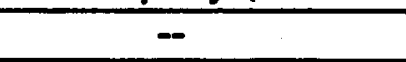 \\
\hline High & $2.8 \times 10^{-2} \mathrm{~g} / \mathrm{m}^{2} /$ day \\
\hline Average & $2 \times 10^{-4} \mathrm{~g} / \mathrm{m}^{2} /$ day \\
\hline \multicolumn{2}{|c|}{$\begin{array}{l}\text { Originally from Ref. } 13 \text {, under the metamict assumption } \\
\text { O Originally from Ref. } 16 \text {; in the actual analysis this value is multiplied by a } \\
\text { factor somewhat greater than } 30 \text { to reflect intermal fracturing. } \\
\text { ₹ This is the standard unit for corrosion of steel, assuming a flat plate } \\
\text { geometry; to convert to } \mathrm{g} / \mathrm{m}^{2} / \mathrm{day} \text {, multiply by the density of steel (in } \mathrm{kg} / \mathrm{m}^{3} \text { ), } \\
\text { by } 1000 \text { (to convert } \mathrm{kg} \text { to } \mathrm{g} \text { ), by } 10^{-6} \text { (to convert microns to meters), and } \\
\text { divide by } 365 \text { (to convert years to days). }\end{array}$} \\
\hline
\end{tabular}

It should be noted that the aqueous corrosion (or degradation) of individual solid waste package components does not necessarily lead directly to removal from the waste package of elements or ions from those corroded components. Individual elements may remain in a solid altered state, or precipitate in some insoluble mineral. In particular, the evidence to be discussed in the following sections shows that the primary neutron absorber, gadolinium, is nearly insoluble over most of the time period and water chemistry of interest, while the secondary neutron absorber, hafnium, is completely insoluble over the same parameter range.

\subsection{Plutonium Disposition Canister}

The waste forms are contained within the waste packages in stainless steel canisters approximately 3 meters overall length, $61 \mathrm{~cm}$ outer diameter and $1 \mathrm{~cm}$ thick. 


\section{Report on Intact \& Degraded Criticality for Selected Plutonium Waste Forms in a Geologic Repository, Volume II: Immobilized in Ceramic}

\subsubsection{Canister Dimensions}

HLW glass mass (baseline formulation) per DWPF canister: $1680 \mathrm{~kg}$.

$\% \mathrm{HLW}$ glass displaced by Pu waste form cans: $11 \%$

$\%$ HLW glass displaced by rack for cans: $1 \%$

Mass of DWPF canister (empty): $\quad 499 \mathrm{~kg}$

With the density of 316 stainless steel $=7.95 \mathrm{~g} / \mathrm{cm}^{3}$, the following are calculated:

Ceramic mass per canister: $273.15 \mathrm{~kg}$

Mass of rack:

$58.5 \mathrm{~kg}$

Steel can mass per canister: $96.7 \mathrm{~kg}$

HLW glass per canister: $\quad 1478.4 \mathrm{~kg}$

\subsubsection{Canister Mass}

With these parameters the total loaded canister masses are:

Ceramic canister: $2405 \mathrm{~kg}$

DWPF canister: $2179 \mathrm{~kg}$

\subsection{Waste Package Description}

The disposal container will be the same 5 canister design as is planned for the ordinary DWPF HLW canisters. An isometric view of the 5 canister package is given in Figure 2.4-1, with the lids removed, and showing the inner and outer barriers. The nominal Pu loading per waste package is $5 \mathrm{Pu}$ loaded canisters per waste package. Previous analyses of ceramic formulations (Ref. 4) have suggested that criticality prevention would be enhanced by limiting the number of Pu loaded canisters to 1 or 2 per package. However, the results of this study will show that the performance of the current formulation will prevent criticality, even if all 5 canisters are loaded with plutonium ceramic.

The disposal container consists primarily of a corrosion allowance outer barrier and a corrosionresistant inner barrier. The corrosion-allowance outer barrier will likely be carbon steel $10 \mathrm{~cm}$ thick as is used in the Civilian Radioactive Waste Management System (CRWMS) current design for the commercial spent nuclear fuel waste package. The inner barrier will be corrosion resistant, high nickel, Alloy-22, $2 \mathrm{~cm}$ thick, also corresponding to that planned for the commercial SNF WP. The dimensions and compositions of the intact WP components are provided in Table 2.4-1 (Ref. 12, p. 10). 
Report on Intact \& Degraded Criticality for Selected Plutonium Waste Forms in a Geologic Repository, Volume II: Immobilized in Ceramic

Table 2.4-1. The Physical Characteristics of the Main Components of the Five High-Level Waste Canister Waste Package

\begin{tabular}{|c|c|c|c|c|c|c|c|}
\hline Component & Number & Material & $\begin{array}{c}\text { Inner } \\
\text { Diameter } \\
(\mathrm{cm})\end{array}$ & $\begin{array}{l}\text { Outer } \\
\text { Diameter } \\
\text { (cm) }\end{array}$ & $\begin{array}{l}\text { Thickness } \\
\text { (cm) }\end{array}$ & $\begin{array}{c}\text { Inner } \\
\text { Height } \\
\text { (cm) } \\
\end{array}$ & $\begin{array}{l}\text { Outer Height } \\
\text { (cm) }\end{array}$ \\
\hline $\begin{array}{l}\text { Outer } \\
\text { Barrier }\end{array}$ & 1 & $\begin{array}{l}\text { ASTM A } 516 \\
\text { Carbon Steel }\end{array}$ & 177 & 197 & 10.0 & $-\infty$ & 331 \\
\hline $\begin{array}{l}\text { Outer } \\
\text { Barrier Lid }\end{array}$ & $\begin{array}{l}2 \text { (top and } \\
\text { bottom) }\end{array}$ & $\begin{array}{l}\text { ASTM A 516 } \\
\text { Carbon Steel }\end{array}$ & - & 197 & 11.0 & - & - \\
\hline $\begin{array}{l}\text { Inner } \\
\text { Barrier }\end{array}$ & 1 & $\begin{array}{l}\text { ASTM B 575 } \\
\text { N06022 } \\
\text { (Alloy 22) }\end{array}$ & 173 & 177 & 2.0 & $304^{(x)}$ & $\cdots$ \\
\hline $\begin{array}{l}\text { Inner } \\
\text { Barrier Lid }\end{array}$ & $\begin{array}{l}2 \text { (top and } \\
\text { bottom) }\end{array}$ & $\begin{array}{l}\text { ASTM B 575 } \\
\text { N06022 } \\
\text { (Alloy 22) }\end{array}$ & $\infty$ & 177 & 2.5 & $\longrightarrow$ & $=$ \\
\hline Canister & 5 & $\begin{array}{l}\text { ASTM A312 } \\
\text { Type 304L } \\
\text { Stainless Steel }\end{array}$ & 59.055 & 60.96 & 0.9525 & $=$ & 299.72 \\
\hline
\end{tabular}

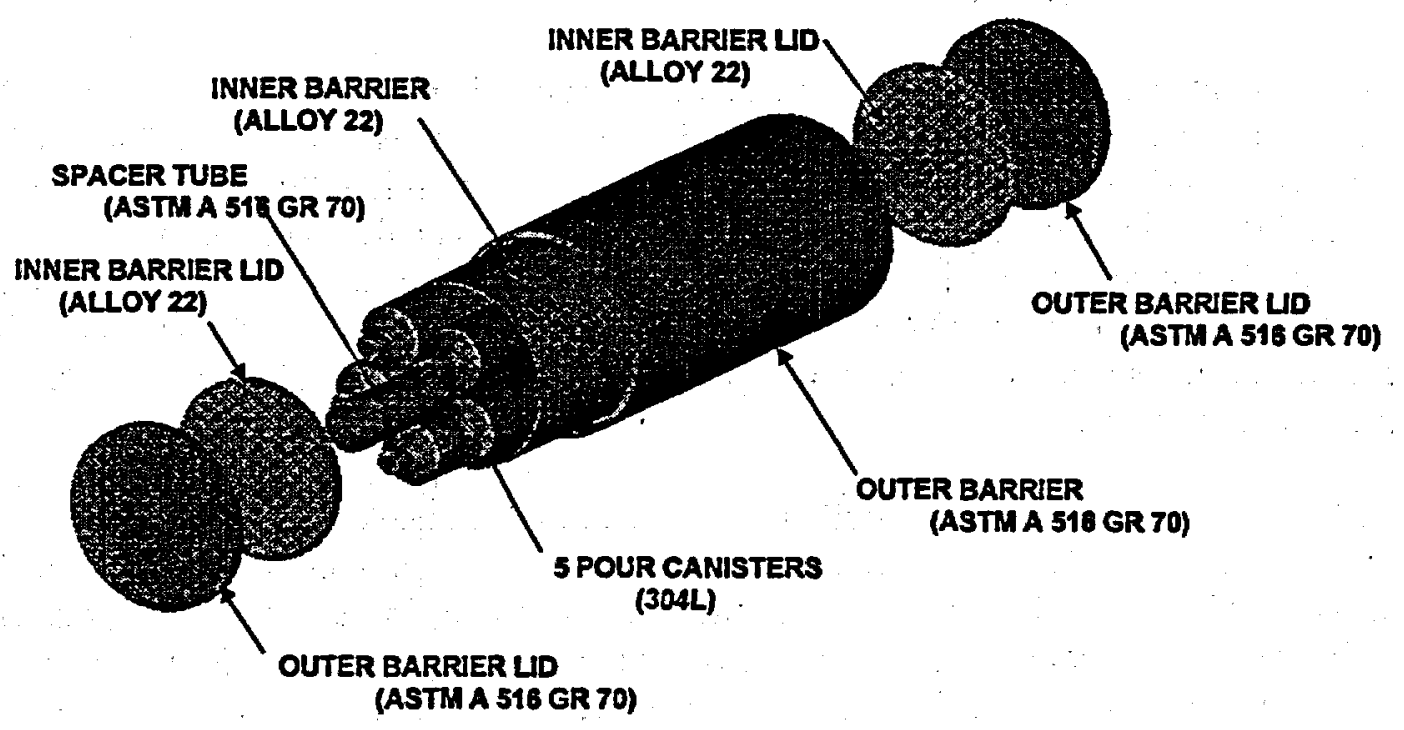

Figure 2.4-1. Five Canister Waste Package for Plutonium Immobilized in Ceramic 


\section{Report on Intact \& Degraded Criticality for Selected Plutonium Waste Forms in a Geologic Repository, Volume II: Immobilized in Ceramic}

\subsection{Waste Package and Canister Quantities}

For the waste form composition given in Table 2.2.3-1, and the loading of 20 disks per can and 28 cans per canister, the total mass of Pu per canister will be $28.68 \mathrm{~kg}$. The total number of canisters required for disposal is summarized in Table 2.5-1. Also given in the table is the number of waste packages required at 5 canisters per waste package.

Table 2.5-1. Canisters Required for Immobilized Plutonium Disposal

\begin{tabular}{|l|l|l|}
\hline & 18 M Ton case & 50 M Ton case \\
\hline Number of Pu containing canisters & 635 & 1744 \\
\hline $\begin{array}{l}\text { Net additional canisters to accommodate DHLW } \\
\text { filler displaced by the Pu ceramic }\end{array}$ & 77 & 210 \\
\hline $\begin{array}{l}\text { Net additional as a \% of total DWPF canisters } \\
(\sim 12000)\end{array}$ & $0.64 \%$ & $1.75 \%$ \\
\hline Number of waste packages containing Pu & 128 & 348 \\
\hline Net additional waste packages & 16 & 42 \\
\hline
\end{tabular}

It should be noted that since the plutonium bearing canisters contain $88 \%$ of their maximum capacity for HLW glass, the impact of immobilized Pu disposal on the number of waste packages is only the net additional canisters required to make up for the $12 \%$ of the HLW displaced by the plutonium bearing cans and their accompanying structure. This net increment is shown for canisters by the second line of Table 2.5-1, and for waste packages by the fifth line.

\subsection{Properties and Behavior Not Related to Criticality}

A previous study (Ref 17, Section 8) provided preliminary evaluations of the shielding, thermal, and structural impacts of an immobilized plutonium waste form using the can-in-canister concept. In that study the waste form matrix carrying the plutonium was glass, instead of the current ceramic; other significant differences were:

- Higher Pu loading per canister in the previous study (approximately $51 \mathrm{~kg}$ versus approximately $29 \mathrm{~kg}$ in the present study)

- $4 \mathrm{Pu}$ bearing canisters per WP compared with the present baseline of 5 .

- $1330 \mathrm{~kg}$ of DWPF filler glass per Pu bearing canister compared with the present $1478 \mathrm{~kg}$.

These differences permit a conservative estimate of the upper bound of the non-criticality impacts of the present immobilized Pu waste, by comparison with the previous study. The specific justifications are given in the following sub-sections. 


\section{Report on Intact \& Degraded Criticality for Selected Plutonium Waste Forms in a Geologic Repository, Volume II: Immobilized in Ceramic}

\subsubsection{Shielding}

The comparison of the dose rates from the immobilized Pu WP with those for the DWPF glass WP given in Ref 17, Table 8-5 showed the former to have less half the dose rate of the latter. This ratio between immobilized Pu and DWPF glass waste package dose rate (less than 0.5 ) should remain approximately the same for the present case in which the number of canisters is increased from 4 to 5 per waste package. The fact that the current Pu disposal canister has approximately $10 \%$ more filler glass would tend to increase the ratio, since the dominant radiation source at emplacement is the filler glass. However, the magnitude of the increase in the 0.5 dose ratio will be less than this $10 \%$ because of the smaller Pu loading per canister in the present case (143 kg Pu compared with $204 \mathrm{~kg}$ Pu in the previous study). In any event, the shielding required for immobilized $\mathrm{Pu}$ WP will still be less than that required for the DWPF waste package.

\subsubsection{Thermal}

The comparison of the peak waste form temperatures and the peak surface temperatures from the immobilized Pu WP with those for the DWPF glass WP were given in Ref 17, Tables 8-7 and 88 , respectively, for the previous immobilized Pu waste form. This data showed the immobilized $\mathrm{Pu}$ WP to have approximately the same, or slightly larger, temperatures as the DWPF WP (with the maximum excess temperature for the immobilized Pu WP being less than $5^{\circ} \mathrm{C}$ ). By the time the peak temperatures occur (approximately 30 years after emplacement for the peak fuel temperature and approximately 60 years after emplacement for the peak WP surface temperature) much of the radioactivity in the HLW has decayed so the principal remaining heat source in the WP is Pu (as is explained in Ref 17, Section 8.3.3.3). Therefore, the temperature comparison between the immobilized Pu WP and DWPF WP should be more favorable to the former in the present case than it was in the previous study, because the present case has a much smaller Pu loading per canister and per WP.

\subsubsection{Structural}

As explained in Ref 17, Section 8.3.3.4, the design basis structural hazard for this type of WP is a rockfall; this event has the same impact for both the immobilized Pu WP and the DWPF WP. The present waste package design for HLW show satisfactory performance for both cases. 


\section{Report on Intact \& Degraded Criticality for Selected Plutonium Waste Forms in a Geologic Repository, Volume II: Immobilized in Ceramic}

\section{CRITICALITY EVALUATIONS}

\subsection{Methodology}

\subsubsection{Methodology for Specifying Degradation Processes and Configurations}

The methodology that was used for the analysis of the degradation processes was an extension of the methodology used in the previous study of the potential for criticality of the immobilized plutonium waste forms, Ref. 4 . That methodology was also used in the most recent evaluation of degraded mode criticality in waste forms having highly enriched uranium, Ref. 5 . The methodology is described in further detail in Ref. 6, and involves the following steps:

- Evaluation of available data on the range of dissolution rates for the materials involved, to be used as material/species input for each time step.

- Determination of the sequence of the expected degradation processes, for those waste packages that are dripped on sufficiently to experience barrier breach and degradation of contents. Such sequences will generally be some variant of the following:

- breach of the waste package due to aqueous corrosion, permitting wetting of all interior surfaces,

- breach of the stainless steel canisters containing the HLW filler glass and the Pu ceramic waste form,

- dissolution of the HLW filler glass,

- breach of the inner cans that actually contain the plutonium ceramic disks,

- corrosion of the stainless steel of the canisters and cans, and

- dissolution of the ceramic waste form.

The configurations used for criticality evaluations, which typify these processes, are described in Section 3.3.2.

- Tracing the progress of reactions using the geochemistry code EQ6 (Ref. 6) in order to estimate the concentrations remaining in solution and the composition of the precipitated solids. For this purpose, water is added continuously to the waste package and builds up in the waste package over a sequence of time steps. The duration of a time step modeled for the individual EQ6 time steps range from 0.01 seconds to 1000 days as determined automatically by the program. The modeled duration of a sequence, including the initial sequence, stays constant within the limits imposed internally by the program. The rate of water buildup during each time step is determined by the drip rate of water entering the waste package, which varies over a range with the maximum, $0.5 \mathrm{~m}^{3} / \mathrm{yr}$, as specified in the Controlled Design Assumptions (CDA) (Ref. 7, p. 10-19), and minimum of $0.0015 \mathrm{~m}^{3} / \mathrm{yr}$. This latter value is equivalent to an infiltration rate of $0.2 \mathrm{~mm} / \mathrm{yr}$ over the waste package horizontal cross section area and is in the range of the lowest infiltration rate used in recent hydrologic models, 0.05 to $.3 \mathrm{~mm} / \mathrm{yr}$ (Ref 15, Section 4.2 ). The reaction progress is also controlled by the flushing action (removal of water added during one EQ6 sequence), which is simulated by specifying smaller amounts of water and solutes for input to the next EQ6 sequence than 


\section{Report on Intact \& Degraded Criticality for Selected Plutonium Waste Forms in a Geologic Repository, Volume II: Immobilized in Ceramic}

were present at the end of the preceding sequence. The mass of water simulated as removed equals the mass of water added, adjusted for water identified by EQ6 calculations as entering, or being released from, solids (including mineral precipitates). Solutes are removed from the WP in proportion to their concentrations in that mass of water simulated as removed.

The results of this analysis are used to define the configurations that are evaluated for criticality, particularly the following determinations:

- Concentrations of neutronically significant elements in solution, as a function of time (from the output of EQ6 sequences over times up to or greater than 100,000 years).

- The amount of fissile material released from the waste package as a function of time (which thereby reduces the chance of criticality within the waste package).

- Composition and amounts of solids (precipitated minerals or corrosion products, and unreacted fragments of waste package components).

- The amounts of fissile elements and neutron absorbers retained within the waste package as a function of time.

\subsubsection{Methodology for Evaluating Criticality}

The methodology for evaluating criticality follows that established in the previous study of immobilized plutonium degraded mode criticality (Ref. 4). The present application of the methodology is further described in the detailed criticality calculation document for this study (Ref. 11). The methodology for estimating the effective neutron multiplication factor, $\mathrm{k}_{\text {eff, }}$ for different degraded internal configurations of the waste package is described by the following steps:

- criticality geometry models, representing different degraded internal configurations of the waste package, are developed for the MCNP4B2 computer code (Ref. 9);

- spreadsheet calculations are used to transform the output of the EQ6 geochemistry computer code (Ref. 8) to the input for MCNP4B, which consists of the amount of chemical elements or isotopes, their total mass, their total volume, and density; and

- the MCNP4B2 computer code, appropriate for performing nuclear criticality analysis, is run, for the computational models developed above, to estimate the $\mathrm{k}_{\text {eff. }}$. It should be noted that this code has not been well validated for values of $k_{\text {eff }}<0.5$ (which is the range of most of the results of this study). While the specific values may be in question, the fact that they are far from one is indisputable.

The analysis described in the above steps is iterated for a range of parameters representing all credible configurations (determined by the geochemistry analysis described in Section 3.1.1, 


\section{Report on Intact \& Degraded Criticality for Selected Plutonium Waste Forms in a Geologic Repository, Volume II: Immobilized in Ceramic}

above) to identify the worst cases.

\subsection{Criticality Evaluations Relating to Intact Configurations}

\subsubsection{Description of Intact Configuration}

The intact configuration is described in Sections 2.2, 2.3, and 2.4 above, for the ceramic disk, canister containing 28 cans of 20 disks each, and the waste package containing 5 canisters.

\subsubsection{Criticality Calculations for Intact Configurations}

The $k_{\text {eff }}$ of the intact configuration has been estimated under two conditions: (1) no water in the waste package, and (2) water in the void spaces within the canister and waste package. The values are $k_{\text {eff }}=0.12$, and 0.11 , respectively (Ref 11 , Table 6-5). The reason for such low values is the relatively large loading of the waste form with the neutron absorber materials, specifically gadolinium and hafnium; the former being particularly effective in the thermal region of the neutron spectrum.

\subsection{Criticality Evaluations Relating to Degraded Configurations}

\subsubsection{Degradation Processes, Scenarios, and Chemical Descriptions of Final Configurations}

This section provides a summary of the degradation analysis given in Ref. 6, Section 2. An internal criticality could be possible if the fissile material remained behind in the waste package, and the $\mathrm{Gd}$ and $\mathrm{Hf}$ neutron absorbers are flushed from the system. Uranium and plutonium are quite soluble in the alkaline, $\mathrm{CO}_{2}$-rich solutions produced when the $\mathrm{HLW}$ glass degrades; on the other hand, the gadolinium mineral $\mathrm{GdOHCO}_{3}$ is soluble in the acid solution that may be produced when stainless steel degrades after the strongly alkaline period of HLW glass degradation. One general scenario that maximizes the amount of gadolinium release from the waste package involves early breach of the 304 stainless steel canisters containing the HLW, followed by fast degradation of the HLW glass and removal of the alkaline components during a period of relatively high drip rate. This scenario continues with breach of the 316 stainless steel, exposing the Pu-bearing ceramic disks; in this second stage, the $\mathrm{pH}$ of the ambient solutions is controlled to low values ( 5.25 to 6.0 ), in part by the degradation of the stainless steel. The duration of this period is prolonged, and the depth of the $\mathrm{pH}$ lowering is increased, by the conservative assumption of a low drip rate during this second stage.

The scenarios chosen for this study build upon two previous analyses of $\mathrm{U}, \mathrm{Pu}, \mathrm{Gd}$ and $\mathrm{B}$ loss from waste packages containing fissile waste forms co-disposed with HLW glass (Refs 4 and 5). These prior studies suggested that the greatest removal of $\mathrm{Gd}$ would occur at low drip rates which would produce lower $\mathrm{pH}$ values caused by more strongly concentrating chromic acid (produced by corroding stainless steel) and by prolonging the period during which the chromic acid remains in the waste package. There were no sets of cases aimed at testing sensitivity to Hf 


\section{Report on Intact \& Degraded Criticality for Selected Plutonium Waste Forms in a Geologic Repository, Volume II: Immobilized in Ceramic}

loss, because the geochemistry analysis had indicated that $\mathrm{Hf}$ was virtually insoluble and would not be flushed from the waste package, as is explained in the discussion following Tables 3.3.1-2 and 3.3.1-3.

Two basic types of scenarios were modeled. In the first type, all package materials degrade simultaneously, albeit at different rates, and the drip rate of J-13 water into the package is kept constant throughout the run. Only one EQ6 case of the first type is reported, and that for reference purposes only. This limitation is because the first type of scenario maintains a moderate to high $\mathrm{pH}$ (minimum value 6.33, and that for only a few thousand years), so that there is little opportunity for loss of gadolinium.

In the second type of scenario, the sequence of EQ6 runs is divided into two stages with different drip rates. The first stage models the early degradation process in which all of the glass degrades, much of the stainless steel package materials degrade, but little, or none, of the ceramic degrades. This is consistent with the fact that the glass has the highest degradation rate, followed by the stainless steel, while the ceramic has a very low degradation rate, and is also somewhat protected from the water by the glass and steel. During this stage the drip rate is assumed to be the high nominal value $\left(0.5 \mathrm{~m}^{3} / \mathrm{yr}\right.$, Ref. 7, p. 10-19). The first stage lasts as long as the degrading glass or period of high $\mathrm{pH}$; the stage is terminated when the $\mathrm{pH}$ reaches a plateau minimum of $\sim 6$, at $\sim 3.8 \times 10^{3}$ years. During this period of high $\mathrm{pH}$ and high drip rate, nearly all the uranium from the HLW filler glass is dissolved and flushed from the waste package. At a lower drip rate the first stage would last somewhat longer because some of the glass degradation products would maintain an elevated $\mathrm{pH}$ until a major fraction of the silica could be flushed from the waste package by the dripping water.

The second stage chemistry is dominated by the degradation products of the ceramic waste form and possibly the corroding stainless steel (via the formation of chromic acid). The worst case, with respect to gadolinium solubility, is expected to be the low drip rate; however, this inverse relationship between gadolinium loss and drip rate is weakened by the fact that reducing drip rate also reduces the rate at which dissolved gadolinium can be flushed from the waste package. Accordingly, most of the cases used second stage drip rates of 0.015 or $0.0015 \mathrm{~m}^{3} / \mathrm{yr}$, the former value corresponds to the present low estimate of this parameter (Ref. 10), and the later corresponds to the lowest estimate of recent hydrologic models (Ref 15), as was mentioned in Section 3.1.1. The ceramic is assumed to be in contact with the degradation products of the steel and glass, particularly with all the components in solution. During this phase the $\mathrm{pH}$ may then drop to $\sim 5.25$, as the stainless steel continues to corrode, and the rate of influx of J-13 (which is mildly alkaline) water is reduced. There follows a period of relatively low $\mathrm{pH}$, which may persist for thousands to tens of thousands of years; in this period of low $\mathrm{pH}$, the solubility of $\mathrm{GdOHCO}_{3}$ is at its highest, and dissolved Gd concentrations can reach $10^{-3}$ to $10^{-2}$ molal. The $\mathrm{pH}$ gradually rises, due to several factors: the inherent alkalinity of the J-13 water; the alkalinity built into the ceramic waste form; and the buffering capacity of the clays that were formed in the system. Seven simulations of this second type were run; only four (scenarios 4, 5,6, and 7 ) produced a significant loss of $\mathrm{Gd}(\sim 10$ to $15 \%)$ from the system. 


\section{Report on Intact \& Degraded Criticality for Selected Plutonium Waste Forms in a}

Geologic Repository, Volume II: Immobilized in Ceramic

Table 3.3.1-1 summarizes the conditions used and total Gd loss for 8 scenarios that span the range of possible environmental parameters; also shown are the minimum $\mathrm{pH}$ values achieved in the scenarios, the peak Gd concentration in solution, and the width of the peak (time between the half-maximum points). A typical time history of $\mathrm{pH}$ and $\mathrm{Gd}$ concentration in solution is shown in Figure 3.3.1-1, corresponding to Scenario \#6 in Table 3.3.1-1, and covering the time period of greatest potential Gd loss. It should be noted that the width of the Gd peak given in Table 3.3.11 can be verified from Figure 3.3.1-1, as being from the rising half peak point at approximately 5000 years to the declining half-peak point at approximately 9000 years.

Table 3.3.1-1. Key Parameters of Typical Degradation Scenarios (from Ref. 6, Table 5.3-1)

\begin{tabular}{|c|c|c|c|c|c|c|c|c|}
\hline \# & $\begin{array}{c}\text { Number } \\
\text { of } \\
\text { Stages }\end{array}$ & $\begin{array}{l}\text { Corrosion } \\
\text { Rates }^{1}\end{array}$ & $\begin{array}{c}\text { J-13 Drip } \\
\text { Rates } \\
\left(\mathrm{m}^{3} / \mathrm{yr}\right)\end{array}$ & $\begin{array}{c}\text { Modeled } \\
\text { Time } \\
\text { (yr) }\end{array}$ & $\begin{array}{l}\text { Min } \\
\mathrm{pH}\end{array}$ & $\begin{array}{l}\text { Peak Gd } \\
\text { conc. } \\
\left(\mathrm{kg} / \mathrm{m}^{3}\right)\end{array}$ & $\begin{array}{l}\text { Width of } \\
\text { Gd peak } \\
\text { (yr) }\end{array}$ & $\begin{array}{l}\% \mathrm{Gd} \\
\text { Loss }^{2}\end{array}$ \\
\hline 1 & 1 & $\begin{array}{l}\text { HLW: avg } \\
\text { SS: avg } \\
\text { Cer: avg }\end{array}$ & 0.0015 & $1.07 \times 10^{6}$ & 6.33 & N/A & N/A & $\begin{array}{c}0.043 \\
2\end{array}$ \\
\hline 2 & 2 & $\begin{array}{l}\text { HLW: high } \\
\text { SS: high } \\
\text { Cer: avg }\end{array}$ & $\begin{array}{c}0.5 \\
\& \\
0.0015\end{array}$ & $\begin{array}{c}3.77 \times 10^{3} \\
\& \\
6.49 \times 10^{5}\end{array}$ & 5.25 & 0.18 & 3640 & 1.86 \\
\hline 3 & 2 & $\begin{array}{l}\text { HLW: high } \\
\text { SS: high } \\
\text { Cer: avg }\end{array}$ & $\begin{array}{c}0.5 \\
\& \\
0.015\end{array}$ & $\begin{array}{c}3.77 \times 10^{3} \\
\& \\
1.12 \times 10^{5}\end{array}$ & 5.49 & 0.019 & 2481 & 1.24 \\
\hline 4 & $\overline{2}$ & $\begin{array}{l}\text { HLW: high } \\
\text { SS: avg } \\
\text { Cer: avg }\end{array}$ & $\begin{array}{c}0.5 \\
\& \\
0.0015\end{array}$ & $\begin{array}{c}3.78 \times 10^{3} \\
\& \\
1.46 \times 10^{6}\end{array}$ & 5.47 & 0.19 & 30000 & 14.8 \\
\hline $5^{*}$ & 2 & $\begin{array}{l}\text { HLW: high } \\
\text { SS: high } \\
\text { Cer: high }\end{array}$ & $\begin{array}{c}0.5 \\
\& \\
0.0015\end{array}$ & $\begin{array}{c}3.77 \times 10^{3} \\
\& \\
6.52 \times 10^{5}\end{array}$ & 5.32 & 2.50 & 2965 & 9.58 \\
\hline $6^{*}$ & 2 & $\begin{array}{l}\text { HLW: high } \\
\text { SS: high } \\
\text { Cer: high }\end{array}$ & $\begin{array}{c}0.5 \\
\& \\
0.0015\end{array}$ & $\begin{array}{c}.77 \times 10^{3} \\
\& \\
6.50 \times 10^{5}\end{array}$ & 5.32 & 2.83 & 3285 & 13.2 \\
\hline 7 & 2 & $\begin{array}{l}\text { HLW: high } \\
\text { SS: avg } \\
\text { Cer: high }\end{array}$ & $\begin{array}{c}0.5 \\
\& \\
0.015\end{array}$ & $\begin{array}{c}3.78 \times 10^{3} \\
\& \\
1.33 \times 10^{5}\end{array}$ & 5.87 & 0.036 & 25680 & 12.2 \\
\hline 8 & 2 & $\begin{array}{c}\text { HLW: high } \\
\text { SS: high } \\
\text { Cer: very } \\
\text { high }\end{array}$ & $\begin{array}{c}0.5 \\
\& \\
0.0015\end{array}$ & $\begin{array}{c}3.77 \times 10^{3} \\
\& \\
1.09 \times 10^{6}\end{array}$ & 6.13 & N/A & N/A & $\begin{array}{c}0.036 \\
9\end{array}$ \\
\hline
\end{tabular}

Scenarios 5 and 6 are identical, except that 6 has a carbon dioxide partial pressure that is an order of magnitude smaller. This near duplication was intended to test the sensitivity to carbon dioxide partial pressure, which turned out to be small. 


\section{Report on Intact \& Degraded Criticality for Selected Plutonium Waste Forms in a Geologic Repository, Volume II: Immobilized in Ceramic}

It should be noted that the values for the three designations for ceramic corrosion rate: average, high, and very high are given in Table 2.2.5-1, which is a copy of Table 5.1.1.6-1 of Ref. 6. The values in that reference were taken from Ref. 13, Table 6.2, and correspond to the metamict condition (most conservative, or highest, corrosion rate) under the range of environmental parameters. It can be seen from Table 3.3.1-1 that the percent gadolinium loss turns out to have very little dependence on ceramic corrosion rate for the scenarios represented in Table 3.3.1-1, since they all have the moderately high, metamict, corrosion rate. If the corrosion rate were much slower than the stainless steel corrosion rate, the majority of the Gd release from corroding ceramic could occur later than the $\mathrm{pH}$ minimum caused by the stainless steel corrosion. This would ensure that no $\mathrm{Gd}$ would be available for release at the time of peak Gd solubility, so very little Gd would be lost from the waste package. Such non-metamict corrosion rates were not evaluated in the present study because, as Table 3.3.1-1 shows, the Gd loss will be small for even the worst metamict conditions.

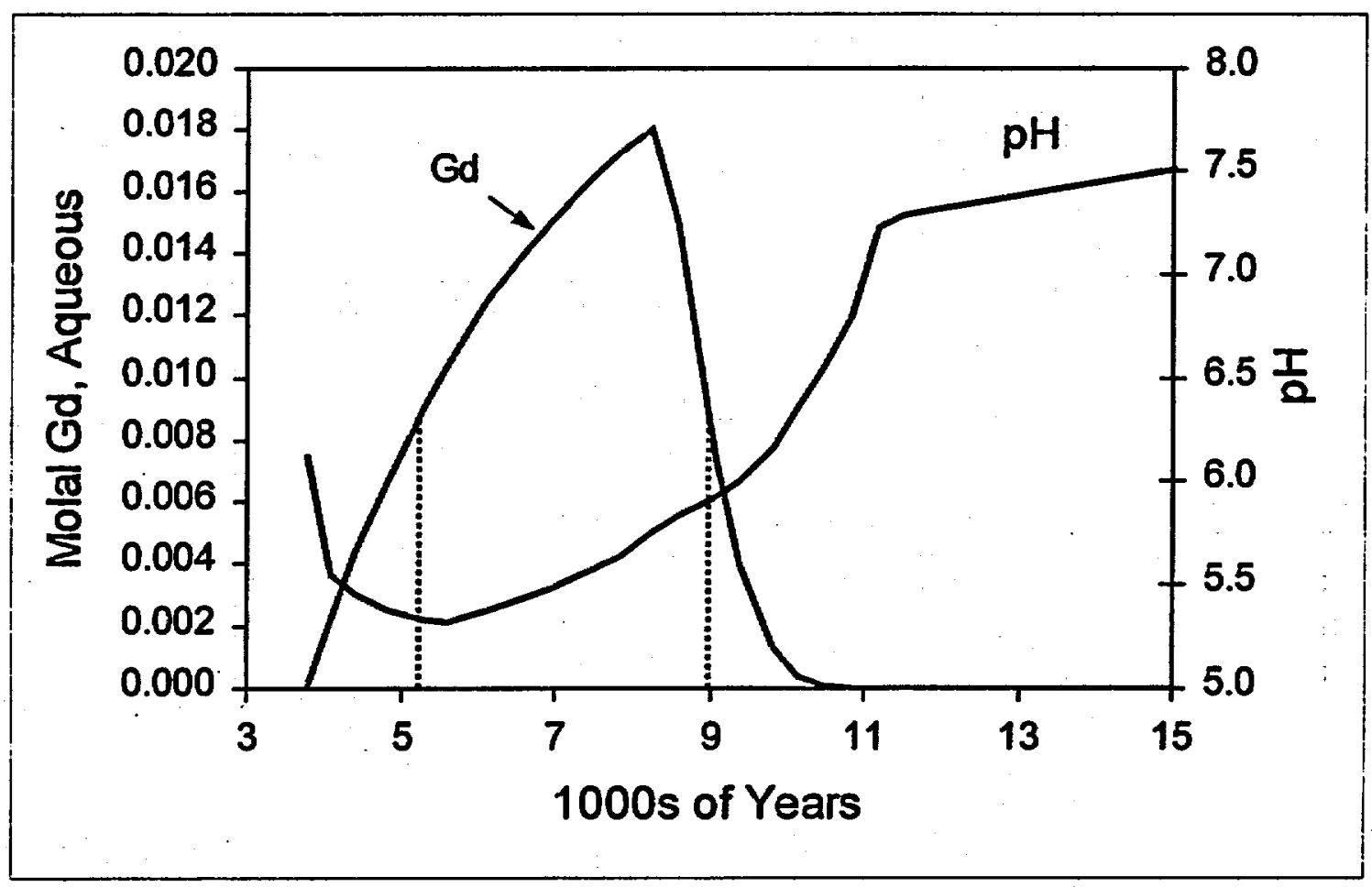

Figure 3.3.1-1. Gd concentration in solution and $\mathrm{pH}$ as a Function of Time (Scenario \#6)

The results presented in Figure 3.3.1-1 show the inverse correlation between $\mathrm{pH}$ and $\mathrm{Gd}$ concentration in solution. The displacement between the time of minimum $\mathrm{pH}$ and the time of peak Gd concentration in solution, shown in Figure 3.3.1-1 indicates that the solubility of Gd depends on a balance of other species concentrations, as well as the $\mathrm{pH}$, as explained later in this section and in Ref 6, Section 5.3.4. 


\section{Report on Intact \& Degraded Criticality for Selected Plutonium Waste Forms in a Geologic Repository, Volume II: Immobilized in Ceramic}

The Gd loss is inferred from the amount of Gd remaining, as calculated by EQ6. It can also be computed by numerically integrating the product of the Gd concentration in solution, multiplied by the outflow from the waste package (approximated by the drip rate into the waste package). It will be noted that the Gd concentration in Figure 3.3.1-1 has a simple triangular peak over a limited range of time, and is nearly zero elsewhere. This suggests a simple approximation to illustrate the chemical and physical processes and to check the consistency of the EQ6 calculation of Gd loss (last column of Table 3.3.1-1). The numerical integral can be approximated by multiplying the drip rate by the average $\mathrm{Gd}$ concentration in solution and by the time period of interest. The latter product, the average $\mathrm{Gd}$ concentration in solution multiplied by the time.period, can be approximated by product of the peak $\mathrm{Gd}$ concentration in solution multiplied by the width of the peak (since the Gd concentration is negligible for times outside of the peak). For scenario \#6 this is $(0.0015 \times 2.83 \times 3285=13.9 \mathrm{~kg})$; dividing by the initial $94 \mathrm{~kg}$ Gd gives a percent loss of $14.8 \%$, which is close to the $13.2 \%$ from the EQ6 calculation, as given in Table 3.3.1-1. This consistency check also shows that the total Gd loss is really determined by the peak Gd concentration in solution over a relatively short fraction of the total time period being evaluated. For those scenarios that do not lead to a significant peak (e.g., scenarios 1 and 8), there will be no significant Gd loss at all. It should be noted that this discussion is for illustration only, the precise calculation of Gd loss is determined from the EQ6 output, and given in the last column of Table 3.3.1-1.

The largest loss of $\mathrm{Gd}$ from the waste package in Table 3.3.1-1 is only slightly greater than $13 \%$ (scenarios \#4 and \#6). This low loss is small compared with the two previous studies that examined the chromic acid mechanism (Refs 4 and 5), and found some conditions under which all of the Gd was lost from the waste package. The first study of the subject (Ref. 4, for immobilized plutonium waste forms) was an evaluation of a similar waste form, but used only a heuristic functional dependence of Gd solubility on $\mathrm{pH}$. The second study (Ref. 5, for highly enriched research reactor SNF) used analytic tools similar to those used in the present study, but the waste package was somewhat different, and the waste form was quite different. The following paragraphs explain, in more detail, why the present waste package is more robust with respect to limiting acidification, and why it will always retain nearly all the $\mathrm{Gd}$.

- The U-Al alloy waste form used in Ref. 5 was itself a producer of acid during oxidation; in contrast, the Pu-ceramic is somewhat alkaline. Since the ceramic waste form is degrading during the entire period of interest, it is capable of neutralizing some of the acid produced by the corroding stainless steel.

- Alloy 22 is used for the inner barrier of the present waste package design, instead of the Alloy 625 used in previous studies. The latter was assumed to have a sufficiently high corrosion rate (albeit a much smaller rate than the stainless steel components of the waste package) that it could contribute a significant amount of chromic acid. Of course, the increment of chromic acid from Alloy 625 was small compared to that from the canisters inside the waste package, and was not enough to maintain an acid condition after the canisters had completely corroded. Nevertheless, it was enough to cause a significant solubility of Gd.

- For those scenarios with long corrosion times of the stainless steel there will generally be alkaline precipitates from earlier degradation of the ceramic and the HLW filler glass. These 


\section{Report on Intact \& Degraded Criticality for Selected Plutonium Waste Forms in a Geologic Repository, Volume II: Immobilized in Ceramic}

precipitates, principally the calcium containing minerals, calcite and dolomite, will slowly be re-dissolving and producing an alkalinity that counters the acidification tendency of the corroding stainless steel, so the gadolinium will remain virtually insoluble. Furthermore, the EQ6 results that show the peak Gd concentration occurring after the minimum $\mathrm{pH}$ (Figure 3.3.1-1) indicate that the dissolving process of these minerals has a limiting effect on the $\mathrm{Gd}$ solubility, beyond the action of the $\mathrm{pH}$. Only after the calcite and dolomite have been completely re-dissolved and the calcium ions flushed from the waste package (which may take upwards of 20,000 years), will the gadolinium become sufficiently soluble to be flushed from the waste package. The difference between the research reactor SNF (Ref 5) and the present ceramic waste form with respect to this mechanism, is that the ceramic waste form contains nearly $10 \%$ calcium (Table 2.2.3-1) while the research reactor SNF contains none. Both waste forms are co-disposed with HLW glass, which contributes approximately as much calcium as does the ceramic waste form. Therefore, although this buffering effect will be present in both cases, it will be approximately twice as large for the ceramic waste form.

The following observations can be made from the results given in Table 3.3.1-1:

- The results are not particularly sensitive to the second stage drip rate; the higher drip rate generally means a lower chromic acid concentration (higher minimum $\mathrm{pH}$ ), which, in turn, means a lower peak Gd concentration in solution. However, this factor is balanced by the fact that the higher drip rate will remove what $\mathrm{Gd}$ is in solution at a faster rate. Hence, comparing scenarios 2 and 3 in Table 3.3.1-1 shows the former to have nearly a ten times higher peak Gd concentration in solution, but it has approximately the same Gd loss because of the 10 times lower drip rate.

- A slower corrosion rate for the stainless steel will prolong the acidic period, and hence will enlarge the width of the Gd concentration in solution peak. This behavior can be seen by comparing scenario 7 with scenario 3 (for the low drip rate) and scenario 4 with scenario 6 (for the high drip rate). The slower stainless steel corrosion rate will also make the $\mathrm{pH}$ minimum occur later. The time of $\mathrm{pH}$ minimum is not given in Table 3.3.1-1, but Ref. 6, Table 5.3-2 shows that the two scenarios with average stainless steel corrosion rate ( 4 and 7 ) have the $\mathrm{pH}$ minimum occurring at just under 60,000 years. The rest of the scenarios have the minimum occurring at less than 6,000 years. As would be expected, the time of peak Gd concentration in solution shows a similar behavior, but a wider variation across scenarios. For scenarios 4 and 7, the times of peak Gd concentration are under 60,000 years, respectively; for the rest of the scenarios with high stainless steel corrosion rates, the times of peak $\mathrm{Gd}$ concentration range from less than 4,000 years to over 13,000 years.

- A higher ceramic corrosion rate will sharpen the Gd concentration in solution peak (higher peak and narrower width), but have little effect on the overall $\mathrm{Gd}$ loss. This can be seen by comparing scenarios 4 and 7 , which have different ceramic corrosion rates but similar total Gd loss. These two scenarios also have differing drip rates, but that has little effect on the width of the Gd concentration peak, as can be seen by comparing scenarios 2 and 3 . In this regard, it should be noted that the principal effect of a high ceramic corrosion rate is to convert most of the $\mathrm{Gd}$ from the ceramic into $\mathrm{GdOHCO}_{3}$, from which it can be re-dissolved if, and when, the $\mathrm{pH}$ is decreased below 5.9. The duration of the $\mathrm{pH}$ decrease is determined by a balance between the acidification produced by the corroding steel and the alkalinity 


\section{Report on Intact \& Degraded Criticality for Selected Plutonium Waste Forms in a Geologic Repository, Volume II: Immobilized in Ceramic}

produced by the corroding ceramic. The balance is further complicated by the fact that even after all the ceramic has corroded, the alkalinity can still be maintained by the calcite and dolomite minerals that were produced from the calcium in the ceramic and the glass. The $\mathrm{pH}$ decrease, and Gd concentration in solution peak, will generally occur immediately after all the calcium in calcite and dolomite has been re-dissolved and flushed from the waste package, provided that there is still stainless steel left to degrade and produce the acidification.

Scenarios \#2 and \#6 are used to illustrate the time history of the most neutronically significant elements in the waste package solids (both initial component fragments and precipitates of degradation products). These scenarios are typical of the high and average stainless steel corrosion rates, respectively. The amounts of principal elements remaining as solids (which approximate the total amounts in the WP, except as noted) are shown as a function of time for these two scenarios in Tables 3.3.1-2 and 3.3.1-3, respectively. These tables also show the effect of the decay of the remaining ${ }^{239} \mathrm{Pu}$ to ${ }^{235} \mathrm{U}$ ( $4^{\text {th }}$ and $5^{\text {th }}$ columns), under the conservative assumption that this decay begins at time zero, or the time of waste package breach. Since the decay of ${ }^{239} \mathrm{Pu}$ has already begun by the time of emplacement, this evaluation overstates the ${ }^{239} \mathrm{Pu}$ compared with its daughter product, ${ }^{235} \mathrm{U}$. Since the latter is generally less reactive by comparison with the former, this approximation is conservative. Furthermore, $U$ is more soluble than $\mathrm{Pu}$, and would be flushed from the waste package more quickly. Therefore, understating the ${ }^{235} \mathrm{U}$ (which is the result of delaying the initiation of ${ }^{239} \mathrm{Pu}$ decay) will overstate the total fissile material, a further conservatism. It should be noted, however, that this latter conservatism is not of much significance for the parameter ranges considered here, because even the fastest ceramic degradation rates are much slower than the glass degradation rate so that there will be very little fissile material released from the ceramic during the brief period of glass degradation (which is the only time of high $\mathrm{pH}$ to enable high solubility of $U$ ).

Although only those lines of the table corresponding to times of 11,500 years and 30,000 to 31,000 years are used in the criticality evaluations, the other time history information presented in these tables does provide useful insights into the geochemical processes, as described below. 


\section{Report on Intact \& Degraded Criticality for Selected Plutonium Waste Forms in a Geologic Repository, Volume II: Immobilized in Ceramic}

Table 3.3.1-2. Total WP Kilograms of the Principal Elements Remaining as Solids ${ }^{(6)}$ Scenario \#2 (From Ref. 6, Table 5.3.2-2)

\begin{tabular}{|c|c|c|c|c|c|c|c|c|c|c|c|c|}
\hline Time $^{2}$ & $\mathbf{U}^{1}$ & $\mathrm{Hf}(\mathrm{Zr})^{3}$ & $\begin{array}{l}{ }^{509} \mathrm{Pu} \\
\mathrm{raw} \mathrm{w}^{4}\end{array}$ & ${ }_{\text {decayed }}^{20} \mathrm{Pu}$ & $\begin{array}{l}{ }^{235} \mathrm{U} \\
\text { gen }^{5}\end{array}$ & Fe & $\mathbf{N i}$ & $\overline{M n}$ & $\mathrm{Na}$ & $\overline{\mathbf{A l}}$ & $\overline{\mathbf{S i}}$ & $\overline{\mathrm{Gd}}$ \\
\hline 0.0 & 427.4 & 126.7 & $\overline{144.2}$ & 144.2 & 0.0 & 2561.1 & 360.7 & 177.1 & 653.2 & 176.5 & 1679.4 & 93.6 \\
\hline 0.1 & 412.8 & 126.7 & 144.2 & 143.8 & 0.4 & 2559.5 & 360.4 & 177.1 & 588.9 & 176.6 & 1647.3 & 93.6 \\
\hline 0.3 & 385.5 & 126.7 & 144.2 & 143.0 & 1.2 & 2552.0 & 359.3 & 176.9 & 468.3 & 176.7 & 1587.2 & $\overline{93.6}$ \\
\hline 1.0 & 287.8 & 126.7 & 144.2 & 140.1 & 4.0 & 2527.6 & 355.7 & 176.3 & 35.9 & 176.8 & 1371.2 & 93.6 \\
\hline 3.8 & 285.3 & 126.7 & 144.2 & 129.5 & 14.4 & 2520.5 & 338.6 & $\overline{176.1}$ & 3.9 & 176.8 & 1683.1 & $\overline{93.6}$ \\
\hline$\overline{7.8}$ & 285.3 & 126.7 & 144.2 & 115.5 & 28.2 & 2520.8 & 256.3 & 176.1 & 3.8 & 176.9 & 1683.5 & 92.7 \\
\hline 11.5 & 285.3 & 126.7 & 144.2 & 103.9 & 39.6 & 2520.8 & 257.6 & 176.1 & 3.6 & 176.9 & 1683.6 & 91.8 \\
\hline 30.2 & 285.3 & 126.7 & 144.2 & 61.2 & 81.6 & 2520.1 & 259.8 & 176.1 & 2.8 & 176.8 & 1683.1 & $\overline{91.7}$ \\
\hline 62.1 & 285.4 & 126.7 & 144.2 & 24.7 & 117.5 & 2520.2 & 259.8 & $\overline{176.1}$ & 3.3 & 176.8 & 1683.3 & 91.7 \\
\hline 100.3 & 285.4 & 126.7 & 144.2 & 8.4 & 133.6 & 2520.3 & 259.8 & 176.1 & 3.6 & 176.8 & 1683.5 & 91.7 \\
\hline 204.1 & 285.6 & 126.8 & 144.3 & 0.4 & 141.5 & 2520.9 & 259.8 & 176.1 & 4.2 & 176.9 & $\overline{1684.5}$ & $\overline{91.8}$ \\
\hline 302.0 & 285.7 & 126.9 & 144.4 & 0.0 & 142.0 & 2520.4 & 259.8 & $\overline{176.1}$ & 4.4 & 176.9 & 1684.7 & $\overline{91.8}$ \\
\hline 400.3 & 285.9 & 126.9 & 144.4 & 0.0 & 142.0 & 2520.6 & 259.7 & $\overline{176.1}$ & 4.5 & 176.8 & 1685.2 & 91.8 \\
\hline 503.8 & 285.8 & 126.9 & 144.5 & 0.0 & 142.1 & 2520.5 & 259.7 & 176.1 & 4.6 & 176.8 & 1685.7 & 91.9 \\
\hline 601.8 & 285.8 & 126.9 & $\overline{144.5}$ & 0.0 & 142.1 & 2520.7 & 259.7 & 176.1 & 4.6 & 176.8 & 1686.2 & 91.9 \\
\hline$\overline{645.6}$ & 285.8 & 126.9 & 144.5 & 0.0 & 142.1 & 2520.6 & 259.7 & 176.1 & 4.6 & 176.9 & 1686.5 & 91.9 \\
\hline $\begin{array}{ll}\text { 2. } & \mathrm{T} \\
\text { 3. } & \mathrm{Z} \\
& \mathrm{p} \\
\text { 4. } & \mathrm{A} \\
5 . & \mathrm{A} \\
\text { 6. } & \mathrm{In}\end{array}$ & calcula & $\mathrm{in}^{\mathrm{f}}$ & then & . & $C_{T a}$ & $223-1$ & ne the th & $\mathrm{ruv}$ & $r a t$ & rabl & $324-1$ & but \\
\hline
\end{tabular}




\section{Report on Intact \& Degraded Criticality for Selected Plutonium Waste Forms in a Geologic Repository, Volume II: Immobilized in Ceramic}

Table 3.3.1-3. Total WP Kilograms of Principal Elements Remaining as Solids ${ }^{(7)}$, Scenario \# 6 (From Ref. 6, Table 5.3.3-2)

\begin{tabular}{|c|c|c|c|c|c|c|c|c|c|c|c|c|}
\hline Time ${ }^{2}$ & $\mathbf{U}^{1}$ & $\begin{array}{l}\text { Hf } \\
(\mathrm{Zr})^{3}\end{array}$ & $\begin{array}{l}{ }^{239} \mathrm{Pu} \\
\mathrm{raw}^{4}\end{array}$ & $\begin{array}{c}{ }^{239} \mathrm{Pu} \\
\text { decayed }^{5}\end{array}$ & $\begin{array}{l}\operatorname{gen}^{235} U \\
\end{array}$ & $\mathrm{Fe}$ & $\mathrm{Ni}$ & Mn & $\mathrm{Na}$ & $\mathrm{Al}$ & $\mathbf{S i}$ & Gd \\
\hline 0.0 & 427.4 & 126.7 & 144.2 & 144.2 & 0.0 & 2561.1 & 360.7 & 177.1 & 653.2 & 176.5 & 1679.4 & 93.6 \\
\hline 0.1 & 412.8 & 126.7 & 44.2 & 143.8 & $\overline{0.4}$ & 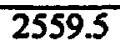 & 60.4 & 77.1 & 588.9 & 76.6 & & 93.6 \\
\hline$\overline{0.3}$ & 385.5 & 126.7 & 4.2 & 143.0 & 1.2 & 1552.0 & 59.3 & 76.9 & 468.3 & 76.7 & 1587.2 & 93.6 \\
\hline 1.0 & 287.8 & 126.7 & 44.2 & 140.1 & 4.0 & 2527.6 & 55.7 & 176.3 & 35.9 & 76.8 & 1371.2 & $\overline{93.6}$ \\
\hline 3.8 & 285.3 & 126.7 & 44.2 & 129.5 & 14.4 & 200.2 & 38.6 & 176.1 & 3.2 & 176.8 & 1683.1 & $\overline{93.6}$ \\
\hline 7.8 & 285.3 & 126.7 & 44.2 & 115.4 & 28.3 & 2520.5 & 92.4 & 176.1 & 2.4 & 776.8 & 683.1 & $\overline{74.6}$ \\
\hline 11.5 & 285.4 & 126.7 & 144.2 & 104.0 & 39.5 & 2520.9 & $\overline{00.4}$ & 76.1 & 1.8 & 176.9 & 683.4 & $\overline{81.3}$ \\
\hline 30.9 & 285.3 & 126.7 & 4.2 & 60.0 & 82.8 & 520.7 & 0.4 & 76.1 & 1.9 & 76.9 & 683.6 & 81.2 \\
\hline 63.1 & 285.3 & 126.7 & 4.2 & & 18.2 & 2520.5 & 0.4 & 76.1 & 2.9 & 76.8 & & 81.2 \\
\hline 01.3 & 285.3 & 126.7 & 44.2 & 0.1 & 133.8 & 2520.3 & 300.4 & 176.1 & 3.8 & 176.8 & 1683.6 & 81.2 \\
\hline 205.1 & 285.3 & 126.7 & 44.2 & 0.4 & 41.4 & 2520.5 & 300.4 & 176.1 & 5.3 & 176.8 & 1684.2 & 81.2 \\
\hline 303.4 & 285.3 & 126.7 & 144.2 & 0.0 & 41.8 & 2520.9 & 00.4 & 176.1 & 6.4 & 76.9 & 1685.0 & $\overline{81.2}$ \\
\hline 401.6 & 285.3 & 126.7 & 144.2 & 0.0 & 41.8 & 2520.6 & 00.4 & 176.1 & 7.0 & 176.9 & 1685.4 & $\overline{81.2}$ \\
\hline 603.2 & 285.3 & 126.7. & 144.2 & 0.0 & 141.8 & 2520.8 & 300.4 & 176.1 & 7.7 & 176.9 & 1686.4 & 81.2 \\
\hline 647.0 & 285.3 & 126.7 & 144.2 & 0.0 & 141.8 & 2520.6 & 300.4 & 176.1 & 7.7 & 176.8 & 1686.6 & 81.2 \\
\hline \multicolumn{13}{|c|}{$\begin{array}{l}\text { Depleted uranium from the ceramic matrix (Table 2.2.3-1) plus the HLW filler glass (Table 2.2.4-1); all but } 5 \\
\text { kg of the U from the filler glass is lost by } 1000 \text { years. } \\
\text { 2. Thousands of years. } \\
\text { 3. Zr used as surrogate for Hf, because of lack of thermodynamic data (explained further in Ref. 6, particularly } \\
\text { Assumption } 3.16 \text {. } \\
\text { 4. As calculated by EQ6, which has no capability to handle nuclear transformations. } \\
\text { 5. All Pu is taken as }{ }^{239} \mathrm{Pu} \text { and decayed to produce } 23 \mathrm{U} \text { (Ref. } 6 \text {, particularly assumption } 3.17 \text { ). } \\
\text { 6. At } 7.85 \times 10^{3} \text { years, }-6.7 \mathrm{~kg} \text { Gd is in solution, but the drip rate is so low that very little is flushed from the WP. } \\
\text { By the next time step given in the table, } 11.5 \times 10^{3} \text { years, most of this Gd has re-precipitated, increasing the } \\
\text { total Gd solids by a corresponding amount. The table also shows that iron (Fe) in solid form takes a similar, } \\
\text { but much smaller, jump between these two time points, for similar reasons. } \\
\text { 7. Insoluble degradation products plus fragments of initial materials. }\end{array}$} \\
\hline
\end{tabular}

These calculations show that nearly all the initial ${ }^{239} \mathrm{Pu}$ (or its daughter product ${ }^{235} \mathrm{U}$ ) is retained in the WP. The tables also show that nearly all the $\mathrm{Fe}, \mathrm{Mn}, \mathrm{Al}$ and $\mathrm{Si}$ in the packages will be retained, and from $72 \%$ to $100 \%$ of the Ni will be retained. A few principal minerals will dominate the bulk volume in the degraded waste package, and will account for all the retention of $\mathrm{Pu}$ (and daughter $\mathrm{U}$ ), $\mathrm{Fe}, \mathrm{Mn}, \mathrm{Al}, \mathrm{Si}$ and $\mathrm{Ni}$. The calculations predict that smectite clay (an Fe-rich nontronite) will overwhelmingly constitute the bulk of the volume, followed by hematite, pyrolusite and $\mathrm{Ni}_{2} \mathrm{SiO}_{4}$. The original Na will be almost completely lost over the course of $\sim 10^{5}$ years. The uranium is mostly contained in soddyite $\left(\left(\mathrm{UO}_{2}\right)_{2}\left(\mathrm{SiO}_{4}\right) \cdot 2 \mathrm{H}_{2} \mathrm{O}\right)$ (Ref 6$)$. 


\section{Report on Intact \& Degraded Criticality for Selected Plutonium Waste Forms in a Geologic Repository, Volume II: Immobilized in Ceramic}

A further observation of interest is that the EQ6 calculations predict no loss of $\mathrm{Hf}$ at all. The insolubility of $\mathrm{Hf}$ is well recognized; the fact that $\mathrm{Zr}$ has been used as a surrogate, because of insufficient experimental data on Hf, should not diminish the significance of this result. The chemical similarity of $\mathrm{Hf}$ and $\mathrm{Zr}$ is well known from the fact that they always occur together in natural minerals. Direct experimental evidence on the solubility of $\mathrm{Hf}$ is now being developed; in the meantime, it should be noted that these results on $\mathrm{Hf}$ insolubility are for information purposes only; none of the general criticality conclusions of this document depend on this interpretation.

In addition to the above general observations, the following time dependencies in Tables 3.3.1-2 and 3.3.1-3 are of interest:

- Depleted uranium from the HLW filler glass (included in the second column of each table, which also includes the depleted uranium from the ceramic matrix, and which has no relation to the ${ }^{235} \mathrm{U}$ in the $6^{\text {th }}$ column) decreases sharply during the first thousand years. This is because of the high $U$ solubility, caused by the high $\mathrm{pH}$ (greater than 9.0), which, in turn, is caused by the HLW filler glass degradation during this time period (Ref 6, Figure 5.3.2-2). This high solubility of $U$ permits rapid flushing, particularly because of the high drip rate during this time period. After this time period the $\mathrm{pH}$ has dropped sufficiently that the $\mathrm{U}$ solubility is too low to permit any significant amount to be flushed from the waste package. Consequently, the $U$ in solids remains constant after 1000 years. It should be noted that nearly all the $U$ left after this initial period of high $\mathrm{pH}$ is the $U$ from the ceramic matrix, which has not degraded significantly by this time, as quantified in footnote 1 of both Table 3.3.1-2 and Table 3.3.1-3.

- Although the solubility of $\mathrm{Pu}$ is also largest during the 1000 years of high $\mathrm{pH}$, the solubility of $\mathrm{Pu}$ is always too small to permit significant flushing. Hence the values in the $4^{\text {th }}$ column do not change significantly over time.

- In this conservative approximation of assuming ${ }^{239} \mathrm{Pu}$ decay to ${ }^{235} \mathrm{U}$ starting at the time of waste package breach, only a small amount of ${ }^{239} \mathrm{Pu}$ has decayed during the fist thousand years when the $U$ solubility is high enough to support a significant amount of flushing. Hence, the small amount of Uranium solids given in the $6^{\text {th }}$ column of each table does represent a small additional margin of conservatism. In future refinements of this analysis the $\mathrm{Pu}$ to $\mathrm{U}$ decay will be simulated in the EQ6 calculation directly, which will ensure that appropriate amounts of $\mathrm{Pu}$ decaying into $\mathrm{U}$ are removed from the waste package to ensure proper mass balance.

\subsubsection{Physical Description of Degraded Configurations (Geometry)}

The chemical configuration descriptions developed in the Section 3.3.1 are combined with the physical and geometric descriptions developed in this section to provide the input for the criticality evaluations presented in Section 3.3.3. Further information on these physical descriptions and criticality evaluations is provided in the degraded mode criticality calculation document, Ref. 12. 


\section{Report on Intact \& Degraded Criticality for Selected Plutonium Waste Forms in a Geologic Repository, Volume II: Immobilized in Ceramic}

For this criticality analysis the degraded configurations are divided into two types:

- Intermediate-level degraded configurations in which the ceramic waste form disks remain largely intact while all the other components have been degraded and/or fragmented (and the soluble degradation products have been removed from the waste package), and

- Fully collapsed configurations, in which the ceramic waste form disks are also physically degraded and/or fragmented with all the fragments and insoluble degradation products mixed into a homogeneous layer at the bottom of the horizontal waste package.

These configurations are described in the following sections.

\subsubsection{Intermediate-Level Degradation Configurations}

Three conservative configurations are analyzed for intermediate-level degradation. These configurations are discussed in the following sub-sections. Since the waste form is intact, these calculations are independent of time. For all three configurations the ceramic disks have the intact composition given in Table 2.2.3-1. The first two configurations have a close packing arrangement of the tubes of disks, and the third is closely related to the second. The close packing arrangement has been shown to be conservative by calculations showing the $k_{i n f}$ (neutron multiplication factor for an infinite array of tubes) increasing with decreasing lattice spacing (Ref 11).

\subsection{Square Geometry, Square Lattice Arrangement of Can Containing Tubes}

The first of the intermediate-level degradation configurations consists of all 35 tubes of the plutonium ceramic in a waste package arranged in a nearly square lattice of the 35 tubes (a $6 \times 6$ array missing the top-right-hand corner tube). Each tube contains its initial load of 4 cans, and the array rests on the bottom of the waste package, with the package voidspace (interstices between the tubes and the package volume outside of the nearly square array) filled with water of several different densities. This arrangement is shown in Figure 3.3.2.1-1. Also shown are the inner and outer waste package barriers and the reflecting layer of water outside the waste package. This reflecting layer represents the most conservative configuration since the drift would have to be filled with water. It should be noted that the removal of the glass and steel (and their degradation products) from the waste package is a conservative simplification, since these materials are likely to be more neutron absorbing, and less neutron moderating, than the water. Although the conservatism is not proved, the simplification is acceptable for this study because the resulting $\mathrm{k}_{\mathrm{eff}}$ turns out to be very low.

It is not expected that this square lattice would actually be achieved, but it does represent something close to a worst case arrangement of intact tubes of cans, or even of intact disks without the cans, since it puts the disks into very close proximity. The disks could be in closer proximity if the lattice were hexagonal close packed, instead of square (or rectangular), but the hexagonal close packing 


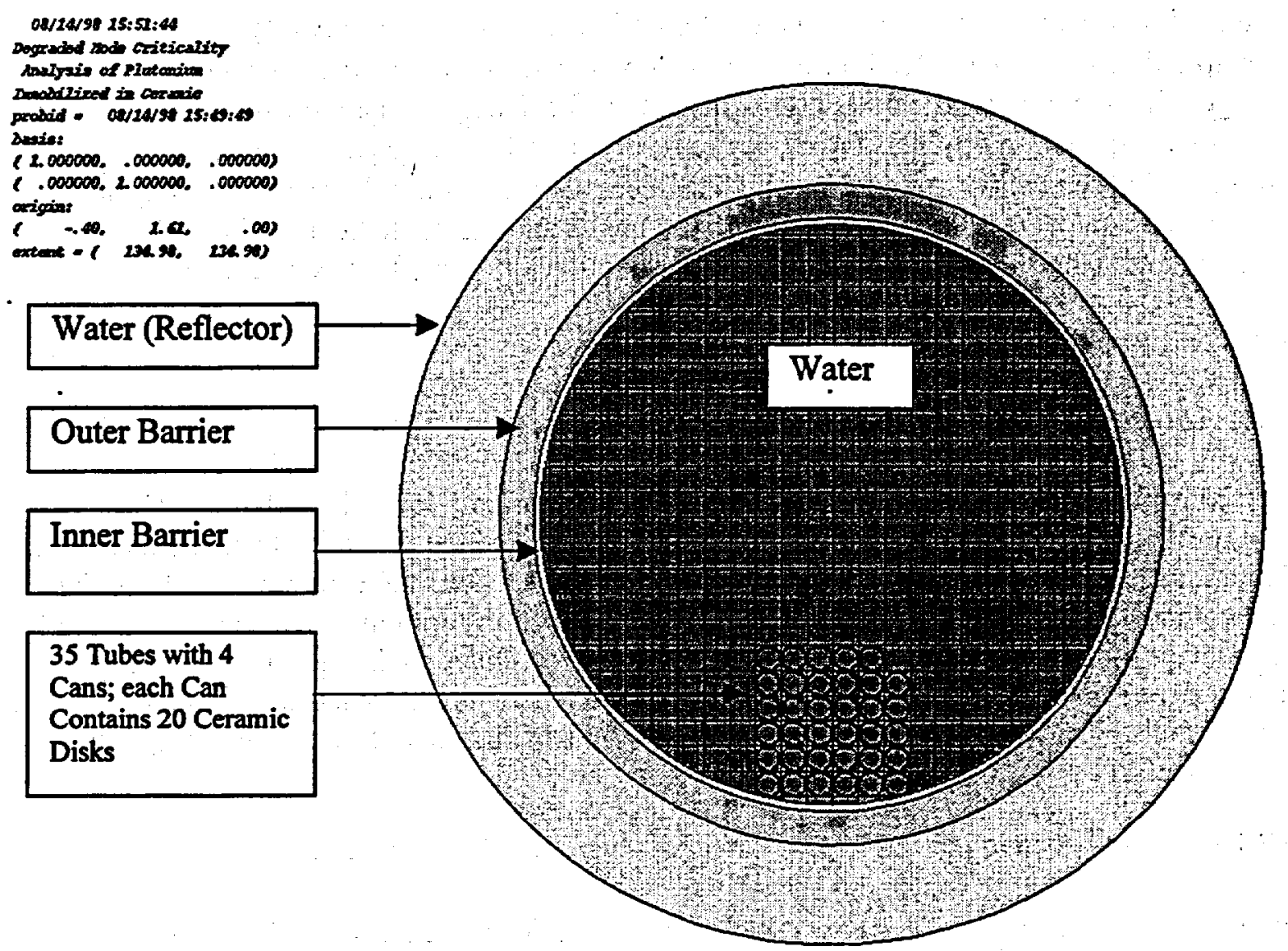

Figure 3.3.2.1-1. Cross-section of a Horizontally Emplaced Waste Package Showing a Square Lattice Arrangement of Tubes in a "Square" Geometry

would be unnecessarily conservative, since it would be impossible for the tubes to fall into such an arrangement. It should be noted that the rectangular close packing is metastable with respect to gravity, but the hexagonal close packing is unstable with respect to gravity. The following are further conservatisms of this configuration:

- There is an absence of degradation products of the other waste package components, since some of these degradation products are neutron absorbers (e.g., iron or manganese).

- The curvature of the waste package bottom would produce a slight vertical displacement of adjacent stacks of tubes; this would lead to a larger separation between tubes in adjacent stacks.

3.3.2.1.2 Pseudo-Cylindrical Segment Geometry, Locally Square Lattice Arrangement of Tubes

A later stage of intermediate-level degradation is represented by the configuration shown in 


\section{Report on Intact \& Degraded Criticality for Selected Plutonium Waste Forms in a Geologic Repository, Volume II: Immobilized in Ceramic}

Figure 3.3.2.1-2. As depicted in this figure, the thirty-five intact tubes (each containing four non-degraded cans of the Pu-bearing ceramic disks) create a "pseudo-cylindrical segment" geometry with tubes stacked at the bottom of the waste package. As with the configuration of Section 3.3.2.1.1, the tube stack lattice has a vertical and horizontal pitch equal to the can outer diameter. This configuration is formed by stacking the tubes vertically, with the bottommost tube of each stack resting on the waste package inner barrier. As with the configuration of Section 3.3.2.1.1, the removal of the glass and steel (and their degradation products) from the waste package is a conservative simplification, since these materials would be more neutron absorbing, and less neutron moderating, than the water. The simplification can be used because the resulting $k_{\text {eff }}$ turns out to be very low.

The configuration of the 35 settled tubes shown in Figure 3.3.2.1-2 has three curved layers of tubes with 14,12, and 9 tubes in the bottom layer, middle layer, and the top layer, respectively. Because of the variation in the vertical position of the inner barrier surface, tubes will be somewhat offset from one stack to the next, so the separation between tubes in adjacent stacks will be somewhat greater than in the completely square lattice of the previous subsection. This pseudo-cylindrical segment is less conservative than the square array of the previous sub-section, because the flatter arrangement will result in considerably more neutron leakage. However, it is a much more likely configuration because it represents a much more stable state with respect to gravity.

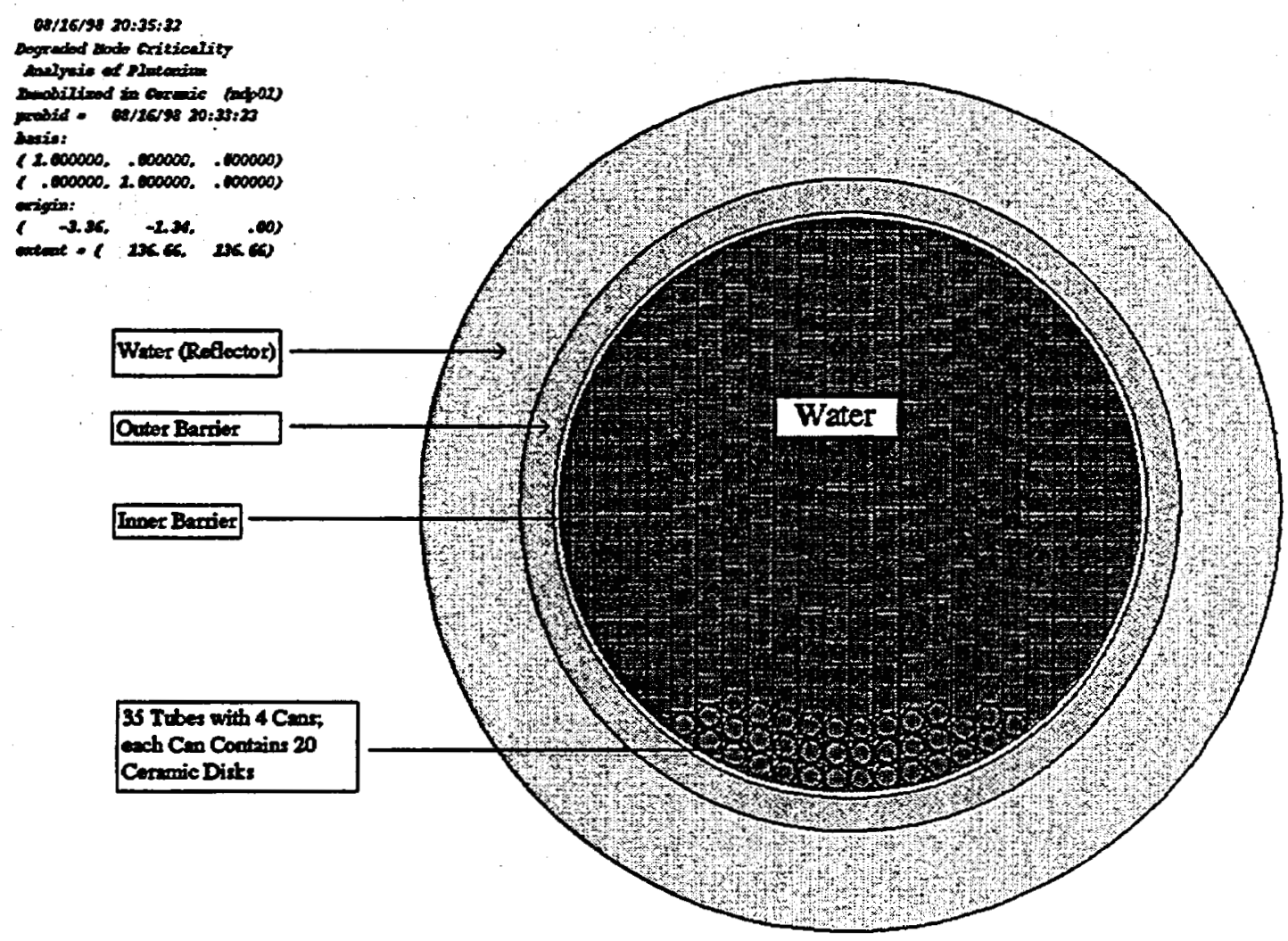




\section{Report on Intact \& Degraded Criticality for Selected Plutonium Waste Forms in a Geologic Repository, Volume II: Immobilized in Ceramic}

Figure 3.3.2.1-2. Cross-section of a Horizontally Emplaced Waste Package Showing a Stacking of 35 Tubes in a Pseudo-Cylindrical Segment Geometry

\subsection{Pseudo-Cylindrical Segment Geometry, Square Lattice Arrangement of Ceramic Disks}

The third and final intermediate-level degradation configuration is similar to those discussed above, but with the stainless steel can material removed. It is assumed that the ceramic disks preserve the same spacing as in the previous configuration (Section 3.3.2.1.2). This configuration may be expected to be more reactive than the previous configuration, due to the absence of the iron (a moderately effective neutron absorber) in the stainless steel. The iron oxide corrosion product of the stainless steel is insoluble, and it would be accurate to include it in the criticality calculation, both for its neutron absorbing effect and its moderator displacement effect. However, the iron oxide is omitted, in keeping with the conservative simplification that has removed all degradation products from the other intermediate-level configurations.

\subsubsection{Fully Collapsed Configuration}

The fully collapsed configuration is depicted in Figure 3.3.2.2-1. In this configuration all of the waste package components are either degraded or fragmented, and the products are homogenized. The sludge in the cylindrical segment at the bottom of the waste package contains a mixture of degradation products (including fissile and neutron absorbing materials) and nondegraded fragments of waste package components. The space above the cylindrical segment is filled with water. The moles of the principal elements, and isotopes, present in the sludge are listed in Table 3.3.2.2-1 for the compositions that have been used for criticality evaluation (taken from Ref 12, Table 5-2). These compositions are given in moles per liter of waste package void volume (3737.9 liters calculated in Ref 18 , spreadsheet masses5.xls) to preserve consistency with the geochemistry calculations of Ref 6, and the MCNP calculations of Ref 12. The consistency between the mole data in Table 3.3.2.2-1 and the kilogram data in Tables 3.3.1-2 and 3.3.1-3 can be verified by dividing the kilograms by the atomic weight (to convert to $\mathrm{kg}$ moles), dividing by 3737.9 (to convert to per liter), and multiplying by 1000 (to convert from kilograms to grams). 
Report on Intact \& Degraded Criticality for Selected Plutonium Waste Forms in a Geologic Repository, Volume II: Immobilized in Ceramic
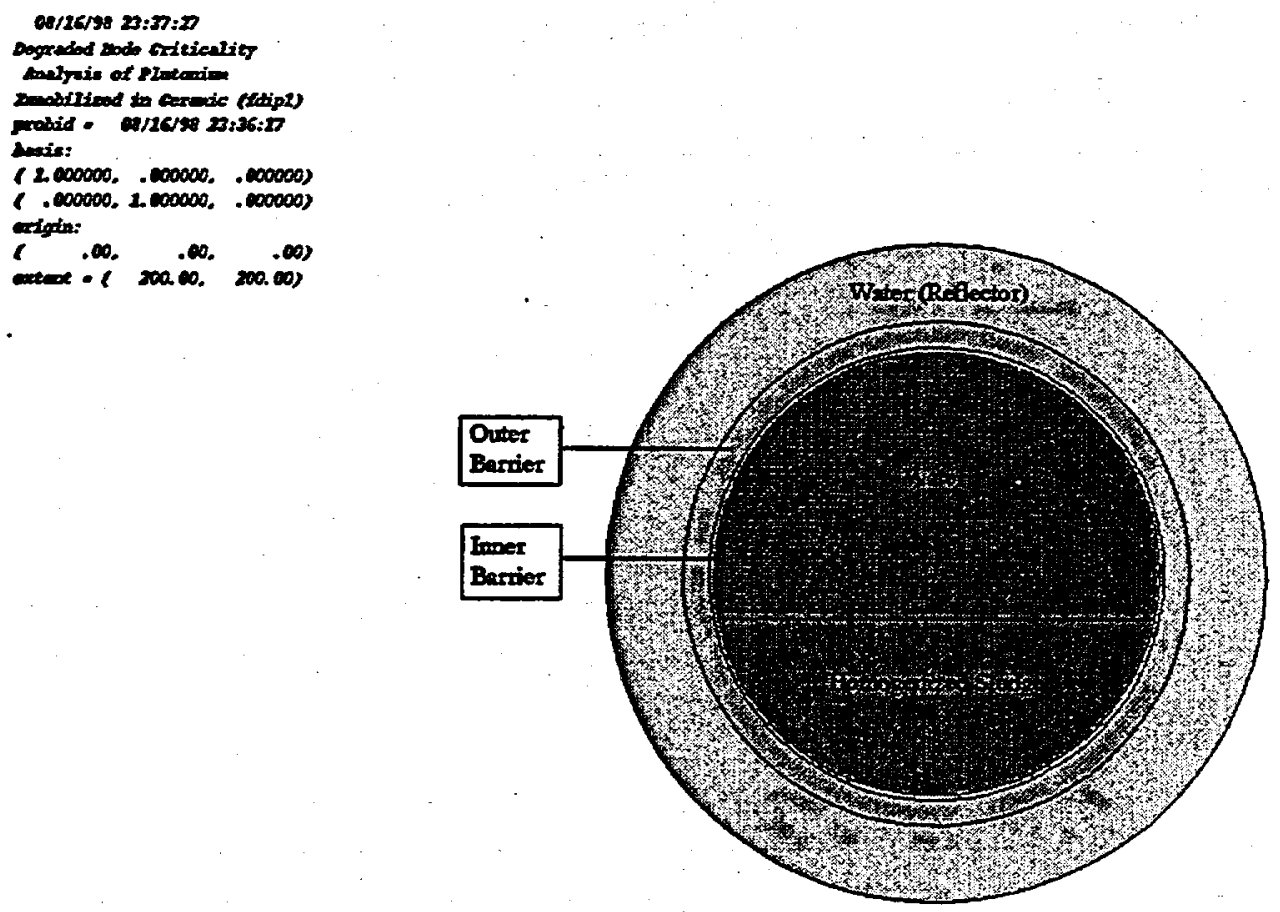

Figure 3.3.2.2-1. A Cross-sectional View of a Horizontally Emplaced Waste Package for the Full Degradation Configuration 
Report on Intact \& Degraded Criticality for Selected Plutonium Waste Forms in a Geologic Repository, Volume II: Immobilized in Ceramic

Table 3.3.2.2-1. Principal Elements or Isotopes in the Sludge Estimated by the EQ6 Code

\begin{tabular}{|c|c|c|c|}
\hline & \multicolumn{3}{|c|}{ Moles Remaining (per liter of WP void volume) } \\
\hline & $1.86 \% \mathrm{Gd}^{2}$ Loss $^{(\mathrm{a})}$ & $13.2 \%$ Gd Loss $^{(0)}$ & All Gd Removed ${ }^{(c)}$ \\
\hline Element or Isotope & At 30,200 Years & At 30,860 Years & At 30,200 Years \\
\hline $0-16^{(1)}$ & 66.097 & 66.738 & 66.097 \\
\hline Ti & 1.534 & 1.642 & 1.534 \\
\hline $\mathrm{U}-238$ & 0.320 & 0.320 & 0.320 \\
\hline Pu-239 & $0.068(0.116)^{(0)}$ & $0.067(0.116)^{(0)}$ & 0.068 \\
\hline Hf & 0.190 & $0: 190$ & 0.190 \\
\hline $\mathbf{C a}$ & 0.911 & 0.478 & 0.911 \\
\hline Gd & 0.156 & 0.138 & 0 \\
\hline Al-27 & 1.753 & 1.754 & 1.909 \\
\hline U-235(e) & $0.094(0.046)^{(d)}$ & $0.095(0.046)^{(d)}$ & 0.094 \\
\hline $\mathbf{F e}$ & 12.072 & 12.075 & 12.072 \\
\hline $\mathrm{Na}-23$ & 0.033 & 0.022 & 0.033 \\
\hline$\overline{\mathbf{N i}}$ & 1.184 & 1.369 & 1.184 \\
\hline$\overline{\mathrm{Si}}$ & 16.032 & 16.036 & 16.032 \\
\hline $\mathrm{Mn}-25$ & 0.858 & 0.858 & 0.858 \\
\hline
\end{tabular}

(a) Developed from values in the eighth line of Table 3.3.1-2.

(b) Developed from values in the eighth line of Table 3.3.1-3.

(c) Developed from the $1.86 \% \mathrm{Gd}$ loss column, with the remaining $\mathrm{Gd}_{2} \mathrm{O}_{3}$ replaced by $\mathrm{Al}_{2} \mathrm{O}_{3}$ to preserve a realistic sludge solids volume, since there was no consistent geochemical analysis (EQ6) that could produce a removal of all the gadolinium. This replacement has no direct effect on criticality, since aluminum has a very low neutron cross section.

(d) Changed to reflect the major isotopic differences between the $7^{\text {th }}$ and $8^{\text {th }}$ lines in both Tables 3.3.1-2 and 3.3.1-3.

(e) Includes 0.0007 moles from the ceramic depleted uranium (at $0.2 \%$ enrichment), but neglecting the less than 0.00002 moles from the less than $5 \mathrm{~kg}$ of HLW filler glass uranium (at $0.5 \%$ enrichment) remaining.

(f) Oxygen in sludge solids. The oxygen in water is accounted separately.

\subsubsection{Criticality Evaluations of Degraded Configurations}

\subsubsection{Criticality Evaluation Results for the Intermediate-Level Degradation Configurations}

The $\mathrm{k}_{\text {eff }}$ estimates, and their corresponding standard deviations for the intermediate-level degradation configurations, which were described in Section 3.3.2.1, are provided in Tables 3.3.3.1-1 and 3.3.3.1-2. As explained in Section 3.3.2.1, filling the waste package with water is a simplification of the actual configuration, which would have the clay degradation product of the HLW glass partly filling the space not occupied by the ceramic. Varying the water density between $0.01 \mathrm{~g} / \mathrm{cm}^{3}$ and $1.0 \mathrm{~g} / \mathrm{cm}^{3}$ provides a simplified model of the sensitivity of $k_{\text {eff }}$ to the concentration of water in such clay. The results show some initial increase in $\mathrm{k}_{\text {eff }}$ with increasing 


\section{Report on Intact \& Degraded Criticality for Selected Plutonium Waste Forms in a Geologic Repository, Volume II: Immobilized in Ceramic}

water density, and that beyond some density, the $\mathrm{k}_{\text {eff }}$ decreases with increasing water density. The initial increase is due to some small amount of moderation to enhance fission. Increasing moderation beyond some optimum simply provides more thermal neutrons to be absorbed by the gadolinium (which has a much higher thermal absorption cross section than the fission cross section of the uranium or plutonium). The limited number of cases, in these tables, does not provide sufficient resolution of the effects of water density to determine the precise location of the maximum $\mathrm{k}_{\text {eff. }}$

Table 3.3.3.1-1. $k_{\text {eff }}$ Estimates for Intermediate-Level Degradation Configuration: Square Arrangement*

\begin{tabular}{|l|l|l|}
\hline Water Density $\left(\mathrm{g} / \mathrm{cm}^{3}\right)$ & $\mathrm{k}_{\text {eff }}$ & Standard Deviation \\
\hline 0.01 & 0.338 & 0.00051 \\
\hline 0.1 & 0.368 & 0.00053 \\
\hline 1.0 & 0.364 & 0.00061 \\
\hline * 6x6 square array missing the top right-hand comer element; \\
geometry shown in Figure 3.3.2.1-1
\end{tabular}

The pseudo-cylindrical segment configuration is generally expected to have a lower $k_{\text {eff }}$ than a square geometry having the same number of tubes because the neutron leakage will be greater due to the higher aspect ratio geometry. This expectation is justified by comparing the $\mathrm{k}_{\text {eff }}$ values for the pseudo-cylinder segment geometry cases in Table 3.3.3.1-2 with the square geometry cases in Table 3.3.3.1-1. The only case in which the cylindrical segment geometry had a higher $k_{\text {eff }}$ is the case having the cans degraded, and the waste package filled with water at a density of $1.0 \mathrm{~g} / \mathrm{cm}^{3}$ (case 6 of Table 3.3.3.1-2 compared with case 3 of Table 3.3.3.1-1). This is because the configuration with more neutron leakage will have its $\mathrm{k}_{\text {eff }}$ increased by a material change that results in more fission by thermal neutrons (which will occur if the moderator displacing, and neutron absorbing, iron is removed). This fact also explains why the cases in Table 3.3.3.1-2 all show increased $k_{\text {eff }}$ with increasing water. It should be recognized that this explanation is only qualitative; the variations in $k_{\text {eff }}$ are the result of several factors, and the magnitude of the changes is so small that the balance among them must be very close.

Table 3.3.3.1-2. $\mathrm{k}_{\text {eff }}$ Estimates for Intermediate-Level Degradation Configuration: PseudoCylindrical Segment Geometry*

\begin{tabular}{|l|l|l|l|}
\hline $\begin{array}{l}\text { Condition of } \\
\text { Stainless Steel Cans }\end{array}$ & $\begin{array}{l}\text { Water Density } \\
\left(\mathrm{g} / \mathrm{cm}^{3}\right)\end{array}$ & $\mathrm{k}_{\text {eff }}$ & $\begin{array}{l}\text { Standard } \\
\text { Deviation }\end{array}$ \\
\hline Present & 0.01 & 0.288 & 0.00051 \\
\hline Present & 0.1 & 0.328 & 0.00065 \\
\hline Present & 1.0 & 0.348 & 0.00075 \\
\hline Removed & 0.01 & 0.309 & 0.00057 \\
\hline Removed & 0.1 & 0.343 & 0.00069 \\
\hline Removed & 1.0 & 0.379 & 0.00078 \\
\hline
\end{tabular}

* Geometry shown in Figure 3.3.2.1-2. 


\section{Report on Intact \& Degraded Criticality for Selected Plutonium Waste Forms in a}

Geologic Repository, Volume II: Immobilized in Ceramic

\subsubsection{Criticality Evaluation Results for the Fully Degraded Configurations}

The selection of worst case scenarios and times for criticality evaluation is based primarily on the following two considerations: (1) The decay of ${ }^{239} \mathrm{Pu}$ to ${ }^{235} \mathrm{U}$ decreases the $\mathrm{k}_{\text {eff }}$ with time because the former is generally more reactive than the latter. (2) The possible loss of $\mathrm{Gd}$ from the WP may increase the $k_{\text {eff }}$ with time. For the Scenario \#6 in Table 3.3.1-1, the Gd loss reaches $13.2 \%$ after 11,500 years and remains nearly constant thereafter, so the $k_{\text {eff }}$ should be largest at this time. On the other hand, in Scenario \#4 of Table 3.3.1-1 the Gd loss reaches a plateau of $14.8 \%$, but not until 60,000 years (Ref 18, files Cerd2W0_00151.allpost and Cerd2W0_00151.lastpost). It is, therefore, necessary to test the relative sensitivity of $k_{\text {eff }}$ to variation in time (which implies a variation in the ratio of ${ }^{239} \mathrm{Pu}$ to ${ }^{235} \mathrm{U}$ ) compared with the variation in $\mathrm{Gd}$ loss. For this purpose the timestep near 11,000 years was compared with the timestep near 31,000 years, and Scenario \#2 (1.86\% maximum Gd loss) was compared with Scenario \#6 (13.2\% maximum Gd loss). The results are shown in Table 3.3.3.2-1. The first six lines of this table are based on Scenario \#2, in which the maximum Gd loss is $1.86 \%$ of the initial loading. The second set of 6 lines is for Scenario \#6, in which the maximum Gd loss is $13.2 \%$ of the initial loading. The sludge compositions for these two sets of cases are given in the second and third columns of Table 3.3.2.2-1, respectively.

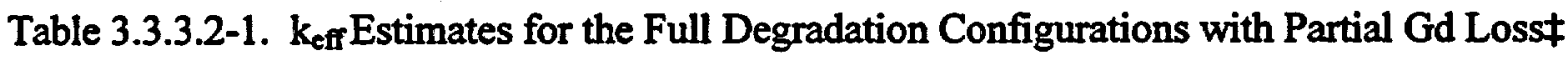

\begin{tabular}{|l|l|l|l|l|l|}
\hline Case \# & $\begin{array}{l}\text { Time after the initial breach } \\
\text { of the Waste Package } \\
\text { (years) }\end{array}$ & $\begin{array}{l}\% \text { Gd } \\
\text { Loss }\end{array}$ & $\begin{array}{l}\text { Water Content of } \\
\text { the Homogenized } \\
\text { Sludge (vol\%) }\end{array}$ & $k_{\text {eff }}$ & $\begin{array}{l}\text { Standard } \\
\text { Deviation }\end{array}$ \\
\hline 1 & 11500 & 1.86 & 0 & 0.353 & 0.00073 \\
\hline 2 & 11500 & 1.86 & $9^{*}$ & 0.366 & 0.00074 \\
\hline 3 & 11500 & 1.86 & $23 \dagger$ & 0.355 & 0.00080 \\
\hline 4 & 30200 & 1.86 & 0 & 0.322 & 0.00060 \\
\hline 5 & 30200 & 1.86 & $9^{*}$ & 0.320 & 0.00057 \\
\hline 6 & 30200 & 1.86 & $23 \dagger$ & 0.295 & 0.00053 \\
\hline 7 & 11500 & 13.2 & 0 & 0.364 & 0.00071 \\
\hline 8 & 11500 & 13.2 & $10^{*}$ & 0.380 & 0.00059 \\
\hline 9 & 11500 & 13.2 & $30 \dagger$ & 0.354 & 0.00063 \\
\hline 10 & 30860 & 13.2 & 0 & 0.332 & 0.00069 \\
\hline 11 & 30860 & 13.2 & $10^{*}$ & 0.327 & 0.00067 \\
\hline 12 & 30860 & 13.2 & $30 \dagger$ & 0.285 & 0.00050 \\
\hline
\end{tabular}

$\neq$ Geometry shown in Figure 3.3.2.2-1.

* $\dagger \quad$ These values do not match between the two different $G d$ loss cases (1.86\% and $13.2 \%)$ because they were developed from different dilution strategies. However, both sets cover sufficient range to demonstrate the decrease in $\mathrm{k}_{\text {eff }}$ with increasing water content.

In Table 3.3.3.2-1 it is seen that the difference in $\mathrm{k}_{\text {eff }}$ for the corresponding members of the set $(1,2,3)$ with the set $(4,5,6)$, is between 0.03 and 0.06 , while the difference between set $(1,2,3)$ and the corresponding members of set $(7,8,9)$ is between 0.010 to 0.001 . Since the former is greater than the latter, it is concluded that the sensitivity to time (surrogate for the ${ }^{239} \mathrm{Pu}^{235} \mathrm{U}$ split) is 


\section{Report on Intact \& Degraded Criticality for Selected Plutonium Waste Forms in a Geologic Repository, Volume II: Immobilized in Ceramic}

greater than the sensitivity to $\mathrm{Gd}$ loss. A similar comparison of the differences between sets $(7,8,9)$ and $(10,11,12)$ with the differences between sets $(4,5,6)$ and $(10,11,12)$ supports the same conclusion. This greater sensitivity to time differences than to $\mathrm{Gd}$ loss differences suggests that Scenario \#6 is more conservative than scenario \#4, even though the Gd loss in the latter is $10 \%$ greater than the Gd loss in the former, because the former reaches its largest $G d$ loss at 11,500 years, while the later only reaches it at 60,000 years.

Another result of interest in Table 3.3.3.2-1 is that the $k_{\text {eff }}$ for the later time (lower ratio of ${ }^{239} \mathrm{Pu}$ to ${ }^{235} \mathrm{U}$ ) is monotonic decreasing as the water content of the sludge is increased, while the earlier time indicates a peaking at some intermediate water concentration (although the precise location is not identified by this coarse analysis). The slight peaking of the higher ${ }^{239} \mathrm{Pu}$ cases is caused by the $35 \%$ higher thermal fission cross section of ${ }^{239} \mathrm{Pu}$ compared with ${ }^{235} \mathrm{U}$, which enables it to better compete for the additional thermal neutrons which result from the initial increase in sludge water content. As the water content increases further, the $\mathrm{Gd}$ and fissile material are spread out, and other factors become dominant, particularly the greater effectiveness of $\mathrm{Gd}$ with decrease in its self-shielding. Consequently, the $k_{\text {eff }}$ decreases with further water content.

It should be further noted that the times near 30,000 years in Tables 3.3.1-2 and 3.3.1-3 differ slightly (30,200 years and 30,860, respectively) because of a slight difference in the way the EQ6 flow-through procedure happened to work out for these two scenarios.

Table 3.3.3.2-2 shows the results for a set of hypothetical configurations in which all the $\mathrm{Gd}$ is lost. The EQ6 analyses of this study have shown that such configurations are not possible, but it is of some interest to evaluate them as a set of non-mechanistic worst cases for comparison purposes only.

Table 3.3.3.2-2. $\mathrm{k}_{\text {eff }}$ Estimates for the Hypothetical Full Degradation Configurations with no Gd Present (for comparison purposes only, since complete removal is non-physical)*

\begin{tabular}{|l|l|l|}
\hline $\begin{array}{l}\text { Water Content of the } \\
\text { Homogenized Sludge (vol\%) }\end{array}$ & $\mathrm{k}_{\text {eff }}$ & $\begin{array}{l}\text { Standard } \\
\text { Deviation }\end{array}$ \\
\hline 0 & 0.581 & 0.00112 \\
\hline 23 & 0.824 & 0.00136 \\
\hline 41 & 0.918 & 0.00137 \\
\hline 60 & 0.946 & 0.00117 \\
\hline
\end{tabular}

Geometry shown in Figure 3.3.2.2-1.

These results show an increase in $k_{\text {eff }}$ with increasing water content of the homogenized sludge. This is because the removal of all $\mathrm{Gd}$ leaves only the Hf as neutron absorber. The thermal neutron cross section of $\mathrm{Hf}$ is much less than that of ${ }^{239} \mathrm{Pu}$ or ${ }^{235} \mathrm{U}$, so it will not out-compete the fissile elements for thermal neutrons.

The results presented in Table 3.3.3.2-2 indicate that for water content greater than $60 \%$ the configuration could be critical. Since none of the degradation scenarios showed any possibility 


\section{Report on Intact \& Degraded Criticality for Selected Plutonium Waste Forms in a Geologic Repository, Volume II: Immobilized in Ceramic}

of a complete Gd loss, such possibility of criticality was not investigated further at this time. The following observations are, however, of interest:

- It was shown in Ref. 4, Section 7.5, that a few kilograms of Gd are generally sufficient to prevent criticality. Therefore, if there were a mechanism for removing most of the Gd, there would most likely be enough left to prevent criticality.

- There is no experimental information on the long-term maximum sustainable homogeneous water concentration. However, water concentrations higher than $60 \%$ are possible in clay (Ref 5, Section 6.5), but it is questionable whether heavy precipitates, such as the minerals produced by these calculations, could remain suspended in such large water concentrations. for long periods of time.

- If a mechanism for large $\mathrm{Gd}$ loss were discovered, it would be possible to prevent criticality by increasing the $\mathrm{Hf}$ content, although $\mathrm{Hf}$ is a much less efficient absorber of thermal neutrons than is $\mathrm{Gd}$. It has been found (Ref 4, Section 7.5.5) that for a similar mass of ${ }^{239} \mathrm{Pu}$ and ${ }^{235} \mathrm{U}$, to that used here $28 \mathrm{~kg}$ of $\mathrm{Hf}$ to equal $.5 \mathrm{~kg}$ of Gd (56 to 1). Based on the analysis in Ref 4 it would take approximately $50 \%$ more $\mathrm{Hf}$ than is already planned for the ceramic to prevent criticality in the complete absence of $\mathrm{Gd}$. 


\section{Report on Intact \& Degraded Criticality for Selected Plutonium Waste Forms in a Geologic Repository, Volume II: Immobilized in Ceramic}

\section{FINDINGS AND CONCLUSIONS}

\subsection{Findings}

\subsubsection{Maximum Loss of Neutron Absorber}

In each of the cases most of the primary neutron absorber, gadolinium, is retained in the waste package because it is just as insoluble as uranium or plutonium. This result is in contrast with previous analyses that showed a higher solubility of gadolinium due to $\mathrm{pH}$ values below 6.0, which could be caused by chromate ion produced by the corrosion of stainless steel. For the. present ceramic waste form, the geochemistry analysis with EQ6 shows that during the time of simultaneous degradation of the ceramic and the stainless steel there will generally be alkaline precipitates from earlier degradation of the ceramic and the HLW filler glass. These precipitates, principally the calcium containing minerals calcite and dolomite, will be slowly re-dissolving and flushing from the waste package. During this re-dissolution process the steady state concentration of calcium ions produces enough alkalinity to counter the acidification tendency of the corroding stainless steel. Therefore, the $\mathrm{pH}$ remains nearly neutral, and the gadolinium remains nearly insoluble. As a consequence the maximum removal of gadolinium is only $13.2 \%$ for Scenario \#6 or $14.8 \%$ for Scenario \#4, with the former taking 11,500 years and the latter requiring 60,000 years (Section 3.3.1).

Since the differing parameters of these two scenarios cover the likely range of corrosion rates for stainless steel and the ceramic waste form, it is concluded that there will be no set of corrosion rates (for ceramic and stainless steel) found to produce a significantly larger $\mathrm{Gd}$ loss.

It was also shown that there is virtually no loss of hafnium in upwards of several hundred thousand years (Section 3.3.1). The criticality prevention capability of this neutron absorber becomes important only if all the Gd is lost (Section 3.3.3.2).

\subsubsection{Criticality of the Intact Configuration}

The completely intact configuration has no potential for criticality at all. The calculated $\mathrm{k}_{\text {eff }}=$ 0.12 for the nominal case, and $k_{\text {eff }}=0.11$ when all of the voidspace in the waste package is filled with water. In most potentially critical configurations water would act as a moderator and increase the $k_{\text {effi }}$ but in this case thermalization of neutrons only facilitates their more efficient absorption by the gadolinium. (Section 3.2.2)

\subsubsection{Criticality of Degraded Configurations}

The successive stages of degradation may be characterized by the following configurations, and by their resulting criticality: 


\section{Report on Intact \& Degraded Criticality for Selected Plutonium Waste Forms in a Geologic Repository, Volume II: Immobilized in Ceramic}

1. Intermediate degradation, with all 5 canister shells corroded and the filler glass degraded to clay. This case has been approximated by replacing the clay with water. The cans containing the ceramic disks are largely intact so that their iron is available for neutron absorption, even though the cans have been penetrated by water. The cans are nominally still contained in 35 tubes ( 5 canisters $\times 7$ tubes per canister), which are stacked in a nearly square geometry at the bottom of the waste package. For the waste package filled with water $\mathrm{k}_{\text {eff }}=$ 0.34 , while the dry case has only $k_{\text {eff }}=0.29$. A hexagonal close packaging arrangement would have been more conservative, but its occurrence would be incredible. (Section 3.3.2.1.1)

2. Intermediate degradation with the same chemistry as the previous configuration, but with all 35 tubes laying at the bottom of the waste package filling a cylindrical segment with a somewhat curved upper surface. These tubes are stacked in a square lattice close packing, similar to the previous configuration. This pseudo-cylindrical configuration gives $k_{\text {eff }}=0.37$ when all of the space around and between the ceramic disks is filled with water having a density of $1 \mathrm{~g} / \mathrm{cm}^{3}$, and a $\mathrm{k}_{\mathrm{eff}}=0.31$ when the this space is empty (approximated by the lowest density used for water, $0.01 \mathrm{~g} / \mathrm{cm}^{3}$ ). (Section 3.3.2.1.2)

3. Completely degraded: the insoluble degradation products of the waste form, the HLW filler glass, and the steel are assumed to form a homogeneous sludge, which is slumped to the bottom of the waste package, where it uniformly fills a cylindrical segment. The rest of the waste package is filled with water, which serves as a reflector. Under these circumstances a maximum of $13.2 \%$ of the neutron absorbing gadolinium will be dissolved and flushed from the waste package. This configuration gives $k_{\text {eff }}=0.33$ when there is no water mixed in the sludge, and $\mathrm{k}_{\mathrm{eff}}=0.28$ when the sludge has $30 \%$ water by volume. (Section 3.3 .2 .1 .3 )

The only change in the waste package contents that can result in a configuration that might have a $k_{\text {eff }}$ near the regulatory limit of 0.95 is the complete, or nearly complete, loss of gadolinium. Previous studies had identified scenarios that could lead to complete loss of gadolinium. These previous studies were either more conservative (but less rigorous) or dealt with a less alkaline waste form. Even though the present study indicates that such large losses of Gd are not credible, the complete loss of gadolinium has been evaluated, for information purposes only, with the finding that criticality cannot occur unless the water content of the remaining sludge is greater than $60 \mathrm{vol} \%$ (Section 3.3.3.2).

\subsection{Conclusions}

No criticality is possible for this ceramic waste form, even with $5 \mathrm{Pu}$ canisters per waste package, primarily because of the small amount of gadolinium lost. (Section 3.3.3)

The findings on gadolinium retention in the waste package are relatively insensitive to ceramic dissolution rate, except for the following two extreme conditions: 


\section{Report on Intact \& Degraded Criticality for Selected Plutonium Waste Forms in a Geologic Repository, Volume II: Immobilized in Ceramic}

- A very low ceramic dissolution rate will prevent the release of any gadolinium from the waste package (not even the small amount, $13 \%$, released under the conditions of finding \#3 of 4.1.2, above), because there will be no gadolinium released from the waste form until after all the stainless steel has corroded and there is no longer any possibility of acidification.

- A very high initial drip rate, extending over several thousand years, coupled with a high corrosion rate of the ceramic waste form, could facilitate a significant removal of gadolinium from the waste package. Under such a condition all of the alkaline minerals could be flushed from the waste package before most of the stainless steel corroded. If this very high drip rate were followed by a period of very low drip rate, the $\mathrm{pH}$ drop could be of long enough duration to remove most of the gadolinium.

The second of these conditions is not credible. A high drip rate persisting over several thousand years would not be credible. Furthermore, the second condition would be prevented by the occurrence of the first. A very slowly degrading ceramic would preclude the early removal of all the alkaline minerals (since some of the alkaline minerals come from the ceramic itself) before most of the stainless steel had degraded. Therefore, the waste package solution could not become acidic, since all the stainless steel (with its acid producing potential) would be gone before much of the ceramic had degraded. (Section 3.3.1) 
Report on Intact \& Degraded Criticality for Selected Plutonium Waste Forms in a Geologic Repository, Volume II: Immobilized in Ceramic

\section{REFERENCES}

1. United States Department of Energy 1996. Record of Decision for the Disposition of Surplus Highly Enriched Uranium Final Environmental Impact Statement. 61 Federal Register 40619. Washington, D.C. TIC 231278.

2. United States Department of Energy 1997. Record of Decision for the Storage and Disposition of Weapons-Usable Fissile Materials Final Programmatic Environmental Impact Statement. Washington, D.C. TIC 239425.

3. Civilian Radioactive Waste Management System (CRWMS) Management \& Operating Contractor (M\&O) 1998. Technical Document Preparation Plan for the Report on Intact \& Degraded Criticality for Selected Plutonium Waste Forms in a Geologic Repository. BBA00000-01717-4600-00011 REV 00. Las Vegas, NV. J.A. McClure. MOL.19980911.0307.

4. Civilian Radioactive Waste Management System (CRWMS) Management and Operating Contractor (M\&O) 1997. Degraded Mode Criticality Analysis of immobilized Plutonium Waste forms in a Geologic Repository. 00000000-01717-5705-00014 REV01. Las Vegas, Nevada. MOL.19980422.0911.

5. CRWMS M\&O 1998. Evaluation of Codisposal Viability for Aluminum-Clad DOEOwned Spent Fuel: Phase II Degraded Codisposal Waste Package Internal Criticality. BBA000000-01717-5705-00017 REV 01. Las Vegas, NV. MOL.19980701.0782

6. CRWMS M\&O 1998. EQ6 Calculations for Chemical Degradation of Pu-Ceramic Waste Packages. BBA000000-01717-0210-00018 REV 00. Las Vegas, NV. MOL pending

7. CRWMS M\&O 1998. Controlled Assumptions Design Document. B00000000-017174600-00032 REV 05. Las Vegas, NV. MOL.19980504.0006

8. Wolery, Thomas J., and Daveler, Stephanie A. 1992. EQ6, A Computer Program for Reaction Path Modeling of Aqueous Geochemical Systems: Theoretical Manual, User's Guide, and Related Documentation (Version 7.0). UCRL-MA-110662 PT IV. Livermore, California: Lawrence Livermore National Laboratory. 205002.

9. Briesmeister, Judith F., Ed. 1997. MCNP-A General Monte Carlo N-Particle Transport Code. LA-12625M, Version 4B. Los Alamos National Laboratory. MOL.19980624.0328.

10. Ho, C. K, and Wilson, M. L. 1998. Unsaturated-Zone Flow: Preliminary Draft Section 2.3 of TSPA-VA Document. Las Vegas, Nevada: CRWMS M\&O. LV.PA.RWA.02/98041. MOL.19980428.0202 
Report on Intact \& Degraded Criticality for Selected Plutonium Waste Forms in a Geologic Repository, Volume II: Immobilized in Ceramic

11. CRWMS M\&O 1998. Criticality Evaluation of Plutonium Disposition Ceramic Waste Form: Intact Mode. BBA000000-01717-0210-00012 REV 00. Las Vegas, Nevada. MOL.19980813.0172

12. CRWMS M\&O 1998. Criticality Evaluation of Plutonium Disposition Ceramic Waste Form: Degraded Mode. BBA000000-01717-0210-00014 REV 01. Las Vegas, Nevada. MOL pending

13. Lawrence Livermore National Laboratory 1998. Plutonium Immobilization Project, Data for Yucca Mountain Total Systems Performance Assessment, Rev. 1. PIP Milestone Report, Milestone 2.b.b. PIP 98-012. Livermore, California. MOL.19980818.0349.

14. CRWMS M\&O 1996. DHLW Glass Waste Package Criticality Analysis (SCPB: N/A). BBAC00000-01717-0200-00001 REV 00. Attachment I, Table 3.3.8. Las Vegas, Nevada: J. Davis. MOL.19960919.0237.

15. Reserved.

16. CRWMS M\&O 1995. Total System Performance Assessment - 1995. An Evaluation of the Potential Yucca Mountain Repository. B00000000-01717-2200-00136 REV 01. Las Vegas, Nevada. MOL.19960724.0188.

17. CRWMS M\&O 1996. Report on Evaluation of Plutonium Waste Forms For Repository Disposal. A00000000-01717-5705-00009 REV 01. Las Vegas, Nevada. MOL.19961210.0066.

18. CRWMS M\&O 1998. Electronic Media for BBA000000-01717-0210-00018 REV 00. QIC80 DT 350 Tape. MOL. 19980831.0169. 


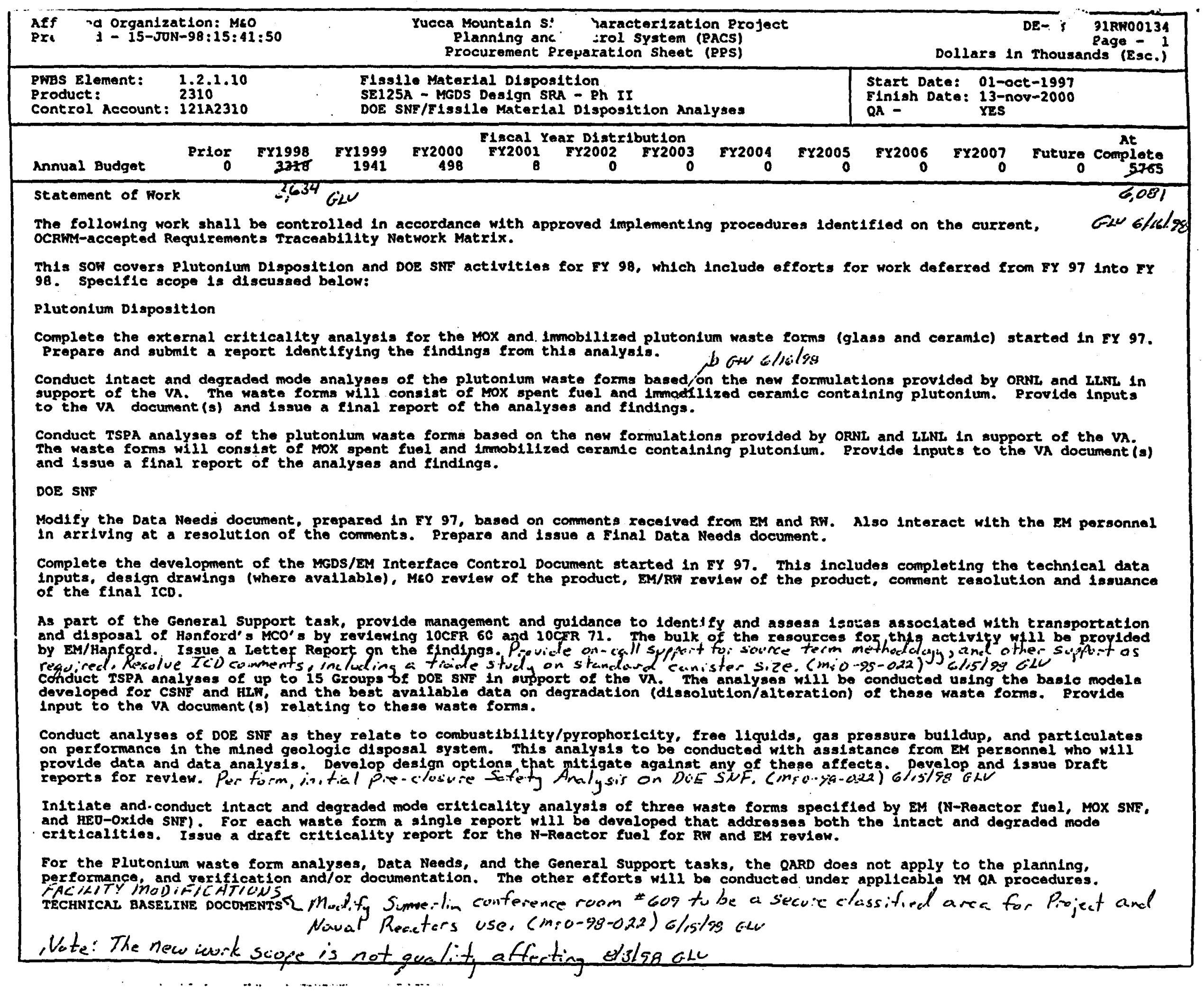




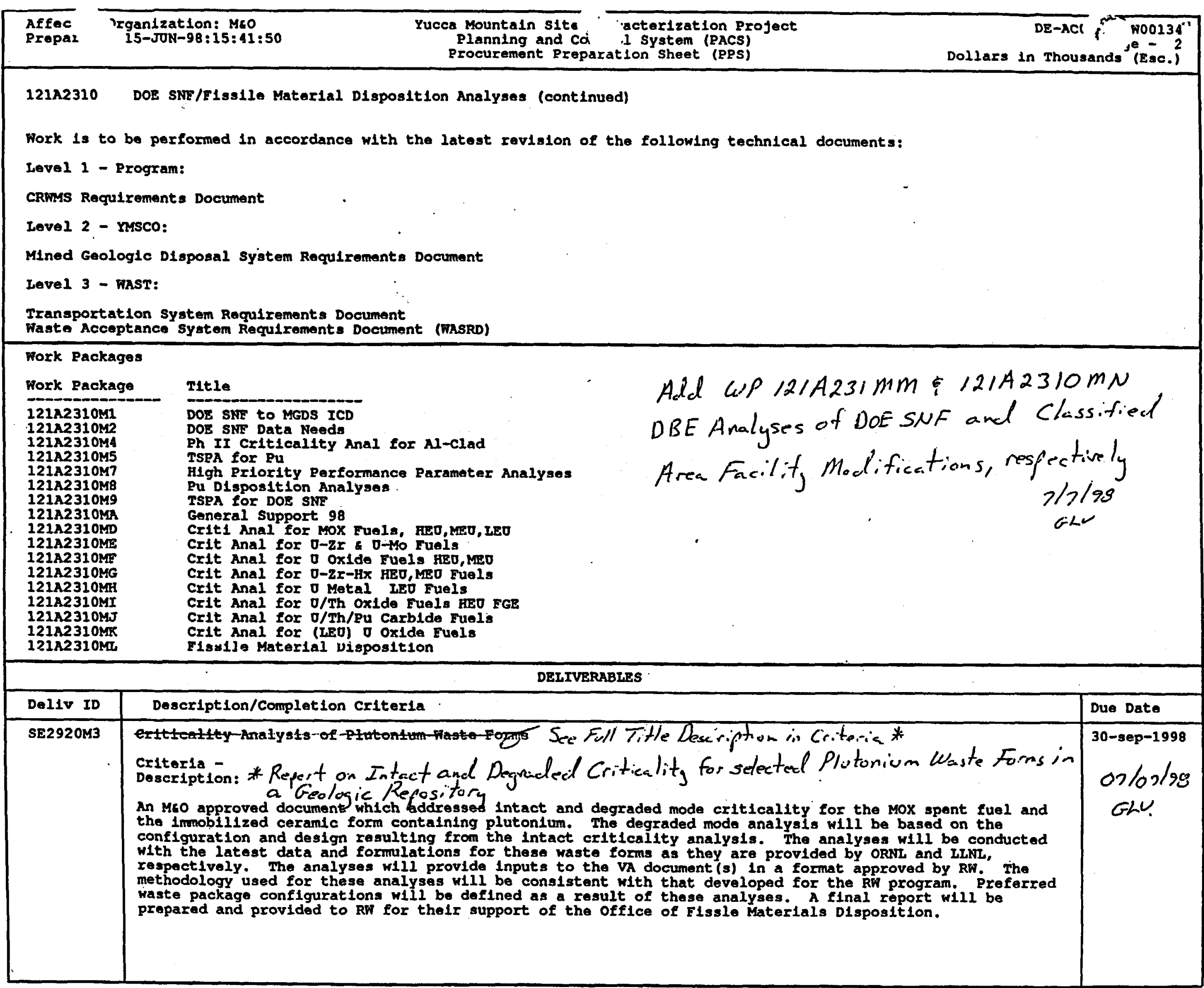




\begin{tabular}{|c|c|c|}
\hline $\begin{array}{l}A_{1}^{\prime} \\
\mathbf{P}_{1}\end{array}$ & \multicolumn{2}{|l|}{$\begin{array}{l}\text { Yucca Mountain f Charactorization Project } \\
\text { planning an. .untrol System (PACS) } \\
\text { Procurement Preparation Sheet (PPS) }\end{array}$} \\
\hline $121 A 2310$ & \multicolumn{2}{|l|}{ DOE SNE/Fiss1le Material D1sposition Analyses (continued) } \\
\hline \multicolumn{3}{|c|}{ DELIVERABLES } \\
\hline Dellv ID & Description/Completion Criteria & Due Date \\
\hline SE3200M4 & 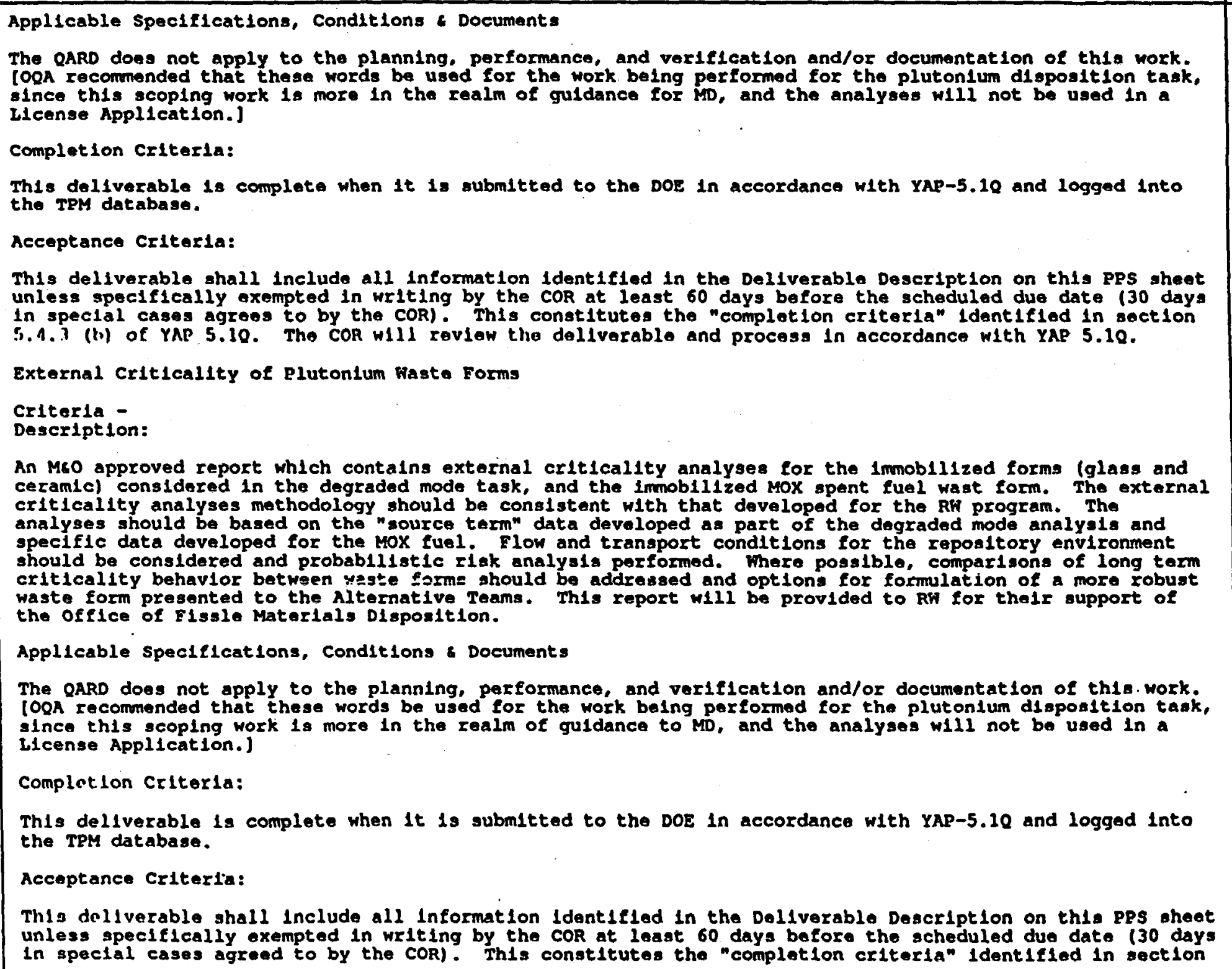 & 14-nov-1997 \\
\hline
\end{tabular}




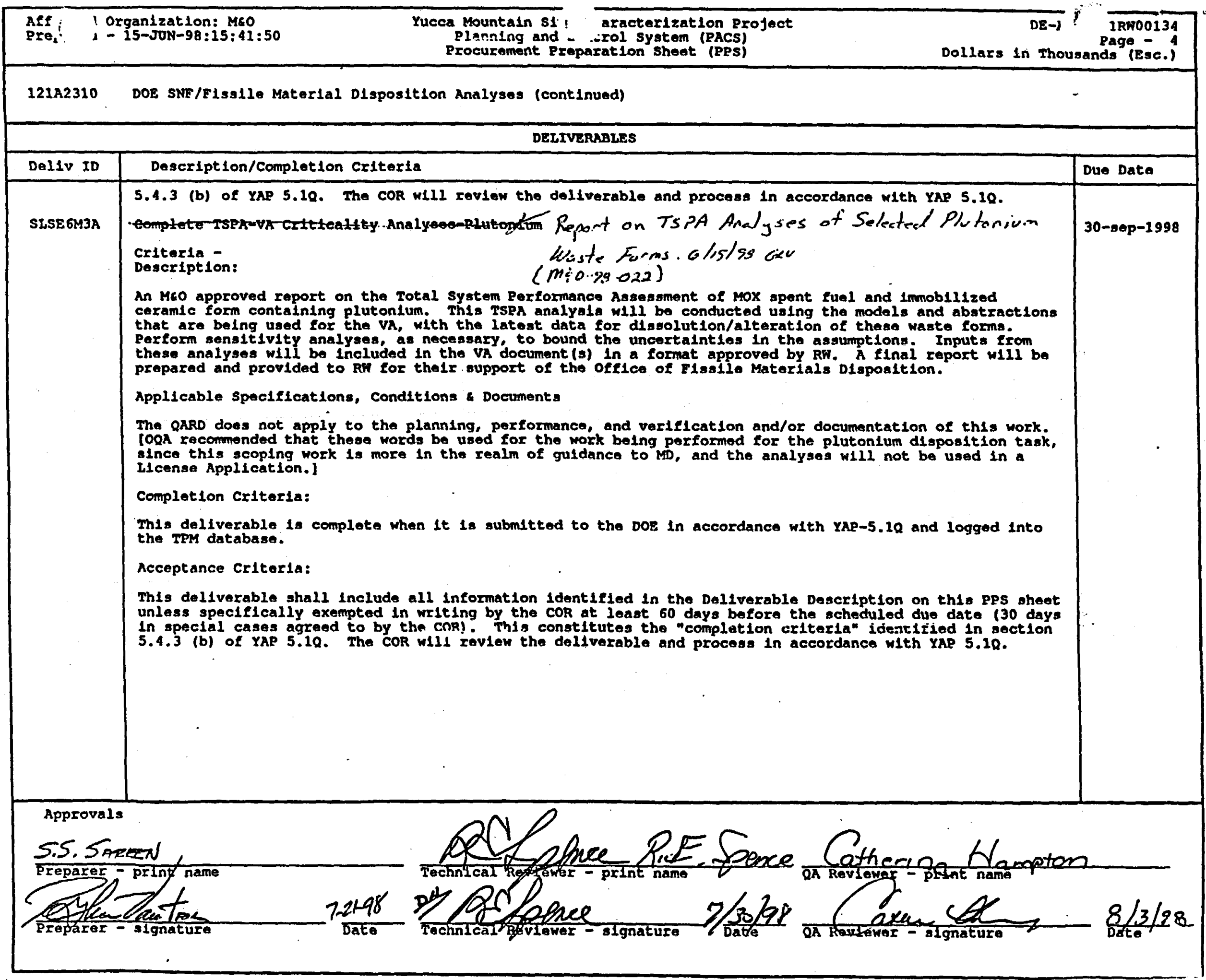

